\title{
Les soucoupes de l'Observatoire (Principauté de Monaco) : contribution à l'étude du phénomène des grands éclats au Paléolithique ancien
}

The soucoupes of the Observatoire cave (Principality of Monaco): contribution to the study of the Large flake phenomenon in the early Palaeolithic

Guillaume Porraz, Élisa Nicoud, Michel Grenet et Patrick Simon

\section{OpenEdition}

Journals

Édition électronique

URL : http://journals.openedition.org/paleo/2793

DOI : $10.4000 /$ paleo.2793

ISSN : $2101-0420$

Éditeur

SAMRA

Édition imprimée

Date de publication : 28 décembre 2014

Pagination : 195-232

ISSN : 1145-3370

Référence électronique

Guillaume Porraz, Élisa Nicoud, Michel Grenet et Patrick Simon, « Les soucoupes de l'Observatoire (Principauté de Monaco) : contribution à l'étude du phénomène des grands éclats au Paléolithique ancien », PALEO [En ligne], 25 | 2014, mis en ligne le 28 juillet 2015, consulté le 07 juillet 2020. URL http://journals.openedition.org/paleo/2793 ; DOl : https://doi.org/10.4000/paleo.2793

\section{(c) (i) $\Theta$}

PALEO est mis à disposition selon les termes de la licence Creative Commons Attribution - Pas d'Utilisation Commerciale - Pas de Modification 4.0 International. 


\title{
Les soucoupes de l'Observatoire (Principauté de Monaco) : contribution à l'étude du phénomène des grands éclats au Paléolithique ancien
}

\author{
Guillaume PORRAZ ${ }^{(1)}$, Élisa NICOUD(2), Michel GRENET(3), Patrick SIMON(4)
}

\begin{abstract}
Résumé : Les fouilles de la grotte de l'Observatoire (Principauté de Monaco), remarquablement publiées dans le premier tome des Archives de l'Institut de Paléontologie Humaine en 1927, avaient révélé la présence dans le « foyer k » d'une vieille industrie composée d'éclats en calcaire de très grandes dimensions, autrement appelés soucoupes par Léonce de Villeneuve. La reprise pour étude de cet assemblage lithique $(\mathrm{N}=132)$ indique une recherche d'éclats normalisés, de morphologie trapézoïdale à quadrangulaire, débités aux dépens de volumes soigneusement sélectionnés, aménagés et exploités selon un débitage préférentiel à séquence unique. Ces grands éclats, structurés autour d'un biseau cortical brut de débitage, fin, biplan, rectiligne à légèrement convexe, recouvrent la définition du hachereau d'un point de vue technofonctionnel. Cette collection de la grotte de l'Observatoire, également composée de galets manuportés ( $N=159)$ et d'un biface, aurait un âge antérieur à 230000 ans BP. À ce jour, cette série ne trouve aucun équivalent régional mais des rapprochements peuvent être effectués avec les " Large Flakes Industries » d'Espagne et d'Afrique du Nord, caractérisées par un débitage d'entames et la présence de hachereaux de type 0. Les soucoupes de la grotte de l'Observatoire conduisent à nous interroger sur les spécificités de cette technologie macrolithique et sur sa signification dans un contexte régional et méditerranéen. Notre étude nous amène finalement à discuter de l'hypothèse de la diffusion pour envisager celle d'une apparition locale, dans le cadre d'un savoir-faire technique qui se serait étroitement adapté à la nature du matériau d'œuvre.
\end{abstract}

Mots-clés : Paléolithique ancien, Acheuléen, Méditerranée, grands éclats, calcaire, hachereau, débitage de l'Observatoire, diffusion, convergence.

Abstract: The soucoupes of the Observatoire cave (Principality of Monaco): contribution to the study of the Large flake phenomenon in the early Palaeolithic. The excavations at the Observatoire Cave (Principality of Monaco), have been well published in the first volume of the Archives of the Institut de Paleontologie humaine in 1927. The authors document the presence in the "foyer k" of large flakes also called soucoupes (saucers or flying saucers in french) by L. de Villeneuve. The study of this lithic collection $(\mathrm{N}=132)$ indicates a production of trapezoidal to quadrangular flakes, detached on limestone cobbles that were cautiously selected, prepared and shortly exploited for one unique preferential product. These large flakes have been structured on a cortical distal end (or biseau), never retouched and characterized by a fine angle, a biplane section and a slightly convex delineation. In a techno-functional perspective, these large flakes clearly overlap the definition of the cleavers. This collection from the Observatoire Cave, which precedes $230000 \mathrm{BP}$, also includes a series of cobbles

(1) CNRS, USR 3336, UMIFRE 25, Institut Français d'Afrique du Sud (IFAS), 62 Juta Street, Braamfontein, Johannesburg, Afrique du Sud. guillaume.porraz@ifas.co.za

(2) École Française de Rome, Piazza Farnese, 67, I-00186 Roma - elisa.nicoud@gmail.com

(3) UMR 5608 TRACES, Maison de la Recherche, Université de Toulouse II - le Mirail, 5 allée Antonio Machado, FR-31058 Toulouse archelmi@gmail.com

(4) Directeur du Musée d'Anthropologie Préhistorique de Monaco, 56bis Boulevard du Jardin Exotique, MC-98000 Monaco -

patrick.simon@map-mc.com 
$(\mathrm{N}=159)$ and one single handaxe. This lithic assemblage finds no regional equivalent, but comparisons can be made with some Acheulean Large Flake Industries from Spain and Northern Africa, characterized by a production of entames and the shaping of proto-cleavers (or type 0). The soucoupes of the Observatoire Cave encourage us to develop further on the peculiarities of this macrolithic technology and on their signification in a regional and Mediterranean context. Our study finally challenges the hypothesis of diffusion and consider the scenario of a local invention as plausible, within a framework of a technology that was closely adapted to the nature of the raw material.

Key-words: Early Paleolithic, Acheulian, Mediterranean, Large flakes, cleaver, limestone, « Observatoire » debitage, diffusion, convergence.

\section{Introduction}

Plusieurs travaux ont récemment souligné comment le Paléolithique ancien, dont l'Acheuléen est une composante, demeurait une période méconnue marquée par une forte diversité géographique mais aussi temporelle (Nicoud 2010, 2011, 2013a, 2013b ; Chevrier 2012a, 2012b ; Rocca 2013). Cette diversité s'inscrit en faux avec l'idée d'une succession ordonnée de types techniques évoluant de concert avec les hominidés et leur environnement. L'un des défis que pose l'étude de ce Paléolithique ancien est alors d'adapter ses échelles d'analyse à la construction d'un discours sur le temps long.

Des traits techniques qui définissent le Paléolithique ancien, le macrolithisme en est certainement l'un des plus caractéristiques. Ce macrolithisme, qui n'est ni exclusif ni constitutif de cette période, porte en lui les idées de masse et de façonnage généralement associées aux outils tels que les bifaces, hachereaux et autres bolas (Tixier et al. 1980 ; Texier 1996). Or ce phénomène technique définit un champ d'investigation tout à fait singulier. Que ce soit la question des usages, ou celle de l'organisation des sociétés et de leurs représentations, les caractères structurants et structurés par le macrolithisme portent en eux une signification qui doit nous aider à mieux reconnaitre ces sociétés passées.

Le débitage des grands éclats est une manifestation macrolithique qui traverse le Paléolithique ancien (Sharon 2007 ; Mourre et Colonge 2010). Celui-ci participe généralement d'une chaîne opératoire de façonnage, mais semble exister en propre dans certains contextes. L'étude de ces grands éclats a permis la reconnaissance de différents modes de production dont certains se rapprochent des principes du concept Levallois (Mourre 2006 ; Sharon 2009). La notion de prédétermination se révèle spécifiquement dans le cadre des chaînes opératoires à hachereaux, dont la pleine expression se réalise au cours du Pléistocène moyen (Mourre 2003). La distribution temporelle et géographique de ces grands éclats a conduit à formuler diverses hypothèses sur leur origine et devenir. En Europe occidentale, ce phénomène technique serait limité à la péninsule ibérique et ses marges, sous la forme privilégiée d'un débitage d'entames associé à des hachereaux de type 0 (Sharon 2007). C'est sur la base de cette distribution techno-typologique qu'a été proposée l'hypothèse d'une diffusion d'un Acheuléen depuis l'Afrique du Nord vers l'Espagne, via le détroit de Gibraltar (Bordes 1966 ; Alimen 1975 ; Tavoso 1986 ; Otte 1996 ; Sharon 2011).

Dans le cadre d'un programme s'intéressant aux successions techniques dans l'arc liguro-provençal, nous avons rapidement été surpris et interpellés par la collection des grands éclats, ou soucoupes (Boule et Villeneuve 1927), de la grotte de l'Observatoire (Principauté de Monaco). En effet, les rapprochements que nous étions tentés d'établir - plus ou moins intuitivement - avec les assemblages de la péninsule ibérique venaient alimenter une discussion nouvelle sur l'aire d'extension de ce phénomène technique et la signification de celui-ci. Que sont ces soucoupes? D'où viennent-elles ?

Dans cet article, nous engageons une description détaillée du corpus des grands éclats de l'Observatoire pour en dégager les structures techno-fonctionnelles, les règles de production ainsi que leurs associations. Cette étude nous permet dans un premier temps de souligner toute l'originalité de comportements techniques qui se sont étroitement adaptés aux matériaux d'œuvre, et nous permet dans un second temps de discuter des hypothèses de diffusion et d'innovation locale dans le cadre du phénomène technique des grands éclats au Paléolithique ancien. L'un des défis soulevés par l'étude du Paléolithique ancien est de réussir à adapter ses échelles d'analyse, l'une des opportunités est d'engager un discours sur les techniques dans un temps long.

\section{Contexte et intégrité de la collection étudiée}

La grotte de l'Observatoire (Principauté de Monaco) est une cavité située sur la ligne côtière de l'arc liguroprovençal, à proximité de la frontière franco-italienne, à une altitude de $104 \mathrm{~m}$ au-dessus du niveau marin actuel (fig. 1). Son entrée est formée d'une large ouverture creusée dans la paroi abrupte des formations calcaires du Jurassique supérieur. Elle débouche sur un réseau karstique long de 


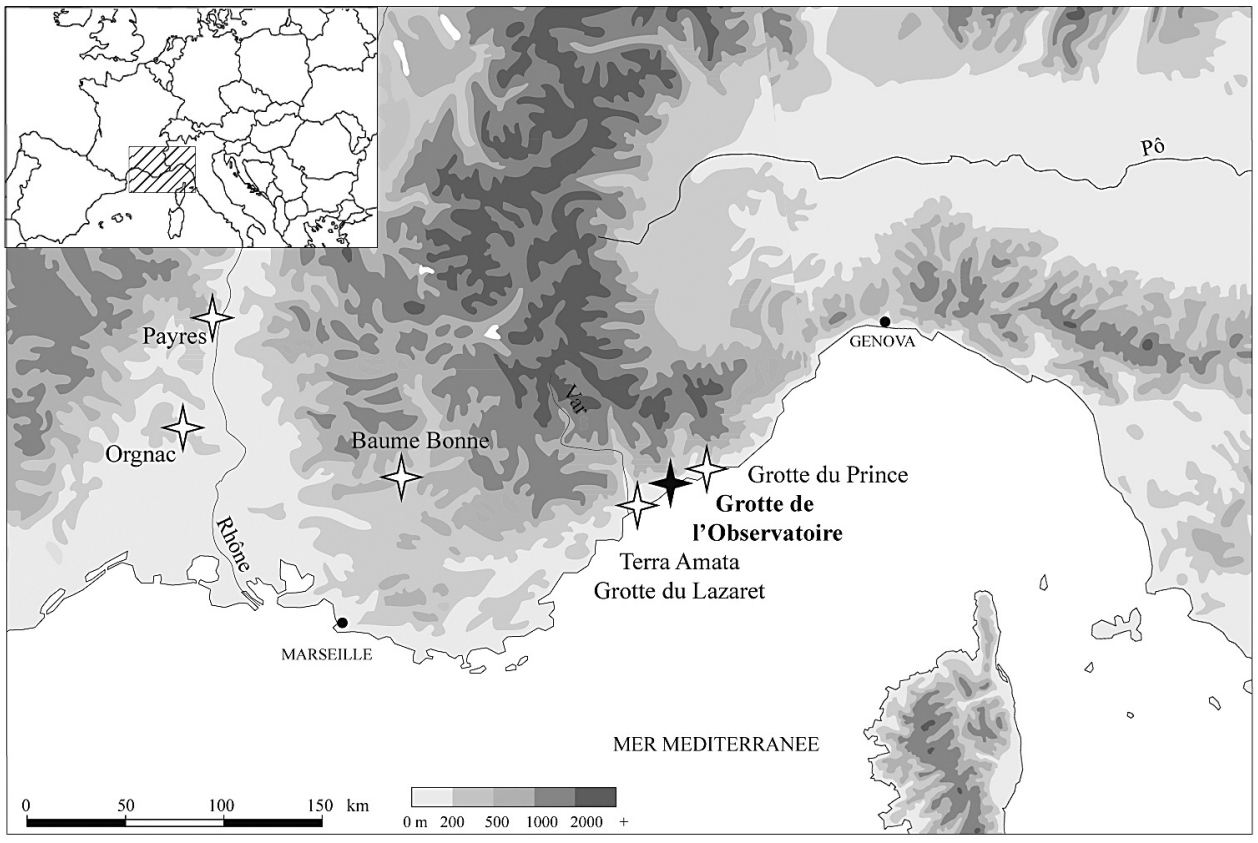

Figure 1 - Localisation de la grotte de l'Observatoire (Principauté de Monaco) et des principaux sites voisins mentionnés dans le texte (DAO G. Porraz).

Figure 1 - Location of the Observatoire Cave (Principality of Monaco) and of the main sites mentioned in the text.
$500 \mathrm{~m}$, s'enfonçant à une profondeur de $100 \mathrm{~m}$ sous la surface actuelle de son entrée. Les témoins sédimentaires piégés dans le karst indiquent une exondation de la grotte depuis la transgression marine du Calabrien (+108 m NGF dans la région niçoise), c'est-à-dire il y a près d'1 Ma BP

La grotte de l'Observatoire a été découverte lors de l'aménagement du Jardin Exotique de la Principauté de Monaco (Boule et Villeneuve 1927). Ces travaux ont conduit les ouvriers à dégager de nombreux vestiges du Paléolithique supérieur, qui ont rapidement attiré l'attention des autorités locales. Cette découverte est intervenue dans un contexte où la recherche préhistorique en Provence et Ligurie connaissait un essor important à la suite des découvertes réalisées dans le secteur des Balzi Rossi (pour une synthèse, voir : Simon 2008), situé à 10 km à l'est de la grotte.

Léonce de Villeneuve entreprit de fouiller entièrement la cavité, à la demande du Prince Albert $1^{\text {er }}$ de Monaco, ce qu'il fit entre 1916 et 1920. L'absence de documentation de terrain est bien sûr préjudiciable à la compréhension des dynamiques de dépôt dans le site. Toutefois, nous devons reconnaitre le mérite au chanoine Léonce de Villeneuve et à Marcellin Boule d'avoir publié leurs résultats rapidement au sein d'une monographie bien détaillée et illustrée, qui permet aujourd'hui de recontextualiser les collections archéologiques. C'est ainsi que nous avons révisé les collections lithiques des niveaux proto-aurignaciens de la grotte de l'Observatoire (Porraz et al. 2010). C'est selon une même démarche que nous publions aujourd'hui nos résultats sur les niveaux archéologiques les plus anciens.

Une chance pour l'étude de la grotte de l'Observatoire est la présence de deux planchers stalagmitiques au sein de la séquence sédimentaire, planchers identifiés en cours de fouille et reportés sur les documents d'étude (plancher I, II : fig. 2). C'est en s'appuyant sur la présence de ces deux planchers que Marcellin Boule et Léonce de Villeneuve ont distingué trois phases principales, dénommées groupe inférieur (groupe 1), groupe moyen (groupe 2) et groupe supérieur (groupe 3). Les dépôts qui intéressent notre étude sont ceux du groupe inférieur, localisé sous le plancher II (fig. 2).

Nous reportons ici les principaux éléments publiés utiles à la compréhension de ce groupe inférieur (Boule et Villeneuve 1927 - p. 25-26) :

« Les éléments de remplissage [sont essentiellement formés] par de l'argile ou terre des cavernes. (...) Cette masse argileuse, fort homogène, est coupée par deux formations stalagmitiques indiquant des temps d'arrêt dans la sédimentation, la nappe IV et la nappe III beaucoup plus importante. Elle est, en quelque sorte, scellée par la vaste nappe II qui règne sur toute la surface de ce premier remplissage.

M. de Villeneuve a relevé également, dans son épaisseur, plusieurs lignes de cendres, les plus anciennes de la caverne : foyer $k$ à la cote 91, foyer $i$ sur le plancher stalagmitique IV (...).On serait tenté de voir, dans ces lignes ou traînées cinéritiques, non de vrais foyers en place, mais des produits de remaniement et de lévitation d'amas de cendres situés primitivement vers l'entrée de la caverne. Cette hypothèse expliquerait mieux la présence, à l'état dispersé dans l'argile, des produits de l'industrie humaine qu'on y a rencontrés (...) »

Ces notes offrent une bonne compréhension générale de la situation sédimentaire et archéologique. Premièrement, et comme nous pouvions le supposer, le comblement du karst et l'accumulation du matériel ont très vraisemblablement 

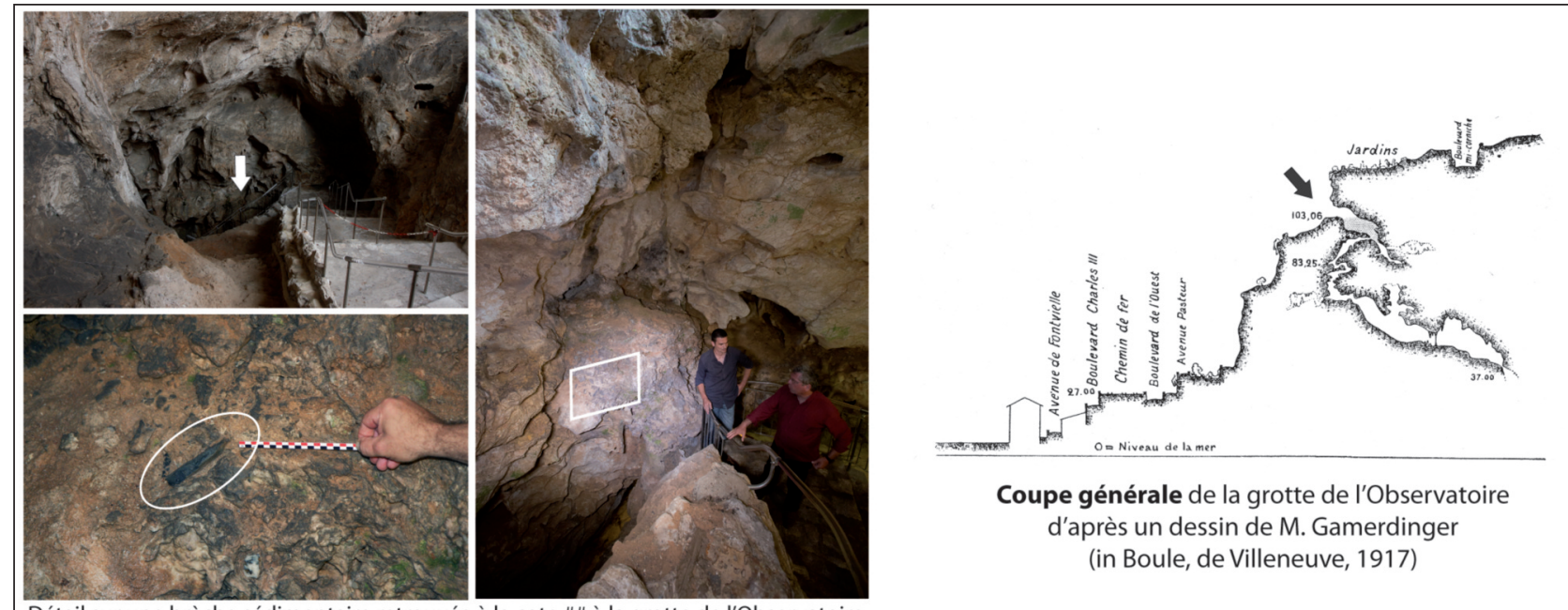

Coupe générale de la grotte de l'Observatoire d'après un dessin de M. Gamerdinger (in Boule, de Villeneuve, 1917)

Détail sur une brèche sédimentaire retrouvée à la cote \#\# à la grotte de l'Observatoire. Ce niveau de brèche laisse deviner la présence de fragments osseux et d'un probable grand éclat en calcaire (entouré). (Clichés de gauche $\odot$ G.Porraz, cliché de droite ODRAC/SRA PACA M.Olive)

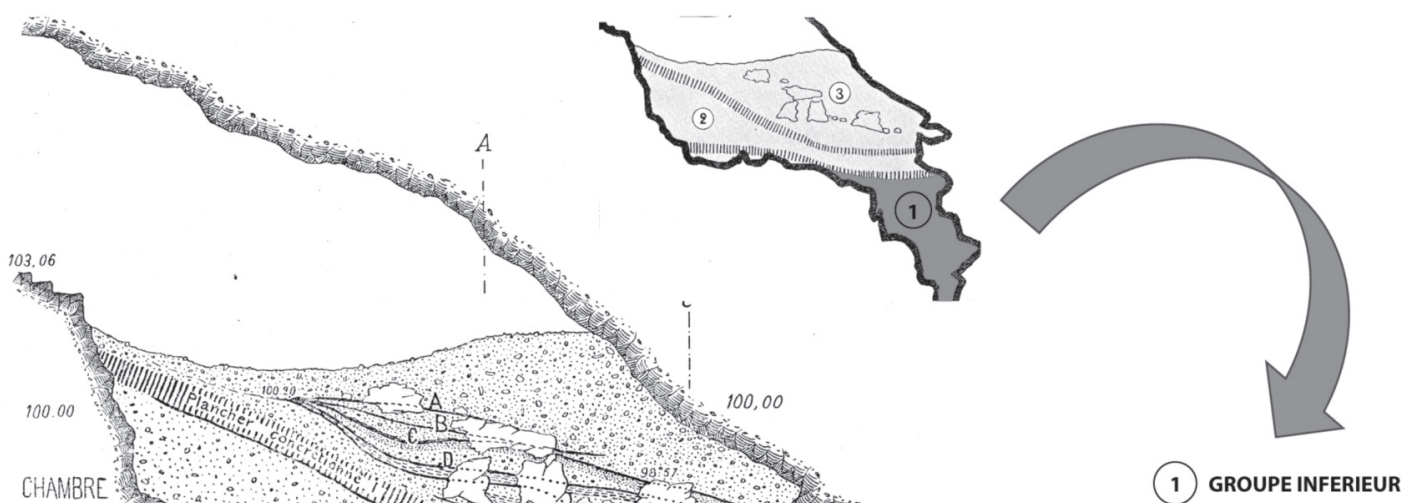

"De la couche argileuse, située entre les planchers III et II, (...) on a extrait neuf éclats, dont six en quartzite ou en calcaire, une pointe moustérienne en quartzite (foyer $f$ ) et une pièce biface " (in Boule, de Villeneuve, $1917: 26$ )

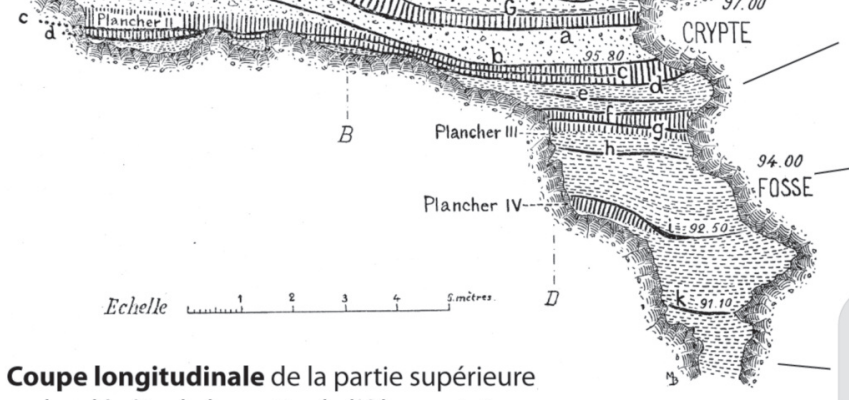

"La couche d'argile comprise entre les nappes stalagmitiques IV et III a fourni dix-huit éclats informes, tous en quartzite» (in Boule, de Villeneuve, $1917: 26$ )

«u-dessus l'argile a livré, notamment vers le foyer k, entre les cotes 87 et 90 , toute la série de grands éclats à peine travaillés et les boules de grès dont M. de Villeneuve a déjà parlé» (in Boule, de Villeneuve, 1917: 26) des dépôts de la grotte de l'Observatoire (in Boule, de Villeneuve, 1917)

Figure 2 - Contexte stratigraphique des dépôts anciens de la grotte de l'Observatoire et localisation du « foyer $k$ »(DAO G. Porraz).

Figure 2 - Stratigraphic context of the lower deposits from the Observatoire Cave and location of the "hearth k" .

une origine colluviale. Mais contrairement à ce que laissent comprendre les notes publiées par $M$. Boule et $L$. de Villeneuve (1927), il n'existerait qu'une seule et unique ouverture dans le karst de l'Observatoire, ainsi que l'indique le relevé à notre disposition. Ces colluvions trouveraient donc leur origine au niveau de l'entrée actuelle de la grotte, probable siège des occupations humaines.
En outre, ce « groupe » sédimentaire inférieur présente l'intérêt d'être polyphasé, comme en témoignent la formation non invasive des planchers III et IV ainsi que la présence de plusieurs "lignes de cendres ", respectivement individualisés sous les foyers k à e (fig. 2). Ce phasage trouve des correspondances d'un point de vue archéostratigraphique. Comme le soulignent les auteurs 
(Boule et Villeneuve 1927 - p. 91) : « Cette industrie n'est pas exactement la même de la base au sommet du groupe ». Trois principaux ensembles technologiques se dégagent ainsi de ce groupe inférieur, que nous avons individualisé par « foyer » :

1. le « foyer k »: les dépôts de base ont livré de grands éclats en calcaire, des galets manuportés et un biface : ces dépôts sont compris entre les cotes 86-87 (non reportées sur la stratigraphie publiée) et le foyer k (cote 91) ;

2. le « foyer $h$ » : les dépôts intermédiaires ont livré un lot d'éclats en quartzite compris entre le plancher IV et le plancher III ;

3. le « foyer e »: les dépôts du sommet ont livré des éclats, une pointe moustérienne et deux pièces bifaciales, entre les planchers III et II.

La collection « foyer k » des grands éclats de l'Observatoire provient donc de la base des dépôts du groupe inférieur, compris entre les cotes 86 et 91 . Cette collection est répartie sur une puissance de près de $5 \mathrm{~m}$, pour une densité de vestiges signalée comme faible. D'après les notes publiées, aucune pièce archéologique n'aurait été retrouvée entre les cotes 91 et 92 , indiquant un possible hiatus dans l'occupation humaine entre les « foyers k » et « $h$ ». Nos propres observations de terrain nous ont permis de retrouver un niveau brèchifié comprenant des fragments osseux ainsi qu'un probable grand éclat en calcaire (fig. 2). Ce niveau brèchique est compris entre les cotes 89 et 91 , soit précisément l'intervalle altimétrique indiqué par Marcellin Boule et Léonce de Villeneuve ${ }^{5}$.

Plus récemment (1984 et 1986-87), S. Simone et P. Simon (Musée d'Anthropologie Préhistorique de Monaco) ont engagé une fouille des probables déblais de de Villeneuve, rejetés dans l'un des conduits karstiques de la cavité. De fait, cette fouille a porté sur les refus les plus récents, soit les dépôts archéologiques les plus anciens. Au cours de cette opération, 10 grands éclats et fragments de grands éclats ainsi qu'une cinquantaine de galets ont été récoltés, auxquels il faut ajouter de nombreux petits éclats et fragments taillés en calcaire $(n>40)$.

La collection aujourd'hui disponible regroupe un total d'environ 350 pièces lithiques et présente une forte homogénéité pétrographique et technologique. La sousreprésentation des éléments de petite dimension est un biais pour l'analyse, quoique l'origine de ce biais demeure incertaine (fouilleurs et/ou occupations et/ou processus post-dépositionnels ?). Par ailleurs il faut relever la présence d'un racloir sur support allongé (pl. XIX, fig.4 : in Boule et Villeneuve 1927), racloir qui détonne au sein de la collection de grands éclats en calcaire. Ce racloir, qui évoque des ambiances plus récentes, est en silex gris bleu à nombreux quartz détritiques dont l'origine est à rechercher dans les formations géologiques frontalières (Tomasso et al. soumis).

\section{Le « vieux paléolithique » de la grotte de l'Observatoire}

L'ancienneté des fouilles explique l'absence relative des grands éclats de l'Observatoire au sein des débats actuels sur le Paléolithique ancien du monde méditerranéen et d'Europe occidentale. Mais cette prudence s'explique aussi par des difficultés héritées à classer et saisir la nature de cette industrie.

Marcellin Boule et Léonce de Villeneuve (1927) sont les premiers à s'exprimer sur ce groupe inférieur, qu'ils qualifient de "vieux paléolithique » (p. 27), « d'un faciès paléolithique très ancien » (p. 91). Les auteurs avancent : " nous avons affaire à une industrie du Paléolithique ancien, renfermant à la fois des types de forme chelléenne, acheuléenne et moustérienne » (p. 97). Ils notent toute l'originalité des grands éclats et s'attardent avec intérêt sur le biface à base réservée découvert dans la partie basse des dépôts (p. 91-93) :

"Ce sont de grands éclats de calcaire jaune, gris clair ou gris foncé, à texture compacte, et munis de beaux bulbes de percussion. La plus grande dimension de ces pièces peut dépasser 0,16 $\mathrm{m}$ (soucoupes ou « assiettes 》 du texte de M. de Villeneuve).(...)

Mais l'objet le plus remarquable de cette première série, et qui provient de la cote la plus basse atteinte par les fouilles (87 mètres), est un bel instrument amygdaloïde taillé dans un gros galet de calcaire jaunâtre à texture compacte, homogène [pl. XIX, fig. 1 : in Boule, Villeneuve, 1927]. C'est un vrai " coup-de-poing ", allongé, pointu, de facture chelléenne (...)»

Assez rapidement, sous l'influence des travaux de l'abbé $\mathrm{H}$. Breuil, l'industrie de la grotte de l'Observatoire va être associée aux groupes des industries dites clactoniennes, caractérisées par la présence " d'éclats souvent très grands, mais également moyens ou petits, taillés sur enclume de pierre (...). Le plan de frappe est généralement très grand, et forme avec le plan d'éclatement un angle très ouvert " (Breuil 1932 - p. 571). II en est ainsi de la publication de M.G. Pottier sur la chronologie du Paléolithique inférieur (1938) qui semble être le premier à classer l'industrie de la grotte de l'Observatoire au sein du groupe Clactonien. En 1954, l'abbé H. Breuil et H. Kelley consacrent cette attribution (p. 17) :

"La grotte de l'Observatoire de Monaco (alt. 90 m.) a donné à sa base un remarquable complexe, également taillé en calcaire compact, se superposant, à plusieurs mètres d'intervalle, à un biface abbevillien; là se trouve un puissant niveau clactonien, au-dessus duquel ont été trouvés deux bifaces acheuléens. Il est donc certain que les épisodes clactoniens ont existé dans cette région. »

(5) Les cotes ont été calculées à partir d'un point de référence reporté dans le relevé de la grotte de l'Observatoire par le cabinet de topographie Rollin (21/12/1989) et positionné à une altitude de 89,47. Ce point de référence ( $\left.n^{\circ} 7\right)$ est fixé dans le karst au pied du niveau bréchifié. 
Les travaux d'H. de Lumley vont le conduire à s'écarter de cette détermination chronoculturelle. Tout en reconnaissant l'existence de similarités avec le Clactonien, l'auteur reconnait un certain nombre de différences qui justifient selon lui l'individualisation en propre de la collection de l'Observatoire (de Lumley 1960 - p. 2) :

« La grotte de l'Observatoire (Principauté de Monaco) et la station de Curson (vallée de Veaunes, affluent de la basse Isère, Drôme) ont fourni une industrie où domine les grands éclats peu retouchés, extraits de gros galets de calcaire gris, possédant un large plan de frappe formant un angle très obtus avec le plan d'éclatement. Plusieurs auteurs ont rapproché ces industries de celle de Clacton dont elles se distinguent cependant par divers caractères. A l'Observatoire, et peut-être à Curson, elle semble associée à des bifaces. (...). Nous isolons ce troisième groupe d'industrie sous le terme de "type de Curson » ».

Ce même auteur propose une étude plus détaillée dans sa riche étude typologique sur le Paléolithique du midi méditerranéen (de Lumley-Woodyear 1969). Dans son article sur les civilisations du Paléolithique inférieur (1976), il y reprend ses principales conclusions, s'éloignant de sa première piste d'interprétation (de Lumley 1976 - p. 834) :

"L'industrie des dépôts du Pléistocène moyen de la grotte de l'Observatoire, taillée en calcaire gris, peut être définie comme un Acheuléen moyen à industrie sur éclat de débitage non Levallois, pauvre en outils retouchés. Les éclats, abondants et de grande taille, sont, le plus souvent, des éclats d'épannelage de galets et ont presque toujours conservé une partie du cortex. Trois bifaces ont été découverts : à base réservé en cortex et à bords ensellés, losangique, ficron lancéolé ».

Sans pour autant parler de consensus, c'est l'attribution à un Acheuléen qui va progressivement s'imposer dans la littérature (Gagnières 1970 ; Villa 1983 ; Cauche 2012). Audelà du contenu sémantique (Nicoud 2013a), il nous faut ici retenir le glissement qui s'est opéré dans l'étude des dépôts anciens de l'Observatoire. En effet, les publications ont progressivement consacré une analyse globale du groupe inférieur, au détriment des origines stratigraphiques, mélangeant ainsi les industries du « foyer $k$ », du « foyer $h$ » et du « foyer e ».

P. Villa, dans son étude du site de Terra Amata (1983), sera la première à mentionner la présence de hachereaux dans la collection de la grotte de l'Observatoire (Villa 1983 p. 239) : «... and about 60 large flakes, some of which were retouched into flake cleavers ". L'auteure, soucieuse de l'origine des collections, restera néanmoins prudente vis-àvis du positionnement chronoculturel de cet assemblage et l'écartera de sa synthèse sur les premiers peuplements de l'Europe occidentale (Villa 1991).

Le flou qui entoure notre savoir sur les premières traditions techniques à la grotte de l'Observatoire est la conséquence d'un parti-pris analytique qui a consisté à étudier les dépôts inférieurs en un seul bloc, sans distinguer des phases pourtant reconnues lors de la fouille. Mais ce flou s'explique aussi par notre méconnaissance des intentions et chaînes opératoires lithiques. Par ailleurs, l'absence d'une chronologie est pareillement préjudiciable à notre connaissance générale sur ces premières occupations. Différents âges ont été proposés dans la littérature pour les dépôts anciens de l'Observatoire, sur la base de la faune et de comparaisons inter-sites. Un bilan sur cette chronologie rend compte d'occupations humaines qui pourraient couvrir le milieu du Pléistocène moyen jusqu'au début du Pléistocène supérieur (de Lumley 1976 ; Bosinski 2006). À ce jour, deux âges sont disponibles. Il s'agit d'un échantillon du plancher II, daté par Uranium/Thorium à >178 000 ans et d'un échantillon du plancher III daté selon la même technique à >230 000 ans BP (Simone 1993). La production des grands éclats de l'Observatoire serait donc contemporaine ou antérieure au stade isotopique 7 (terminus ante-quem).

\section{L'assemblage lithique du " foyer $k$ » de la grotte de l'Observatoire}

L'assemblage étudié est composé de 132 grands éclats, 1 biface et 159 galets non transformés. L'origine stratigraphique des grands éclats a été discutée précédemment. L'origine du biface est quant à elle assurée par la description qu'en donnent spécifiquement Marcellin Boule et Léonce de Villeneuve (1927). Ce biface a été découvert à la cote 87 , soit la limite stratigraphique inférieure de notre assemblage d'étude. Son association directe avec les grands éclats, majoritairement collectés vers la cote 91 , peut donc être discutée. Concernant l'origine des galets non transformés, leur nature, leur homogénéité ainsi que le contexte géologique de la grotte excluent toute accumulation d'origine naturelle (cf. infra). À noter que par souci d'homogénéité et de clarté du discours, nous avons écarté le racloir en silex de l'analyse ci-dessous.

\section{Les grands éclats de l'Observatoire}

"La forme de ces éclats est assez variée : subtriangulaire, lancéolée, discoïde, polygonale. Les plus nombreux sont sans retouche. Les autres ont des retouches plus ou moins nombreuses et distribuées plus ou moins régulièrement. (...) De cette même cote 89 provient un des plus grands spécimens de ce genre, en calcaire gris [Fig.14-15 : in Boule, Villeneuve 1927]. Sa forme, assez régulière, est celle d'un rectangle -presque un carré- arrondi aux quatre coins. L'une des faces est formée par la surface même d'un énorme bulbe de percussion à grand rayon de courbure ; l'autre face est divisée en deux parties inégales par une arête semblable à l'arête d'un toit très surbaissé à double pente. La symétrie de cette pièce est encore accusée par la présence de facettes secondaires produites aux deux extrémités par l'enlèvement de quelques éclats qui lui donnent ainsi l'aspect d'un énorme grattoir double. II semble bien que nous soyons en présence d'une forme voulue, intentionnelle, fabriquée pour un usage spécial » (Boule et Villeneuve 1927 - p. 91-93)

Les grands éclats de la grotte de l'Observatoire sont tous en calcaire, d'un type marneux gris clair à foncé (fig. 3). Ces 

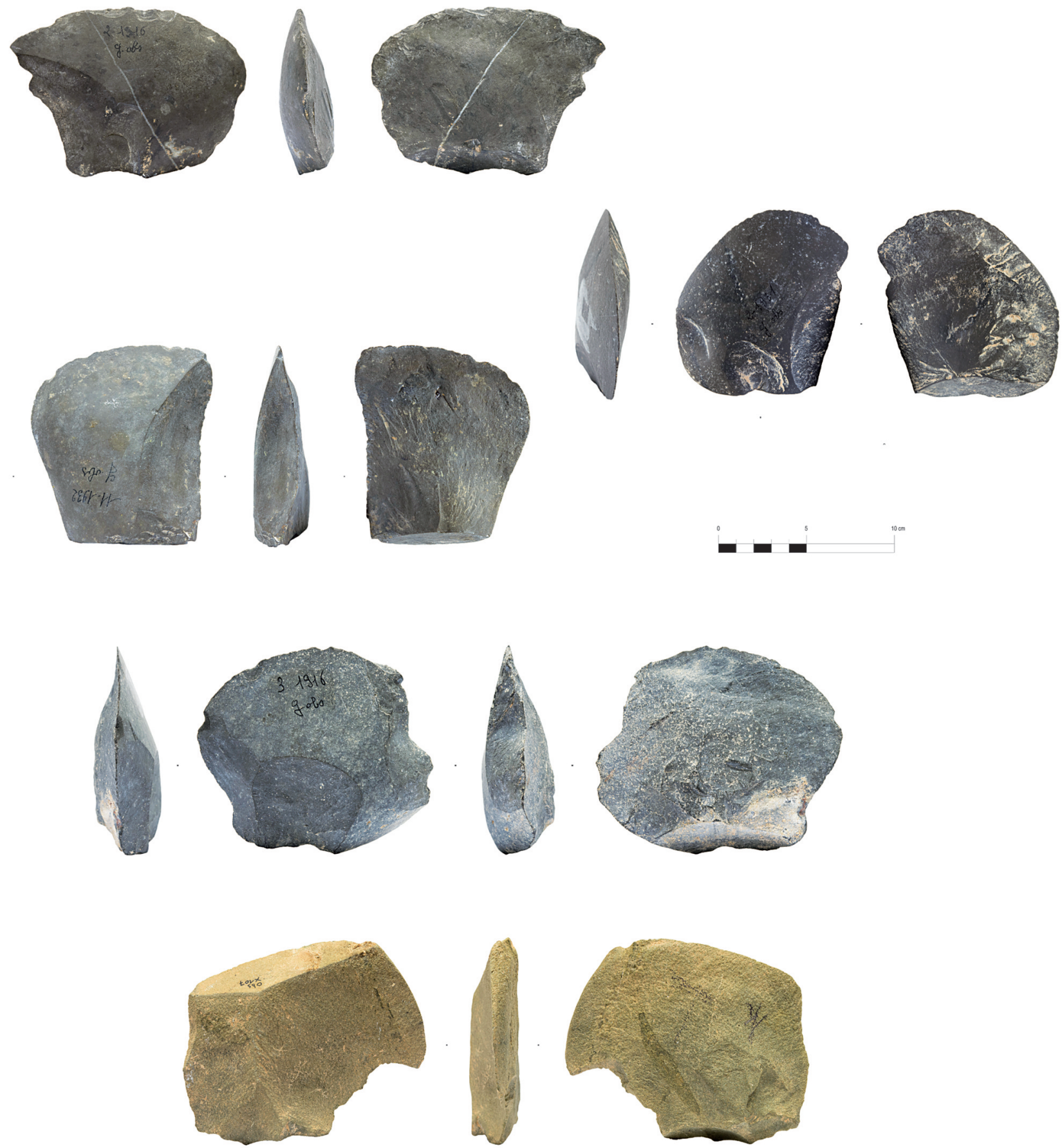

Figure 3 - Grands éclats du foyer k de la grotte de l'Observatoire : aperçu du spectre des calcaires débités (clichés Musée d'Anthropologie Préhistorique de Monaco, DAO F. Burle, G. Porraz).

Figure 3 - Large flakes of the hearth $k$ from the Observatoire Cave and general overview of the types of limestones exploited.

calcaires siliceux, probablement d'âge Crétacé, constituent un matériau fin, homogène, peu ou pas biodétritique, peu élastique et relativement fragile à la taille et à l'usage. La dimension de ces éclats et la nature des plages corticales indiquent qu'ils ont tous été tirés de galets d'un grand volume. De tels galets, présents sur l'ensemble de l'arc de Nice jusqu'à l'embouchure du Var, sont localement disponibles dans le conglomérat Miocène de Roquebrune, soit à environ $2 \mathrm{~km}$ à l'ouest du site.

Un premier classement technologique (fig. 4) permet d'individualiser les entames, les éclats à surface corticale et talon lisse, les éclats à surface corticale et négatif(s) de préparation unilatérale (45\% des effectifs déterminables), 


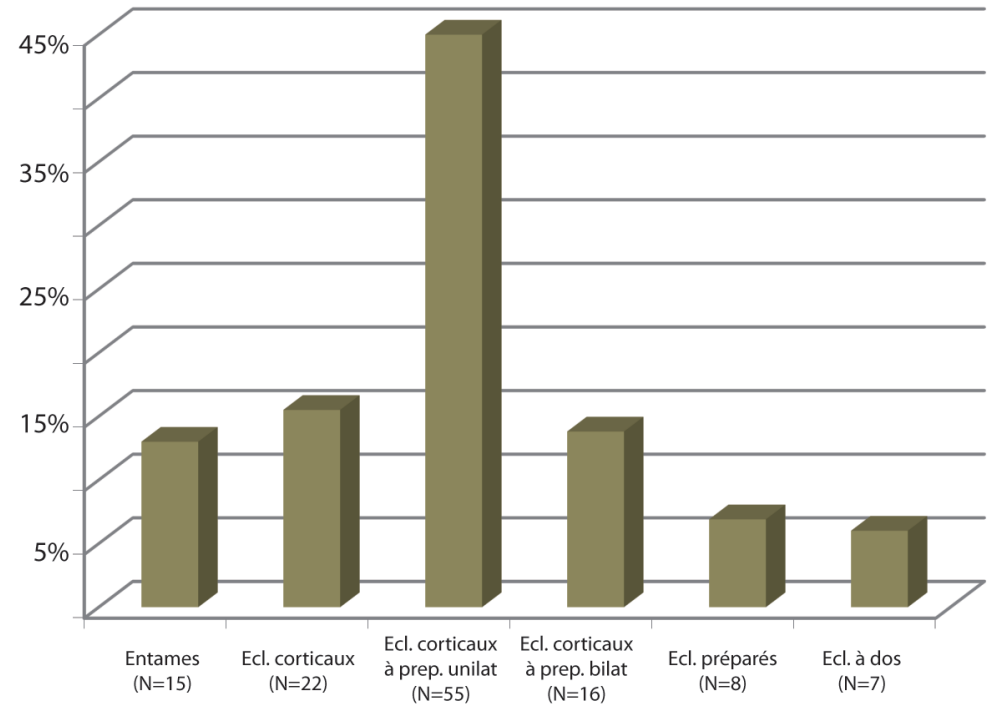

Figure 4 - Histogramme des classes technologiques des grands éclats du foyer $k$ de la grotte de l'Observatoire (DAO G. Porraz).

Figure 4 - Technology of the large flakes from the hearth $k$ of the Observatoire Cave. les éclats à surface corticale et négatifs de préparation bilatérale, les éclats préparés et enfin les éclats à dos cortical ou à dos de débitage. À noter qu'un unique éclat témoigne de l'exploitation de la face inférieure d'un éclatsupport (type Kombewa). Le premier élément marquant de cet assemblage est donc la forte proportion des pièces corticales ainsi que l'absence de nucléus. Nous nous retrouvons face à une collection de produits finis, introduits dans la grotte déjà débités, pour une production qui se singularise par la brièveté de ses séquences opératoires.

D'un point de vue morphométrique ces éclats se remarquent par leurs grandes dimensions, avec une longueur moyenne de 106 mm (mesurée dans l'axe de débitage), une largeur de $101 \mathrm{~mm}$, une épaisseur de 28 $\mathrm{mm}$ et un poids moyen de $345 \mathrm{~g}$ (fig. 5). Ces éclats recouvrent bien la définition des "large flakes » dont le seuil est classiquement situé à $100 \mathrm{~mm}$ de long (Kleindienst 1962). Ces moyennes métriques ne varient que faiblement selon les catégories technologiques considérées (fig. 5), appuyant l'hypothèse d'un seuil (ou standard) dimensionnel. Toutefois, certains éclats sortent du lot par leurs dimensions extrêmes, ainsi illustrées par quelques rares spécimens de forte masse (> $1000 \mathrm{~g})$. De façon générale, on prête à ces éclats une morphologie plutôt ramassée avec un indice d'allongement (L/l pris dans l'axe morphologique) de l'ordre de 1,2.
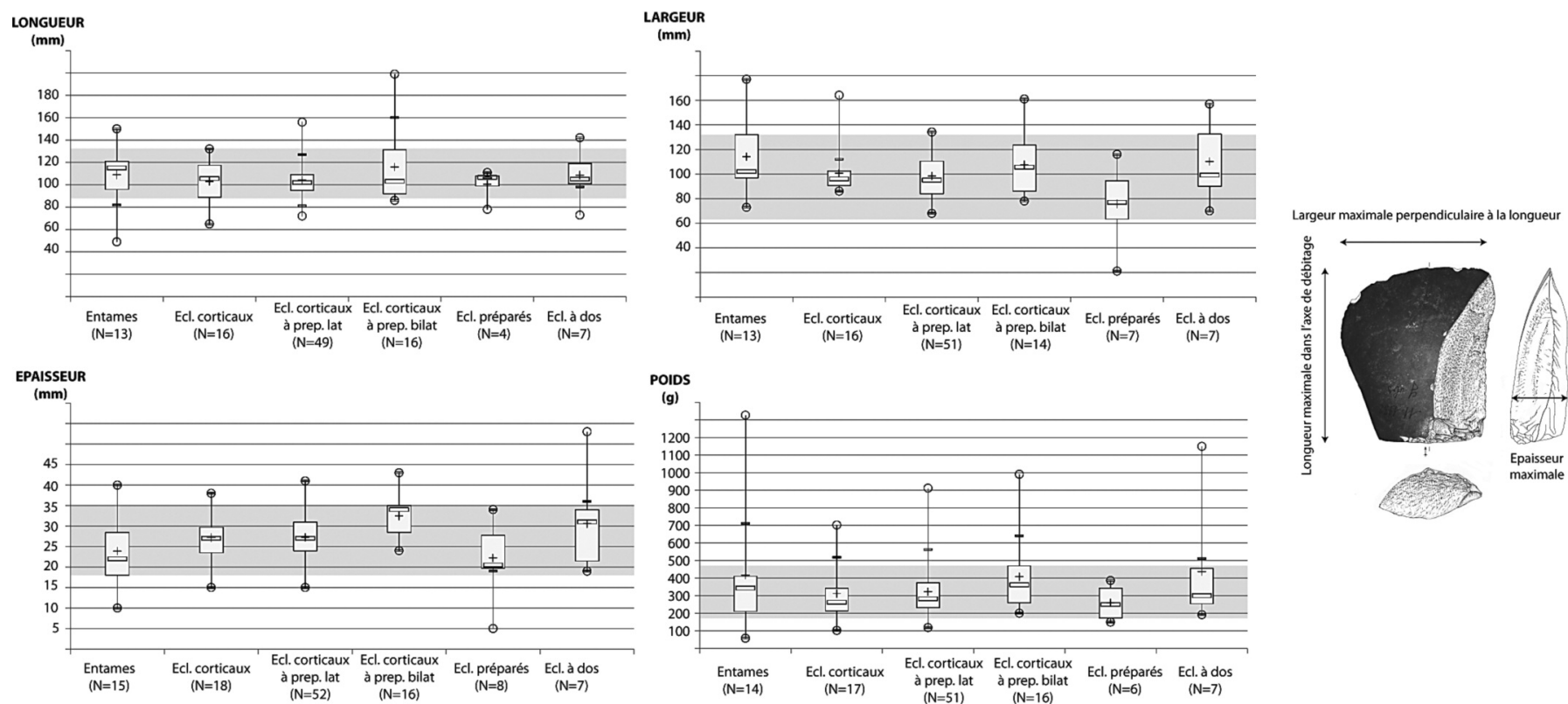

Figure 5 - Boites à moustaches des longueurs, largeurs, épaisseurs et poids des grands éclats du foyer k de la grotte de l'Observatoire, par catégories technologiques (DAO G. Porraz)

Figure 5 - Boxplots of the length, the width, the thickness and the weight of the large flakes coming from the hearth $k$ of the Observatoire Cave, according to their technological categories 
Ces grands éclats (fig. 3, 6-17) présentent une morphologie trapézoïdale à quadrangulaire dans près de $85 \%$ des cas de figure. Cette morphologie est héritée d'un débitage qui s'est organisé vers l'obtention d'un tranchant transversal, ou biseau. Ce-dernier se singularise par la normalisation de ses caractères techniques et fonctionnels : il s'agit d'un biseau cortical (90\% des cas de figure), de délinéation rectiligne à légèrement convexe, de fil droit, de section biplan et aux angles de tranchant compris entre $25^{\circ}$ et $40^{\circ}$ (fig. 18). Ce biseau est positionné dans l'axe de percussion de l'éclat dans près de $75 \%$ des cas de figure (fig. 19).

La normalisation des caractères techno-fonctionnels de ce biseau relève d'une prédétermination qui s'est opérée grâce au respect de 3 principales règles techniques :

1. La règle 1 relève de la phase de sélection du galet et du jeu du tailleur avec les convexités naturelles de celui-ci. L'étude des grands éclats nous montre que les galets sélectionnés n'étaient pas sphériques mais hémisphériques : asymétrie qui engage leur orientation volumétrique. L'indice de planéité des galets, pris dans l'axe de percussion des éclats (fig. 20), montre que la surface de débitage se positionnait sur la surface naturelle la moins bombée, les ondes de percussion venant alors mourir sur des convexités faiblement prononcées.

2. La règle 2 a consisté à mettre en place une convexité directrice de façon à ce que le front de fracture se développe en faisant diverger les deux bords de l'éclat. Cette prédétermination à la divergence s'est mise en place par le détachement d'enlèvements prédéterminants, soit unilatéralisé(s) et alors combiné(s) à la dissymétrie naturelle du bord opposé (fig. 6-9), soit bilatéralisés (fig.10, $\mathrm{n}^{\circ} 1$; fig. 11, $\mathrm{n}^{\circ} 1$; fig. 12). Alternativement, les tailleurs ont tiré parti de la morphologie naturelle de la surface débitée (fig. 16, $\mathrm{n}^{\circ} 1$ ), ou ont aménagé le biseau par un négatif d'enlèvement prédéterminant (fig. 13, $\mathrm{n}^{\circ} 1$; fig. 14).

3. La règle 3 a porté sur la mise en place d'un plan d'éclatement ouvert, présentant un angle moyen d'environ $120^{\circ}$ (fig. 21). Ce plan de frappe (fig. 21) a souvent été préparé par le détachement d'un enlèvement oblique ou perpendiculaire à l'axe de la surface de débitage. Ceci se traduit, notamment pour les éclats à négatif de préparation unilatérale, par la présence d'un talon lisse « à pan » (e.g. fig. 6-7).

C'est le respect de ces trois règles qui a permis d'assurer la répétition et la normalisation des caractères technofonctionnels des grands éclats. La règle 2 est ainsi à l'origine du bon contrôle de la morphologie générale de l'outil, à savoir la présence d'un bord transversal, rectiligne à peu convexe, perpendiculaire à l'axe de percussion. La variabilité observée dans les modes opératoires (enlèvements unilatéralisés ou bilatéralisés, enlèvements unilatéralisés simples ou multiples, enlèvement latéralisé unipolaire convergent ou orthogonal, etc.) n'est donc pas interprétée comme le reflet d'intentions différentes, mais bien comme une souplesse opératoire adaptée à des volumes et à un objectif de taille bien défini. L'effectif nous montre que cette souplesse opératoire visait davantage à corriger les convexités transversales que les convexités longitudinales, préfigurées mentalement et naturellement pour la future partie active de l'outil recherché. Ainsi le tailleur, en sélectionnant et orientant le galet, stabilisait-il la convexité longitudinale puis rectifiait la convexité transversale.

La combinaison des règles 1 et 3 est quant à elle à l'origine de la normalisation des caractères de section et d'angle du biseau. La première opération technique consistait à agencer les caractères techno-fonctionnels en structurant le débitage autour d'une surface naturelle plane ; la seconde opération consistait à contrôler la rupture mécanique en favorisant un étalement des ondes de percussion par la mise en place d'un plan d'éclatement ouvert et un geste de percussion rentrante « étouffée » (cf. infra). L'agencement de ces deux opérations techniques devait favoriser certains accidents de taille, comme en témoignent les « vibrations » fréquemment observées en partie distale des éclats, caractéristiques de la progression d'un front de fracture à la limite du rebroussement.

Ces éclats, que nous appellerons génériquement éclats à biseau cortical, présentent un aménagement dans près d'un tiers des cas de figure ( $\mathrm{N}=37 / 132)$, sous la forme d'une reprise d'un bord $(\mathrm{N}=25)$, plus rarement des $2(\mathrm{~N}=3)$, et/ou sous la forme d'une reprise de la base $(\mathrm{N}=15)$. Ces aménagements, unifaciaux ou bifaciaux, viennent généralement redessiner la morphologie de l'outil et aménager certaines parties de celui-ci (e.g. reprise d'un méplat naturel ou de débitage). A noter que certains grands éclats portent une suite de petits enlèvements détachés sur leur face supérieure en partie proximale, sans toutefois que la chronologie des opérations techniques soit déchiffrable (fig. $6, n^{\circ} 1$ ). Le point d'impact étant généralement porté bien en dessous de la corniche (fig. 20), nous privilégions l'hypothèse d'un aménagement (post-débitage ?) de l'outil.

Le biseau n'est jamais retouché, avec pour seule exception une pièce dont le tranchant semble avoir été repris par une série d'enlèvements. Plusieurs éclats $(\mathrm{N}=13)$ présentent une encoche, soit intentionnelle, soit accidentelle, localisée à proximité du biseau, comme si celle-ci subdivisait la zone transformative et préhensible de l'outil. Une forte proportion de grands éclats à biseau cortical présentent des macrotraces ( $40 \%$ ), sous la forme d'enlèvements marqués localisés sur le tranchant et renvoyant à une utilisation en percussion, plus rarement sous la forme d'un esquillement léger (fig. $7, \mathrm{n}^{\circ} 1$; fig. $10, \mathrm{n}^{\circ} 1$; fig. $9, \mathrm{n}^{\circ} 2$; fig. $12, \mathrm{n}^{\circ} 1$; fig. $\left.16, n^{\circ} 2\right)$. Bon nombre de ces grands éclats présentent cependant des tranchants vierges de toutes traces d'utilisation visibles à l'œil nu ou à faible grossissement.

Si la production des grands éclats semble bien se structurer autour de la présence d'un biseau, certains spécimens combinent plusieurs bords-tranchants et potentiellement plusieurs zones transformatives, ce que confirme dans certains cas la localisation des macrotraces d'utilisation (fig. $8, \mathrm{n}^{\circ}$ 2). Contrairement aux biseaux, les bords adjacents présentent une plus grande variabilité, dans leur délinéation, dans la nature de leurs sections ainsi que dans leurs angles de tranchant (fig. 18). À noter l'existence d'une tendance dans la latéralisation des préparations, puisque $60 \%$ des éclats à biseau cortical à préparation unilatérale $(n=27 / 45)$ l'ont été depuis la droite du nucléus. 
Une partie des grands éclats de l'Observatoire $(n=48 / 132)$ ne recouvre pas notre définition des éclats à biseau cortical. Ces éclats sont soit des entames ( $\mathrm{N}=15$, fig. 15), soit des éclats à surface corticale et talon lisse $(\mathrm{N}=18)$, soit des éclats préparés $(n=8)$, soit des éclats à dos $(n=7$, fig. 17$)$. Néanmoins les grands éclats de l'Observatoire nous semblent tous appartenir à une seule et même chaîne opératoire de débitage : les éclats non biseautés se situant alors en phase amont ou aval du plein débitage. Ceci s'observe notamment par des dimensions et des angles de plan de frappe similaires à ceux observés pour les éclats à biseau cortical, exception faite des éclats préparés (cf. infra). Ces éclats non biseautés présentent des caractères technofonctionnels variables, quoiqu'ils associent toujours la présence d'un tranchant généralement convexe à un méplat, opposé ou adjacent, naturel ou de débitage.

\section{Les galets manuportés de l'Observatoire}

«Nous savons déjà que M. de Villeneuve a recueilli, avec cette grosse et primitive industrie lithique en calcaire et quartzite, un grand nombre de "boules " de pierre. Je n'ai pas examiné toute la collection, mais seulement quatre échantillons choisis à ma demande par $M$. Lorenzi parmi ceux qui lui ont semblé présenter quelques caractères artificiels (...). Sur les quatre échantillons dont je viens de parler, l'un est en calcaire, les trois autres sont en grès. Leur diamètre moyen varie de $0^{m}, 15$ à $0^{m}, 12$; leur poids de 340 à 820 grammes. Tous portent des traces de travail. » (Boule et Villeneuve 1927 - p. 94).

L'effectif de galets manuportés se compose de 159 pièces, auxquelles il convient d'ajouter la présence de 4 galets portant les traces d'un débitage et de 8 éclats corticaux portant les stigmates d'un détachement accidentel survenu lors d'une percussion. Ces galets proviennent pour une bonne partie des fouilles du Musée d'Anthropologie Préhistorique de Monaco qui se sont portées sur les possibles déblais de fouille de de Villeneuve, et leur origine stratigraphique peut donc être questionnée. Toutefois, les descriptions publiées en 1927 (Boule et Villeneuve 1927) ne font état de galets bruts que dans le contexte des grands éclats (cf. supra). Le grand nombre de galets rejetés lors des fouilles de Villeneuve s'expliquerait alors par les doutes qui ont pu entourer leur origine. À ce propos, il faut mentionner la présence de 15 galets d'origine karstique exclus de cette étude. Ces galets présentent une morphologie irrégulière (ca. $50 \%$ des cas de figure déterminable), qui les distingue nettement du reste de la population des galets marins (fig. 22). II s'agit pour la plupart de petits blocs polyédriques émoussés en calcaire dolomitique de couleur beige.

L'effectif de galets manuportés présente des états de conservation variables (fig. 23). Un quart de l'effectif (fig. 22) porte des altérations post-dépositionnelles de type concrétion ou desquamation qui nuisent totalement à la recherche de traces d'utilisation. Par ailleurs certains galets semblent avoir subi les effets d'une chauffe accidentelle, ainsi marquée par la présence de cupules thermiques, de craquelures et de desquamations localisées.
Ces altérations n'ont pas entravé l'analyse pétrographique puisque seulement 2 spécimens restent indéterminés. Le spectre des roches est largement dominé par les calcaires, qui composent près du 3/4 de l'effectif (fig. 22), complété par des grès et des andésites. Les matériaux identifiés reflètent en gros la colonne stratigraphique locale avec surtout des galets du Jurassique supérieur (Tithonien et Kimméridgien) correspondant à des calcaires très fins (boue calcaire), parfois appelés calcaires sublithographiques (de teinte beige à crème). On retrouve aussi des calcaires dolomitiques pulvérulents (dolomitisation du Tithonien) ou massifs à texture plus fine (dolomitisation du Jurassique moyen), quelques calcaires marneux du Crétacé supérieur (Turonien très certainement), ainsi qu'un échantillon en calcaire à pisolithes et glauconie caractéristique des niveaux réduits et condensés du Crétacé inférieur niçois. Les grès eux aussi témoignent d'une certaine variabilité, illustrée par des faciès à détritisme plus ou moins grossier dont l'origine est à rechercher dans les formations du type «Grès d'Annot » (Flysch Oligocène). II y a enfin une petite population qui correspond aux andésites des dépôts volcaniques oligomiocènes de Cap-d'Ail, les galets d'andésite provenant quant à eux du démantèlement des pyroclastites à blocs d'andésite. Tout ce panel de roches est disponible sur le littoral, directement en contrebas de la grotte.

Seul un ou deux galets en grès siliceux caractéristique du Werfénien de la Roya auraient pu être collectés à l'embouchure de ce petit fleuve côtier, soit à une quinzaine de kilomètres à l'Ouest du site.

La collecte des galets ne semble pas avoir été déterminée par un critère exclusif de nature pétrographique. Même si le groupe des calcaires domine, celui-ci comprend en effet une forte diversité des faciès qui définissent autant de qualités différentes (e.g. dureté, homogénéité, etc.). À l'inverse, il se dégage de cette population une certaine homogénéité dimensionnelle (fig. 22). À quelques exceptions près, il s'agit de galets d'un gabarit palmaire, qui présentent des dimensions moyennes de l'ordre de $81 \times 67$ x $55 \mathrm{~mm}$ pour un poids moyen de $455 \mathrm{~g}$, la majorité d'entre eux ayant une morphologie (sub)ovoïde à (sub)triangulaire (présence d'un méplat naturel) (fig. 22).

L'étude préliminaire sur l'intégrité et l'état de surface des galets permet d'avancer de premières hypothèses fonctionnelles. À ce stade de l'étude, nous distinguons deux types de traces principales, que sont le piquetage secondaire et les cassures. Le piquetage secondaire, qui peut être plus ou moins profond et circonscrit sur la surface du galet, correspond à un usage en percussion sur un matériau dur. Celui-ci a été identifié sur près d' $1 / 3$ de la population des galets non altérés. Les cassures sont quant à elles plus difficile à interpréter. Certaines d'entre elles, identifiées sur un petit échantillon $(n=4)$, correspondent effectivement à des négatifs d'enlèvements incipients détachés accidentellement en percussion. D'autres trouvent leur origine dans des processus postdépositionnels. Toutefois nombre de cassures, initiées dans l'axe d'allongement du galet ou dans son épaisseur, ne portent aucun stigmate que nous sommes en mesure d'interpréter. Ces cassures sont certainement d'origine 


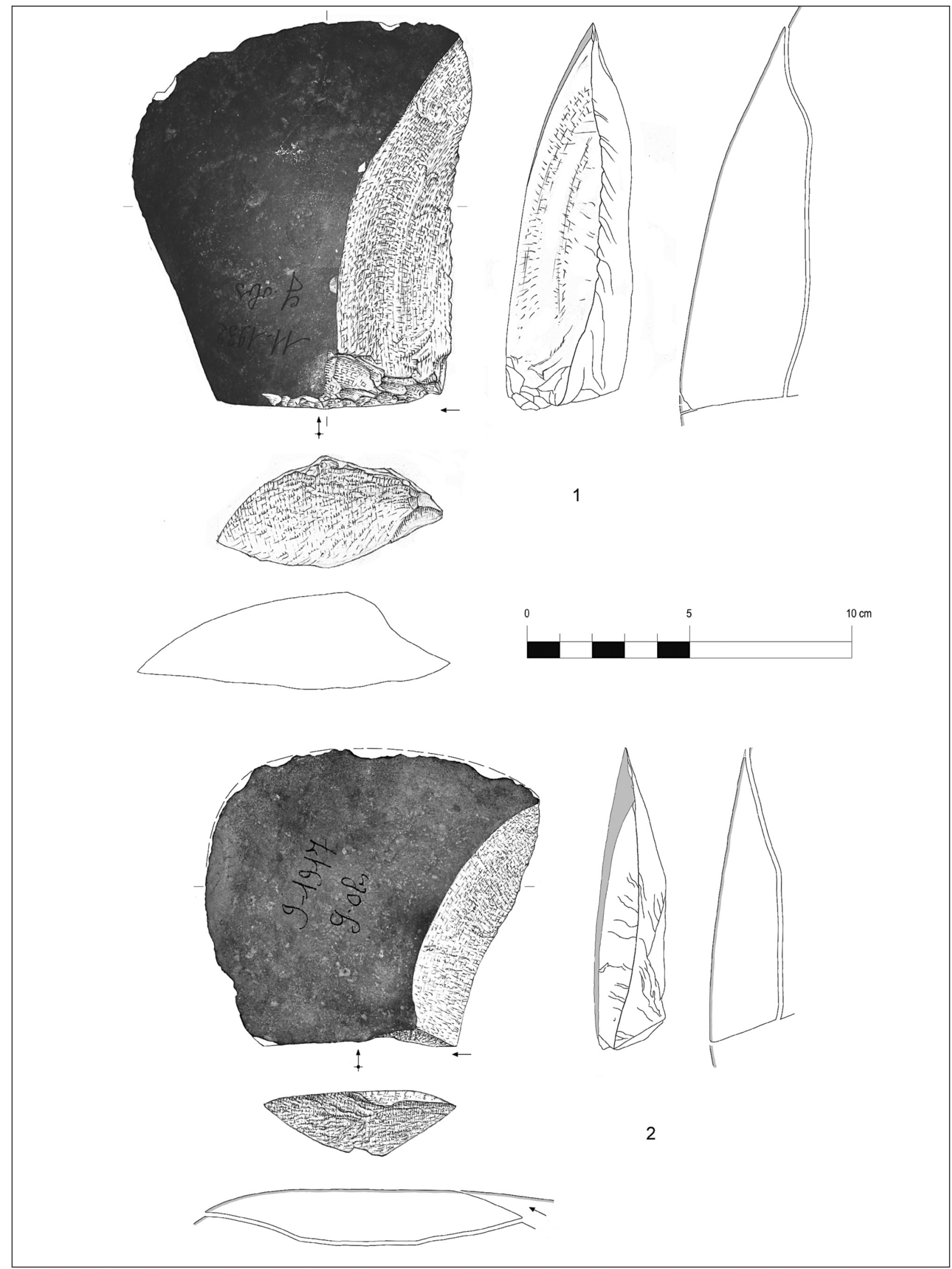

Figure 6 - Éclats à biseau cortical à préparation unilatérale du foyer $k$ de la grotte de l'Observatoire (dessins M. Grenet).

Figure 6 - Large flakes with cortical biseau showing an unilateral preparation, hearth $k$ of the Observatoire Cave (drawings by M. Grenet). 

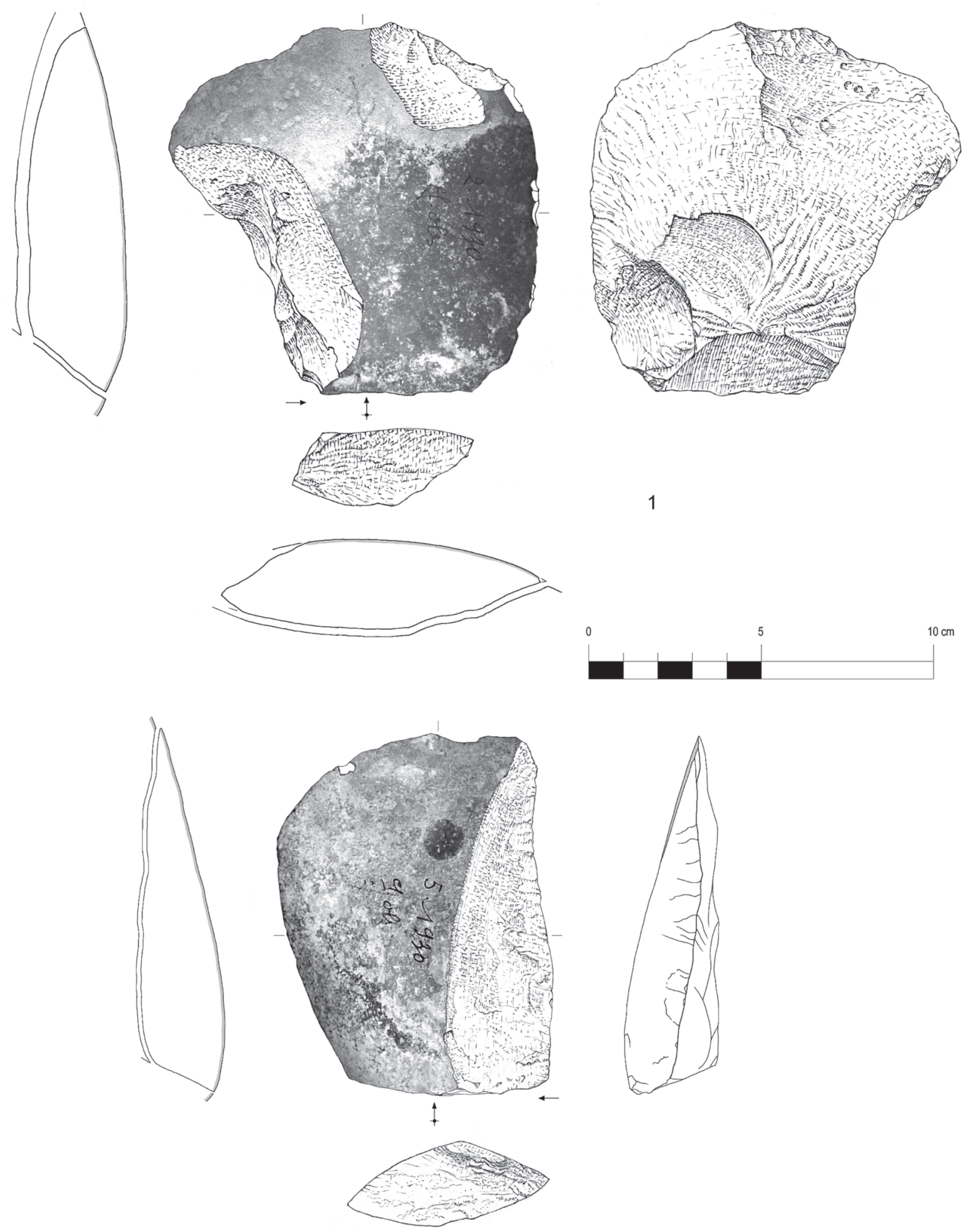

2

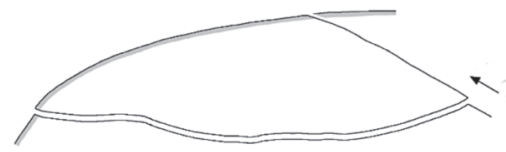

Figure 7 - Éclats à biseau cortical à préparation unilatérale du foyer $k$ de la grotte de l'Observatoire (dessins M. Grenet). Le spécimen $n^{\circ} 1$ montre une reprise bilatérale et un macro-esquillement prononcé du biseau terminal.

Figure 7 - Large flakes with cortical biseau showing an unilateral preparation, hearth $k$ of the Observatoire Cave (drawings by M. Grenet). 


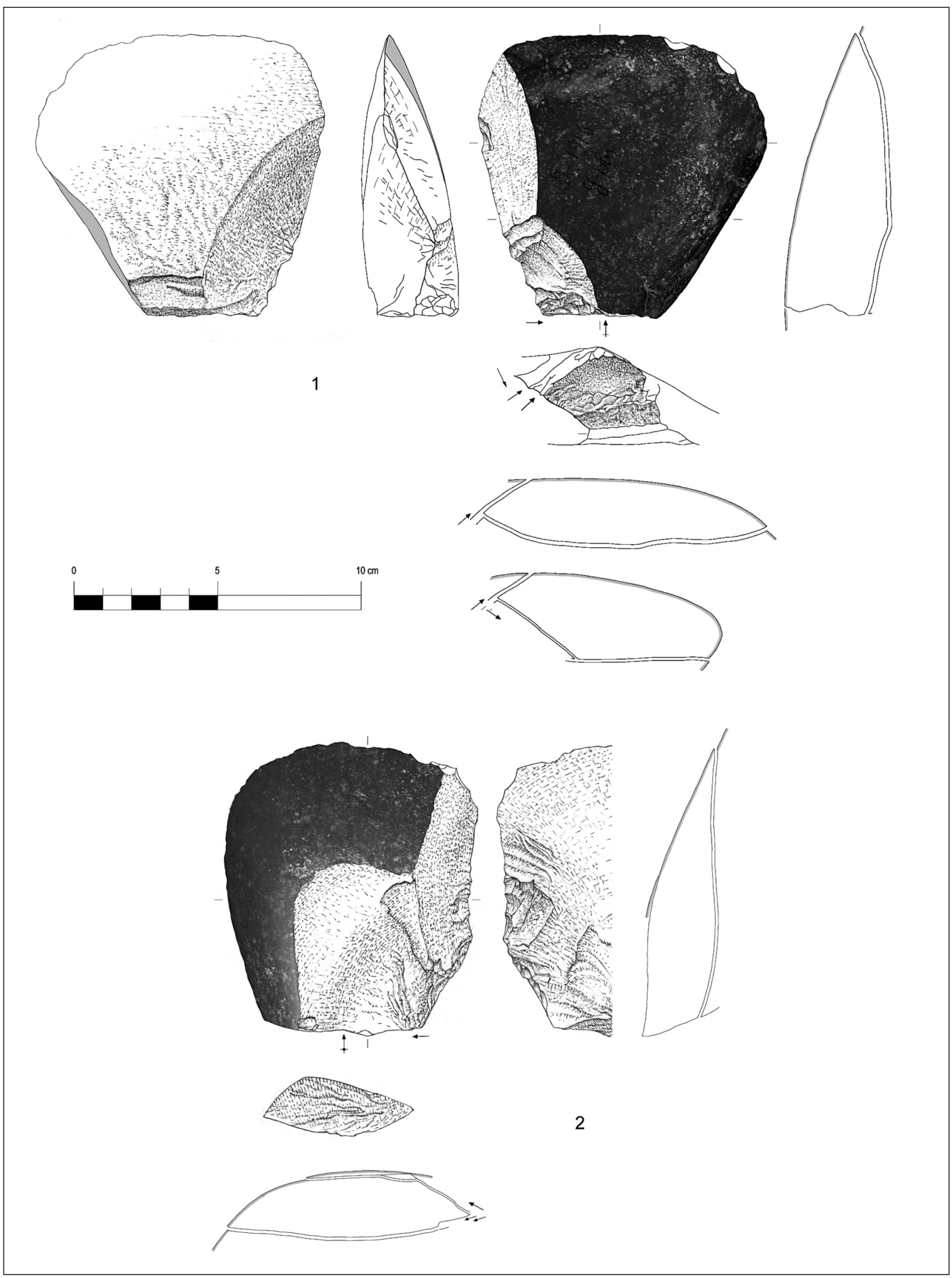

Figure 8 - Éclats à biseau cortical à préparation unilatérale du foyer $k$ de la grotte de l'Observatoire (dessins M. Grenet). Le spécimen $n^{\circ} 1$ montre une reprise bifaciale du bord gauche; le spécimen $n^{\circ} 2$ montre un macro-esquillement prononcé du bord droit.

Figure 8 - Large flakes with cortical biseau showing an unilateral preparation, hearth $k$ of the Observatoire Cave (drawings by M. Grenet). 

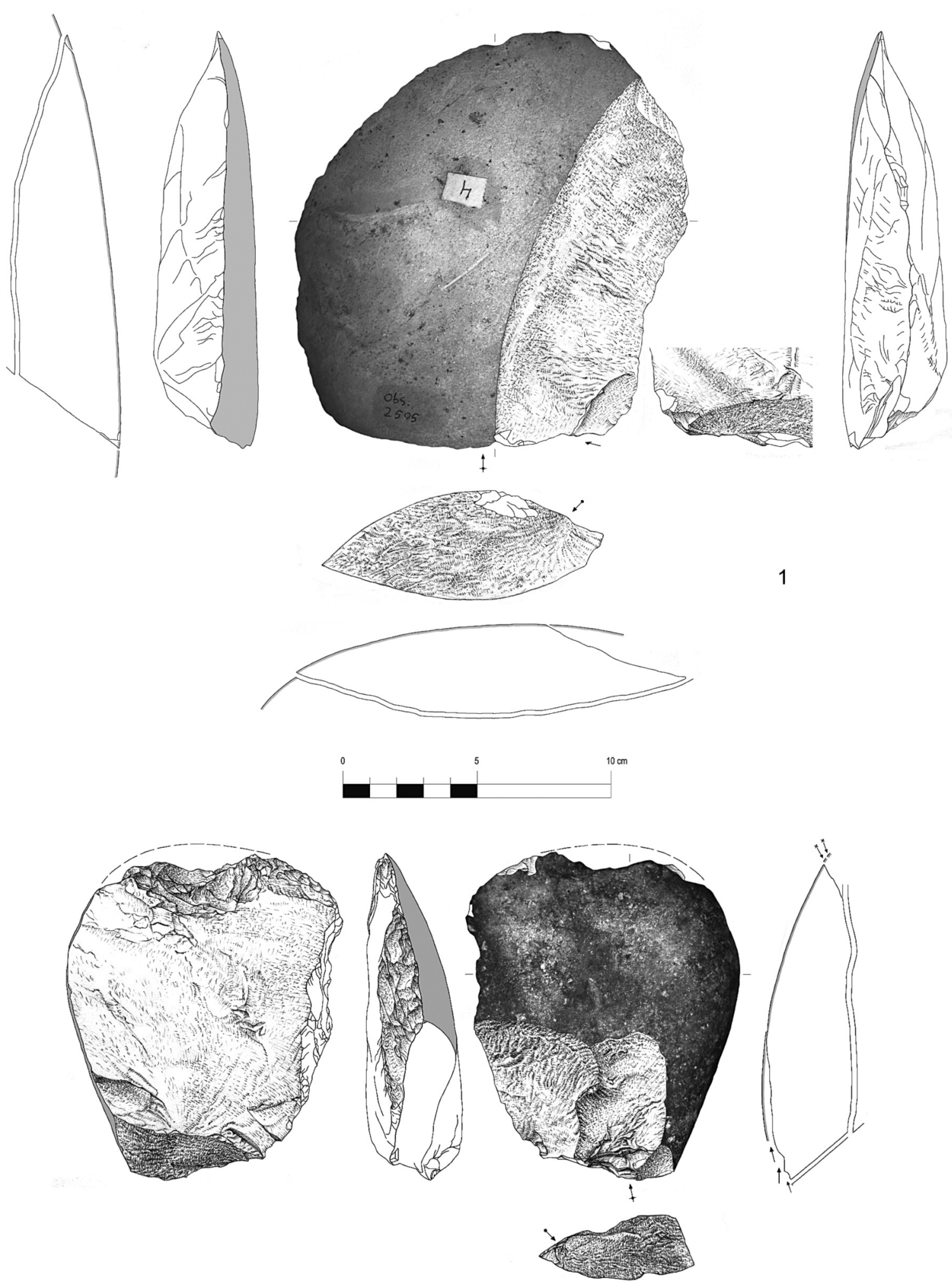

2

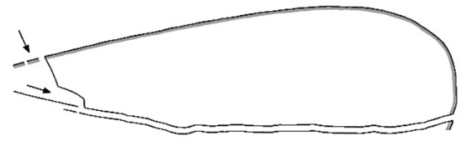

Figure 9 - Éclats à biseau cortical à préparation unilatérale du foyer $k$ de la grotte de l'Observatoire (dessins M. Grenet). Le spécimen $n^{\circ} 2$ montre un macro-esquillement très prononcé du biseau terminal.

Figure 9 - Large flakes with cortical biseau showing an unilateral preparation, hearth k of the Observatoire Cave (drawings by M. Grenet). 

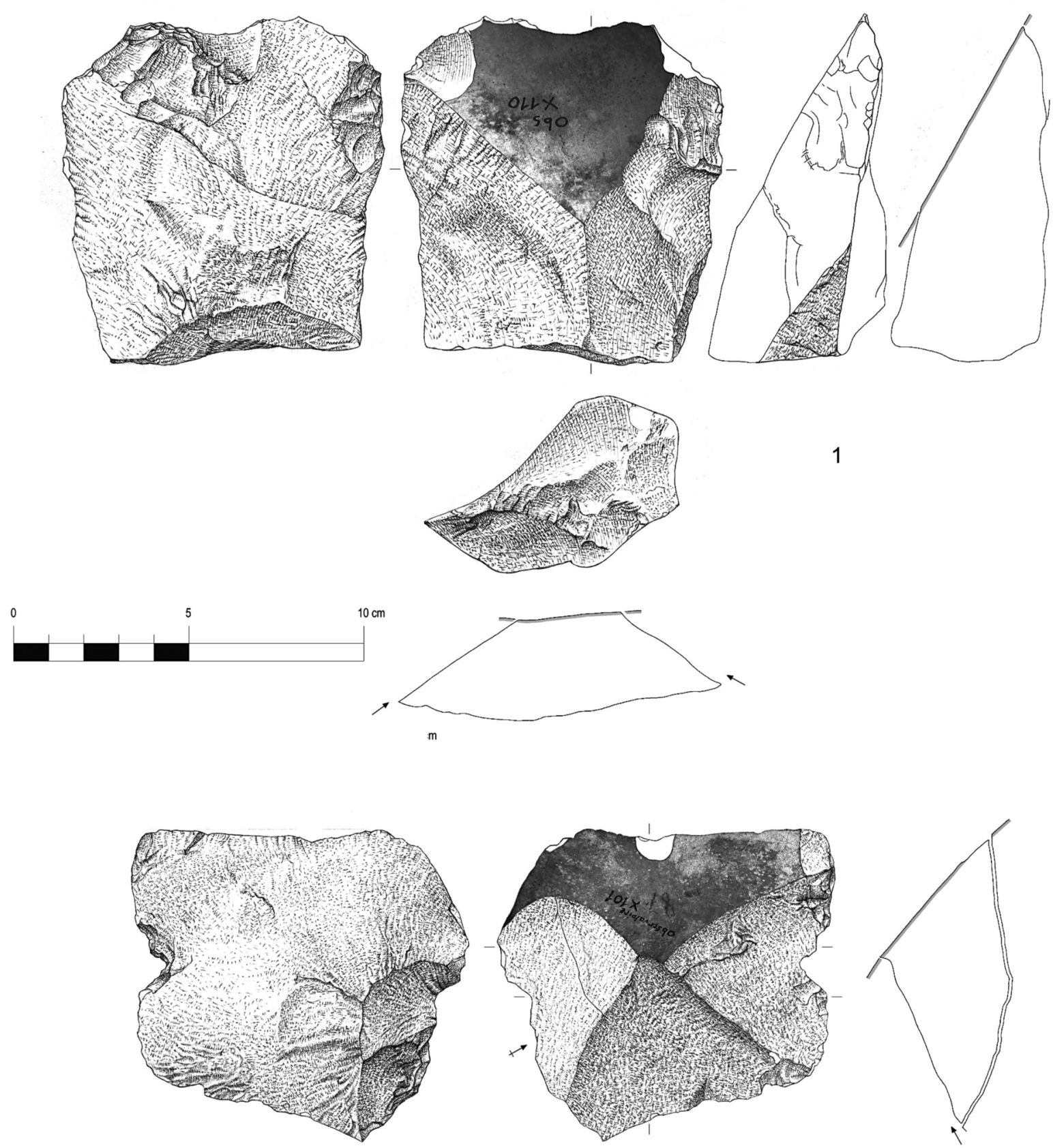

2
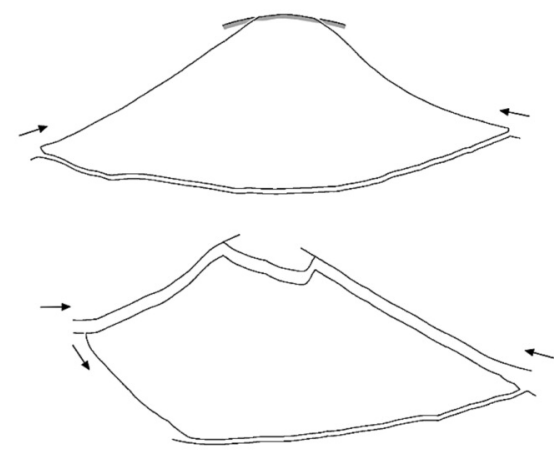

Figure 10 - Éclats à biseau cortical à préparation bilatérale du foyer $k$ de la grotte de l'Observatoire (dessins M. Grenet). Le spécimen $n^{\circ} 1$ montre un macro-esquillement prononcé du biseau terminal ; le spécimen $n^{\circ} 2$ montre un façonnage latéral inverse (axe morphologique).

Figure 10 - Large flakes with cortical biseau showing a bilateral preparation, hearth $k$ of the Observatoire Cave (drawings by M. Grenet). 

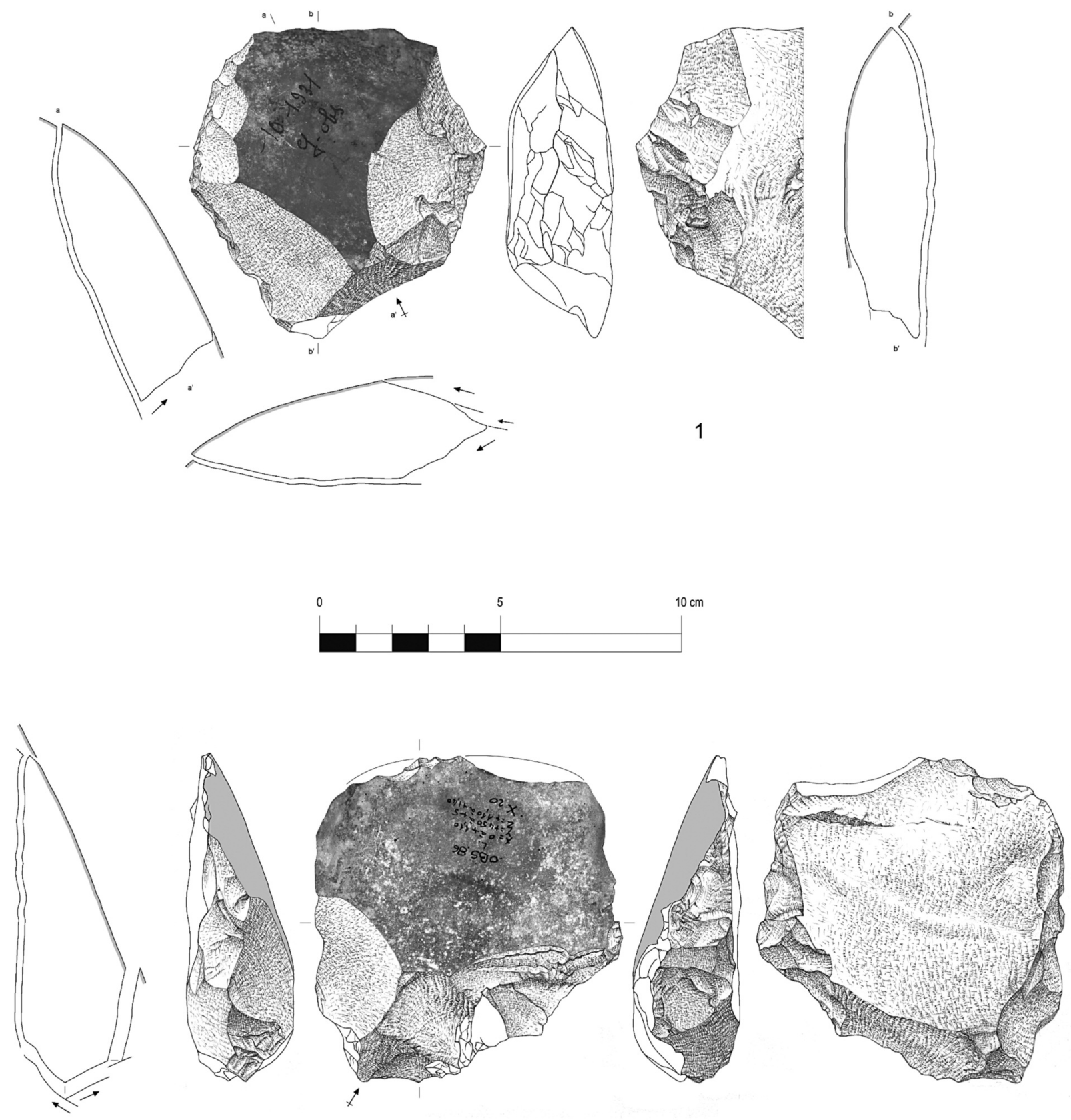

2

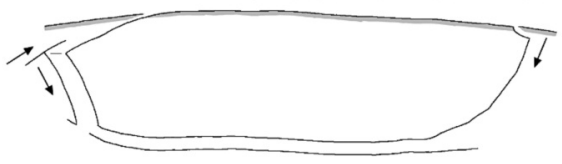

Figure 11 - Éclats à biseau cortical du foyer $k$ de la grotte de l'Observatoire (dessins M. Grenet). Le spécimen $n^{\circ} 1$ est un exemple à préparation bilatérale avec reprise bifaciale du bord droit, le spécimen $n^{\circ} 2$ est un exemple à préparation unilatérale avec reprise bilatérale et bifaciale.

Figure 11 - Large flakes with cortical biseau showing a bilateral $\left(n^{\circ} 1\right)$ an unilateral ( $\left.n^{\circ} 2\right)$ preparation, hearth $k$ of the Observatoire Cave (drawings by M. Grenet). 


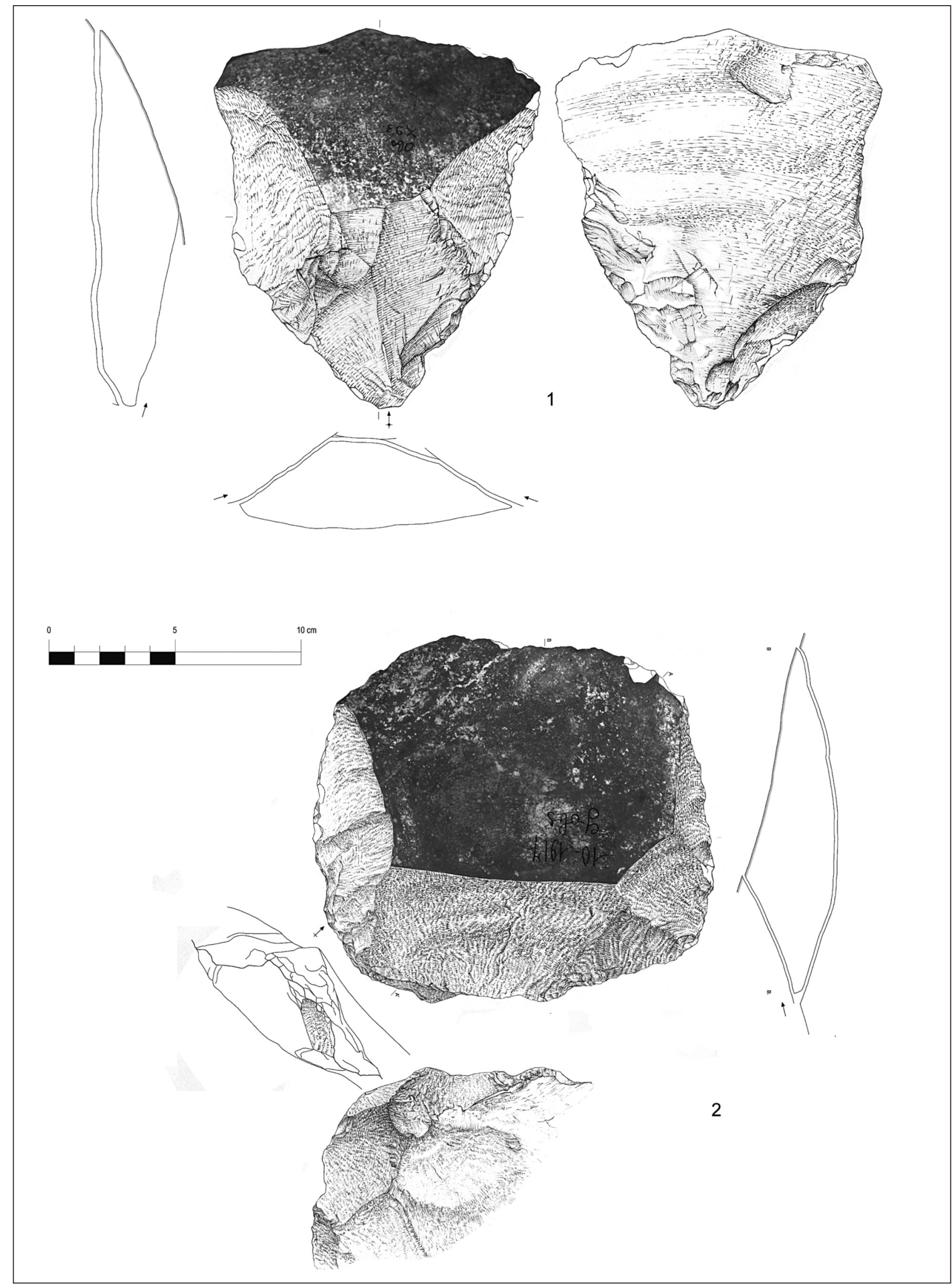

Figure 12 - Éclats à biseau cortical à préparation bilatérale du foyer k de la grotte de l'Observatoire (dessins M. Grenet). Le spécimen $n^{\circ} 1$ montre une reprise bilatérale partielle et un macro-esquillement localisé du biseau terminal ; le spécimen $n^{\circ} 2$ montre une reprise bifaciale latéro-proximale (axe morphologique).

Figure 12 - Large flakes with cortical biseau showing a bilateral preparation, hearth $k$ of the Observatoire Cave (drawings by M. Grenet). 


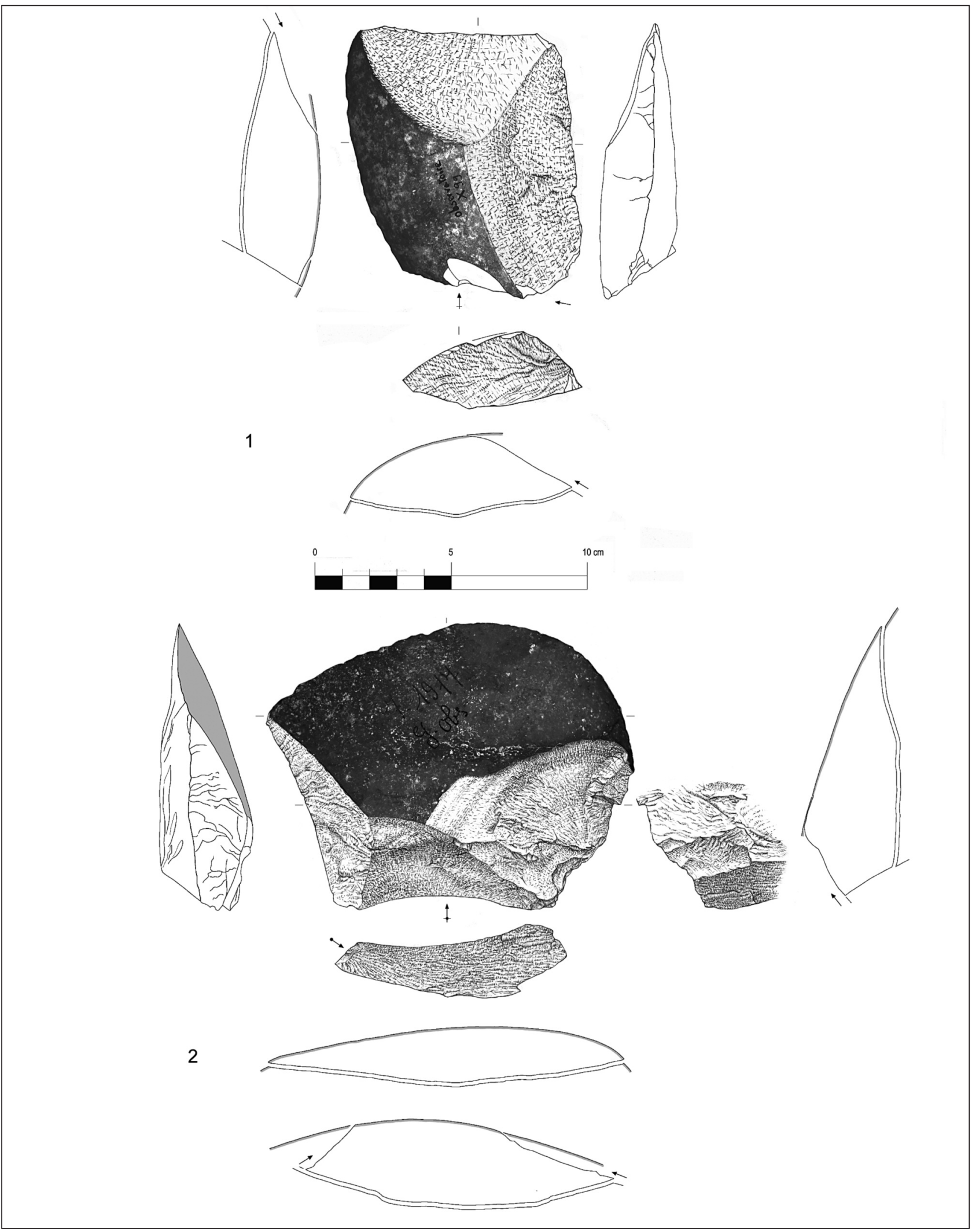

Figure 13 - Eclat biseauté $\left(n^{\circ} 1\right)$ et éclat à biseau cortical à préparation bilatérale $\left(n^{\circ} 2\right)$ du foyer $k$ de la grotte de l'Observatoire (dessins M. Grenet).

Figure 13 - Large flake with a prepared biseau $\left(n^{\circ} 1\right)$ and large flake with cortical biseau showing a bilateral preparation $\left(n^{\circ} 2\right)$ from the hearth " $k$ " of the Observatoire Cave (drawings by M. Grenet). 

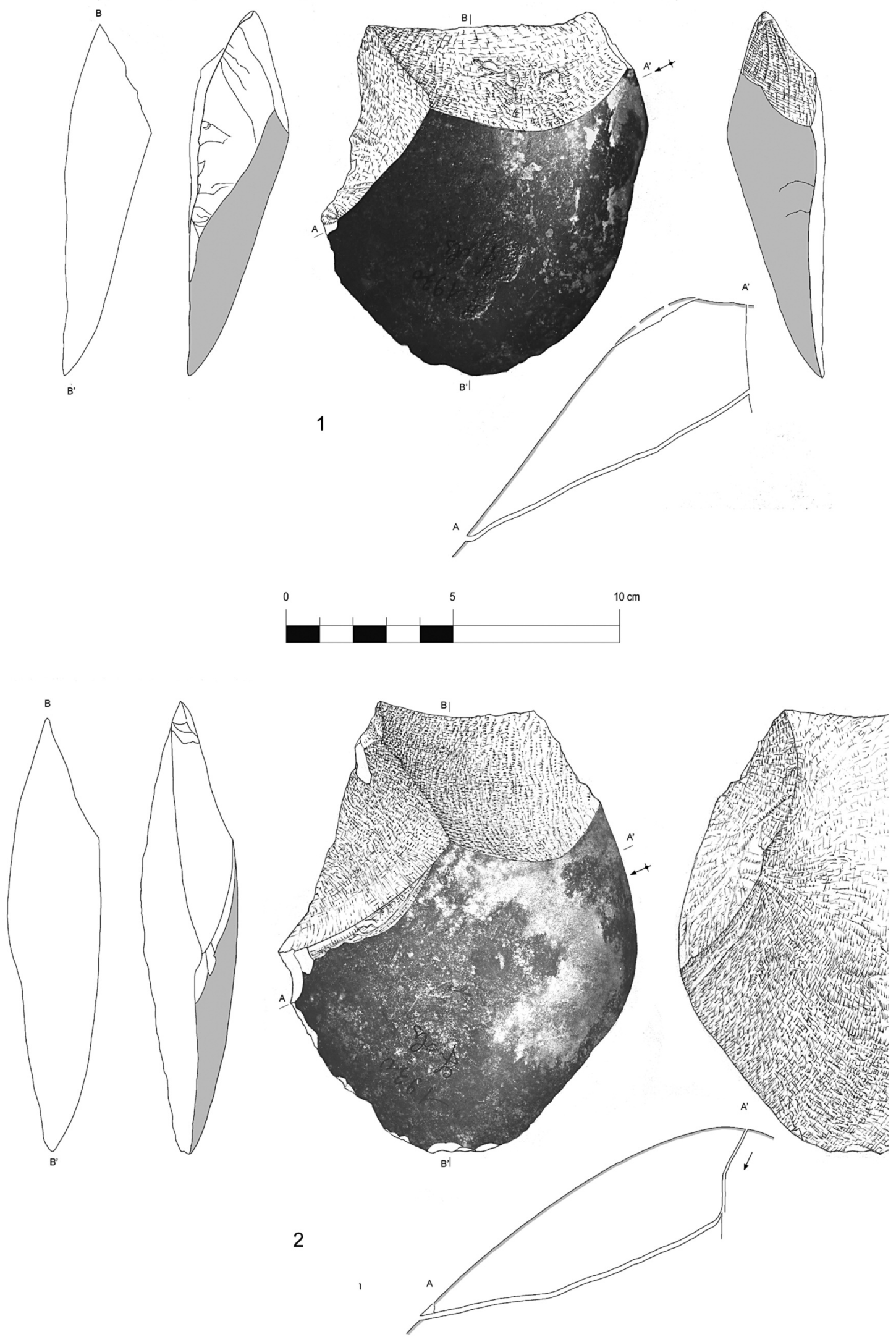

Figure 14 - Éclats biseautés du foyer $k$ de la grotte de l'Observatoire (dessins M. Grenet).

Figure 14 - Flakes with a prepared biseau from the hearth $k$ of the Observatoire Cave (drawings by M. Grenet). 


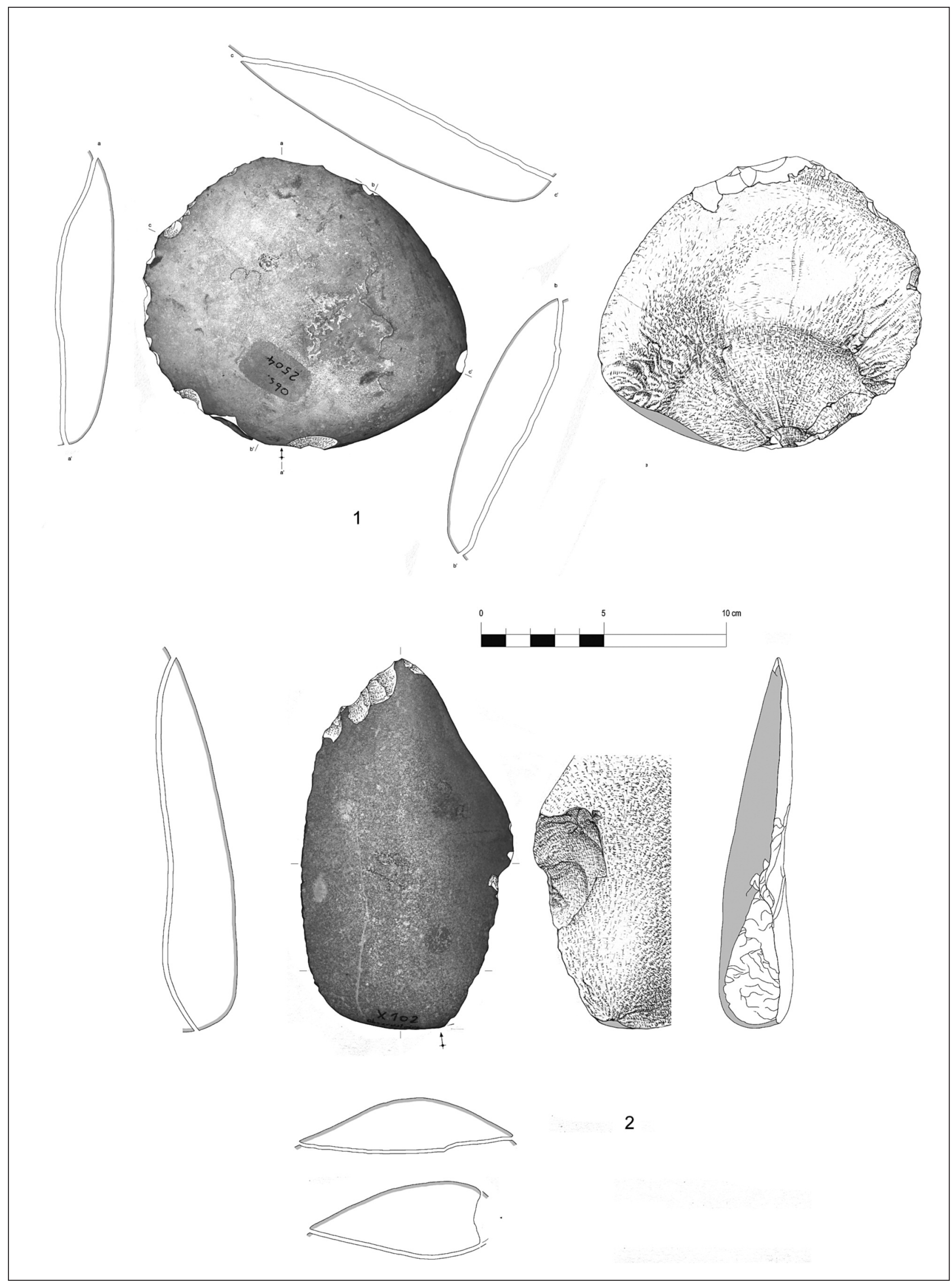

Figure 15 - Entames du foyer $k$ de la grotte de l'Observatoire (dessins M. Grenet). Les stigmates de percussion enregistrés sur le spécimen $n^{\circ} 1$ témoignent d'un probable détachement par percussion sur percuteur dormant.

Figure 15 - Entames from the hearth $k$ of the Observatoire Cave (drawings by M. Grenet). 


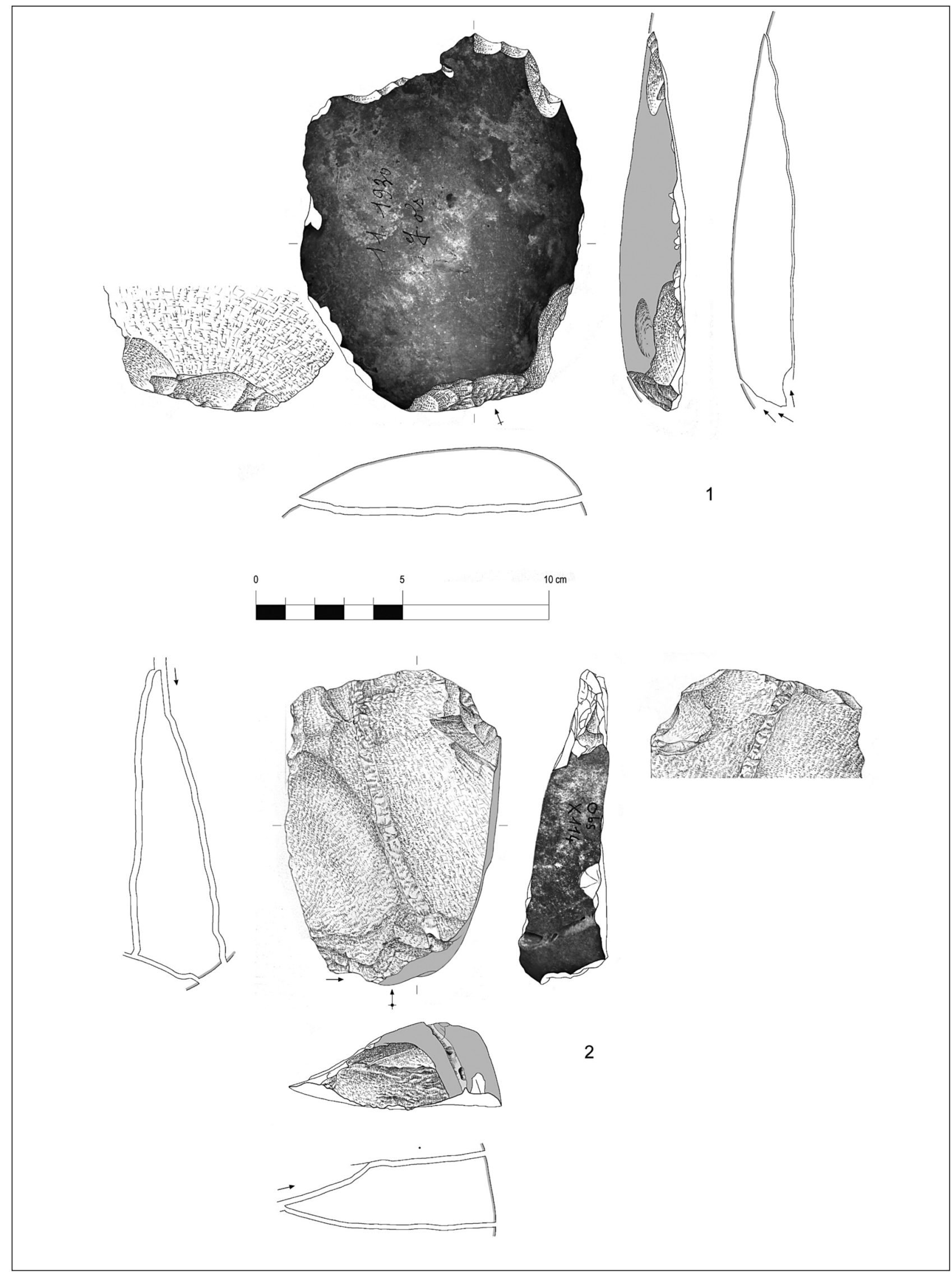

Figure 16 - Entame reprise à sa base $\left(n^{\circ} 1\right)$ et éclat à dos cortical à biseau terminal macro-esquillé $\left(n^{\circ} 2\right)$ du foyer "k" de la grotte de l'Observatoire (dessins M. Grenet).

Figure 16 - Entame and flake with a cortical back from the hearth $k$ of the Observatoire Cave (drawings by M. Grenet). 

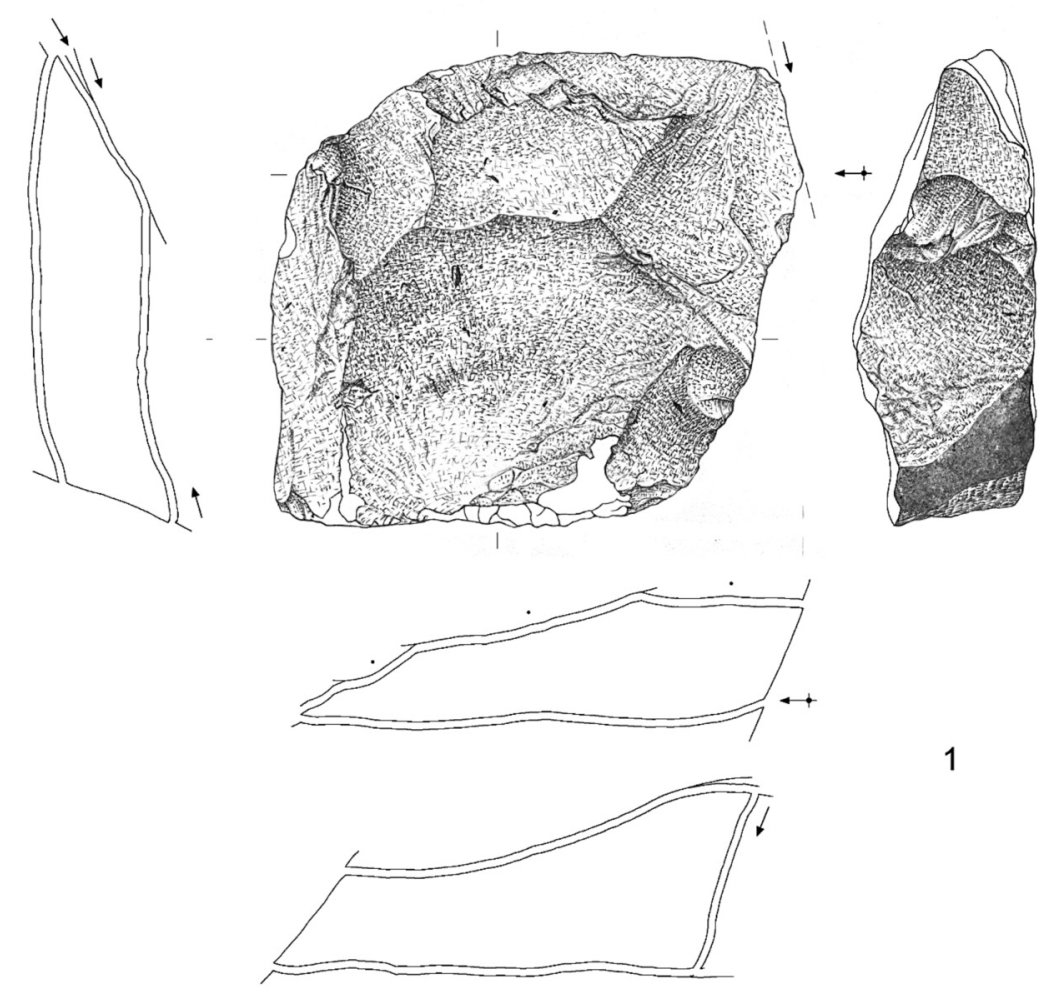

1
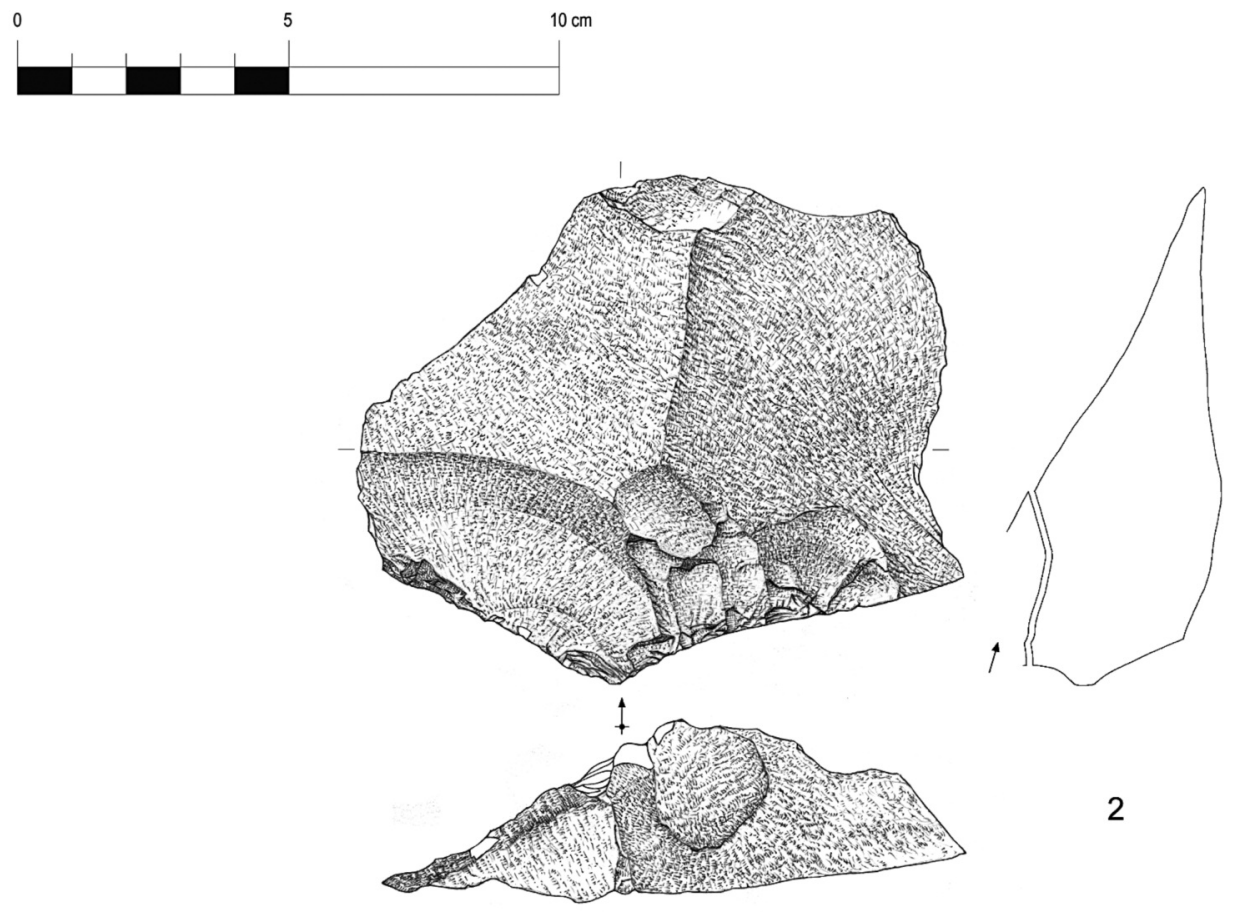

2

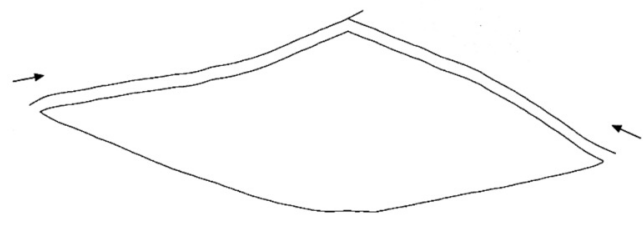

Figure 17 - Éclats à dos de débitage du foyer k de la grotte de l'Observatoire (dessins M. Grenet).

Figure 17 - Flakes with a back of debitage from the hearth $k$ of the Observatoire Cave (drawings by M. Grenet). 


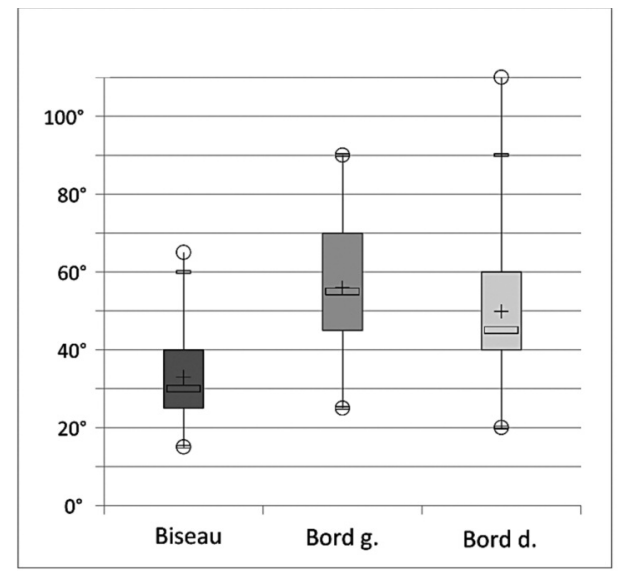

ANGLE DES BORDS-TRANCHANTS

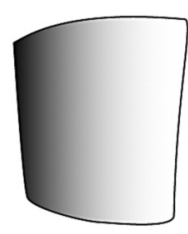

$29 \%$ des éclats à biseau cortical ont un tranchant exclusivement distal
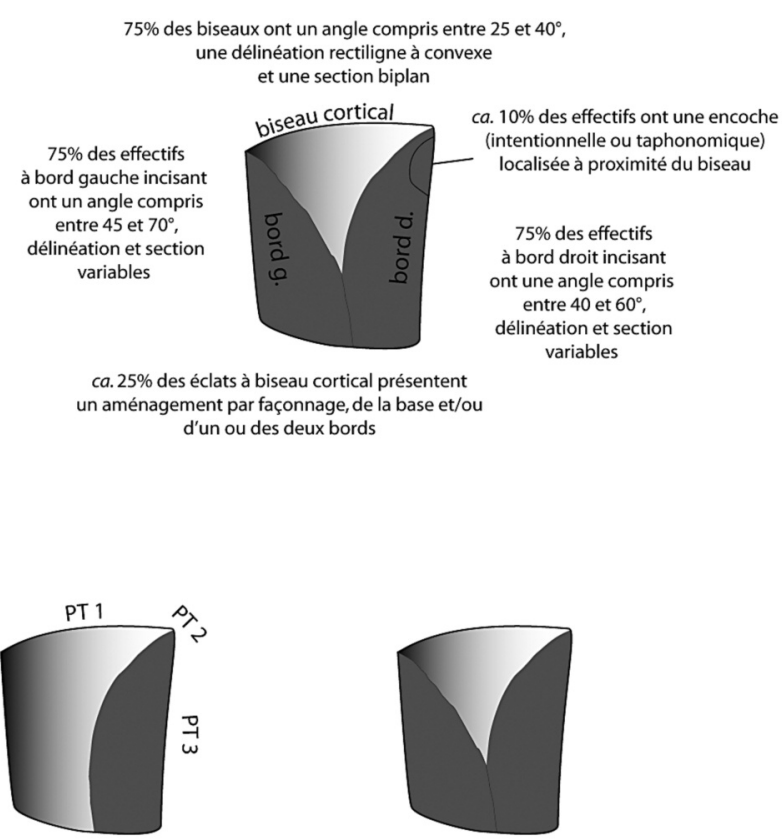

$62 \%$ des éclats à biseau cortical présentent un tranchant adjacent (PT = Partie transformative)

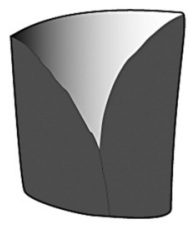

$9 \%$ des éclats à biseau cortical présentent un tranchant périphérique

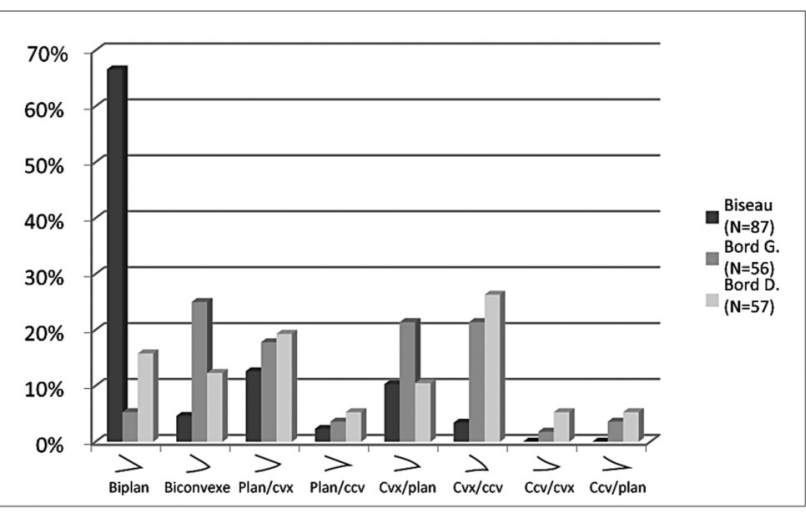

SECTION DES BORDS-TRANCHANTS

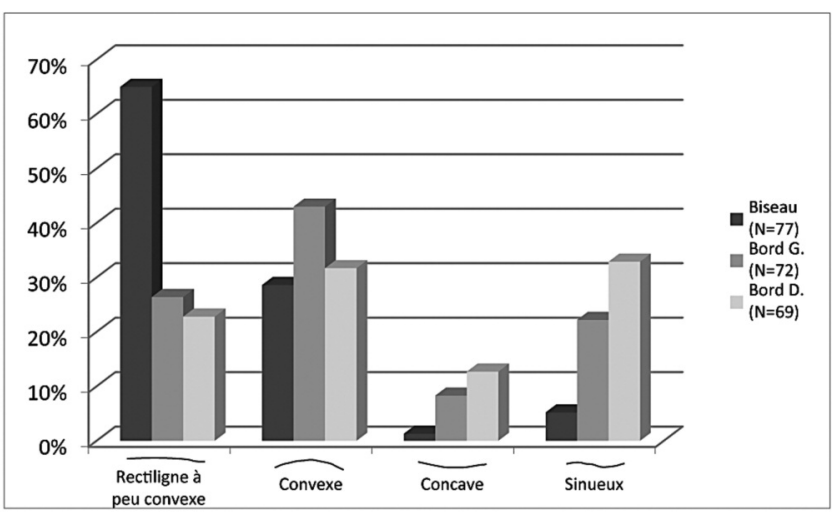

DELINEATION DES BORDS-TRANCHANTS

Figure 18 - Caractéristiques techno-fonctionnelles de la population des éclats à biseau cortical du foyer k de la grotte de l'Observatoire (DAO G. Porraz).

Figure 18 - Techno-functional characteristics of the large flakes with a cortical biseau from the hearth $k$ of the Observatoire Cave.

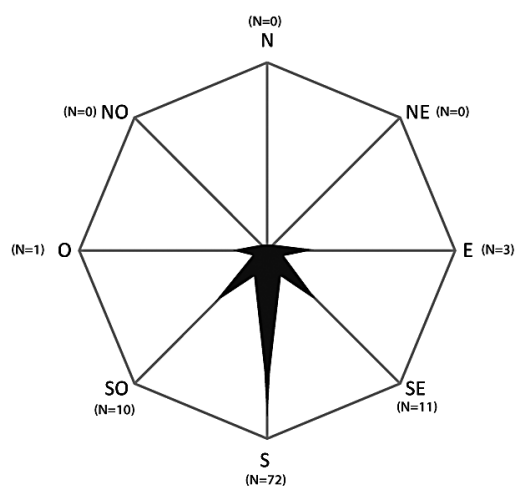

$\underset{(N=72)}{S}$

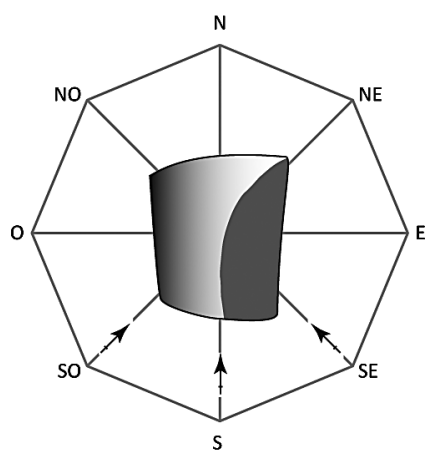

Axes de débitage
Figure 19 - Directions de débitage des éclats à biseau cortical du foyer $k$ de la grotte de l'Observatoire (DAO G. Porraz).

Figure 19 - Directions of the blow for the large flakes with cortical biseau from the hearth $k$ of the Observatoire Cave. 


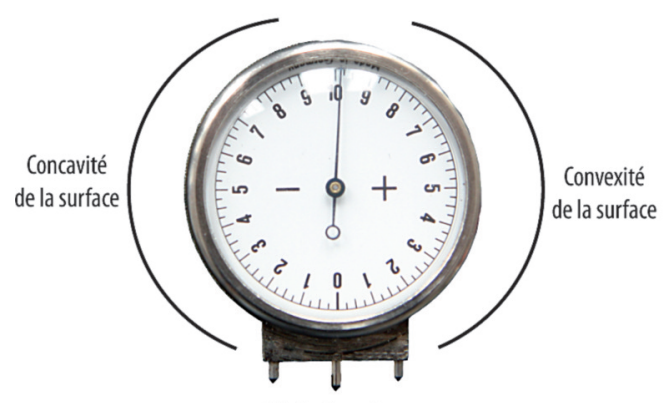

(0) Surface plane

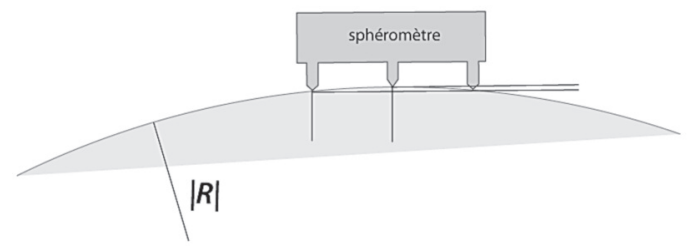

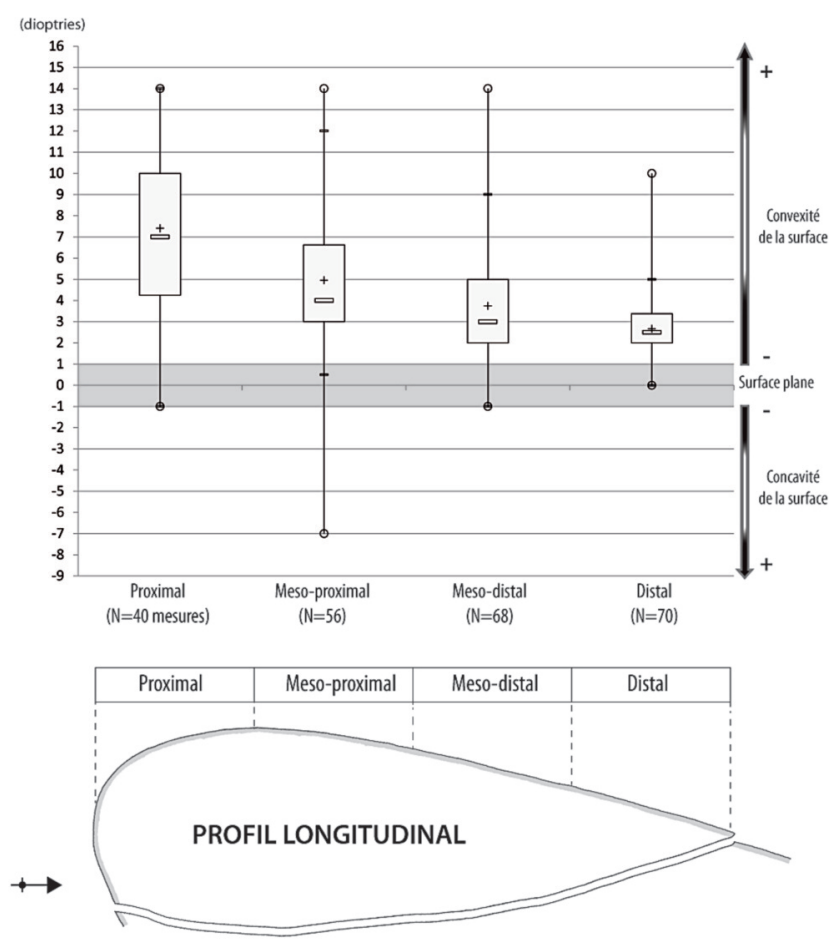

Figure 20 - Planéité des surfaces corticales débitées à la grotte de l'Observatoire. Le calcul de planéité des surfaces corticales des galets débités repose sur la mesure de 4 points équidistants pris dans l'axe de débitage des éclats. Les données affichées sur le sphéromètre (données en dioptrie, image de gauche) correspondent à un rayon de courbure $(R)$. Ces données, restituées sur une boite à moustache (à droite), indiquent une diminution régulière de ce rayon de courbure, qui se rapproche alors d'une surface plane en partie distale. (DAO G. Porraz).

Figure 20 - Planarity of the cortical surfaces exploited at the Observatoire Cave. The calculation of the planarity is based on the measure of 4 equidistant points taken in the axis of debitage of the large flakes. The data appearing on the spherometer (given in dioptries, image on the left) indicate a curvature radius $(R)$. These data, expressed on a boxplot (on the right), express a regular diminution of the curvature radius; which tends to be almost a flat surface on the distal part.

\begin{tabular}{|c|c|c|c|c|c|c|c|c|}
\hline & & entames & $\begin{array}{c}\text { éclats } \\
\text { corticaux }\end{array}$ & $\begin{array}{l}\text { écl. corticaux } \\
\text { à prep lat }\end{array}$ & $\begin{array}{c}\text { écl. corticaux } \\
\text { à prep bilat }\end{array}$ & $\begin{array}{c}\text { céclats } \\
\text { préparés }\end{array}$ & éclats à dos & total (N) \\
\hline \multirow{7}{*}{ ¿ } & cortical & 13 & 0 & 1 & 0 & 2 & 0 & 16 \\
\hline & lisse a pan & 0 & 5 & 32 & 2 & 0 & 4 & 43 \\
\hline & lisse & 0 & 12 & 15 & 6 & 3 & 2 & 38 \\
\hline & préparé & 0 & 0 & 0 & 2 & 0 & 0 & 2 \\
\hline & oté & 2 & 1 & 2 & 6 & 1 & 0 & 12 \\
\hline & indéterminé & 0 & 0 & 2 & 0 & 2 & 1 & 5 \\
\hline & total $(\mathrm{N})$ & 15 & 18 & 52 & 16 & 8 & 7 & 116 \\
\hline
\end{tabular}
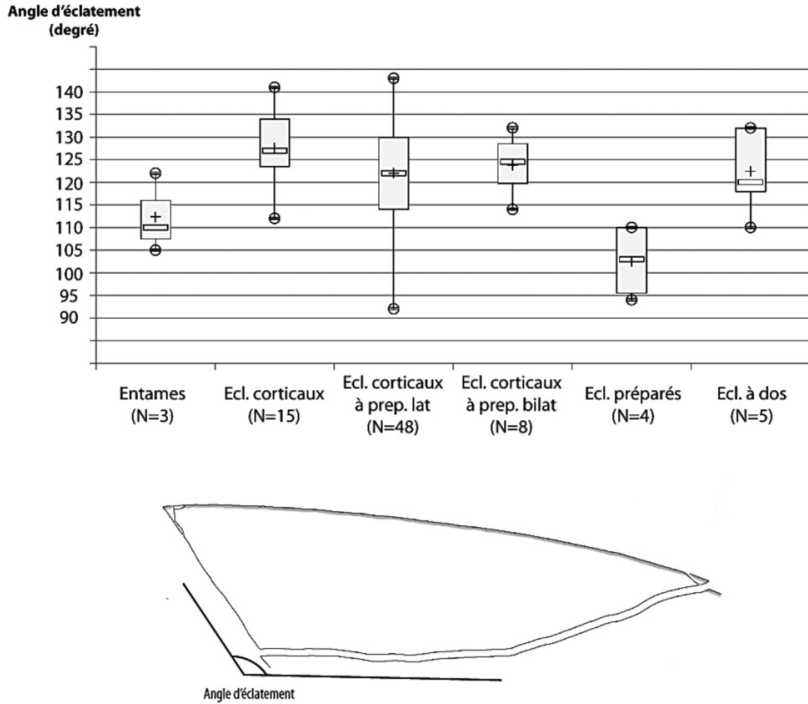

Figure 21 - Classes et angle d'éclatement des talons des grands éclats du foyer k de la grotte de l'Observatoire (DAO G. Porraz).

Figure 21 - Butts types and angles of the large flakes from the hearth $k$ of the Observatoire Cave. 

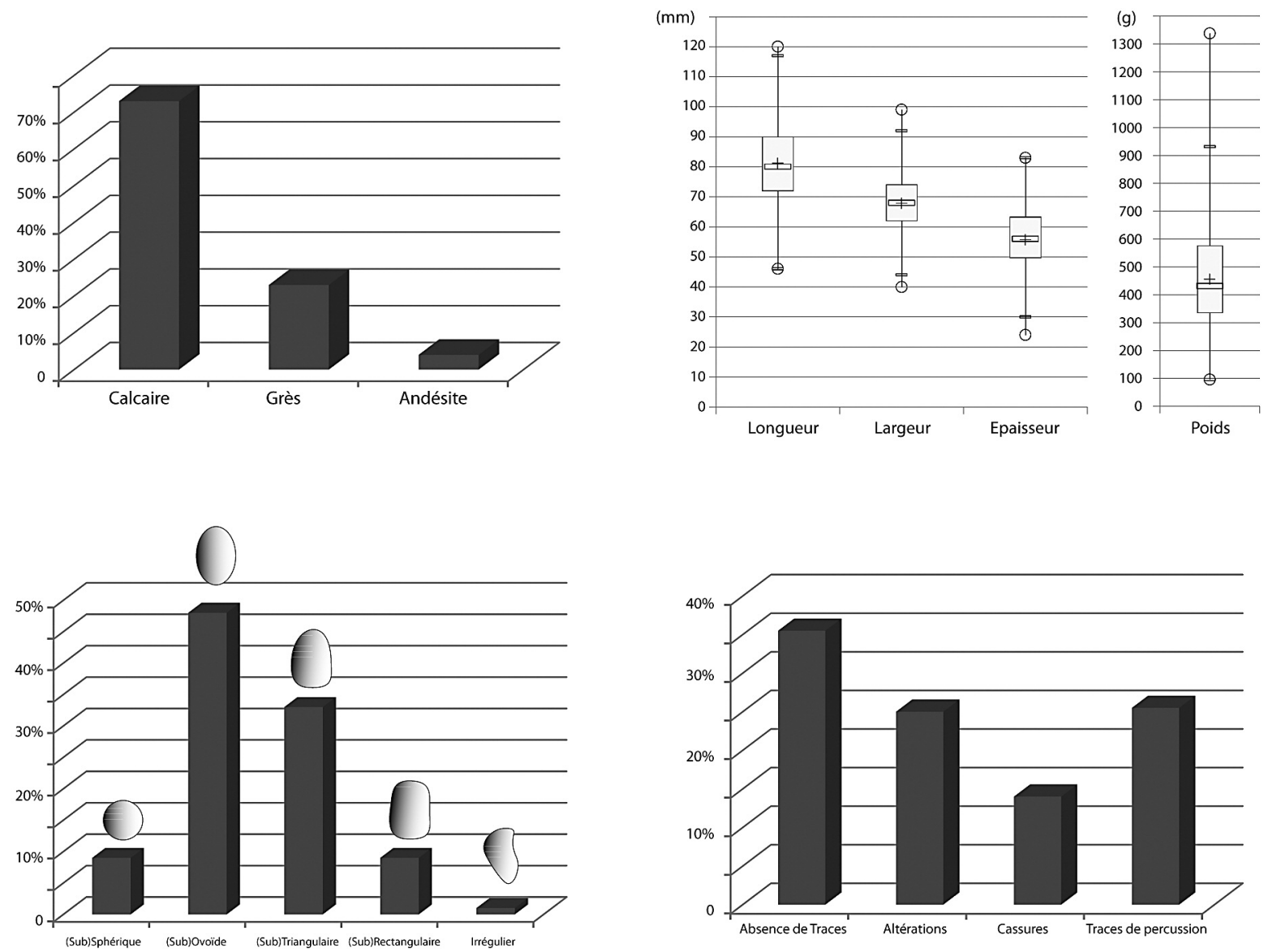

Figure 22 - Données générales (matières premières, dimensions et poids, morphologies, états de surface) sur le corpus de galets manuportés du foyer $k$ de la grotte de l'Observatoire (DAO G. Porraz).

Figure 22 - General observations (raw materials, metrical data, morphologies, presence or absence of natural or functional marks on the surface) on the cobbles from the hearth $k$ of the Observatoire Cave.

anthropique, probablement non intentionnelles, mais l'absence de référentiel et d'expérimentation ne permet pas d'aller plus loin dans cette discussion.

Un second aspect intéressant de l'analyse technologique est la proportion élevée de galets ne portant aucune trace d'utilisation (fig. 22). L'hypothèse nulle est que l'origine de tous les galets serait naturelle, certains ayant alors été sélectionnés de façon peut-être opportuniste, puis utilisés. Toutefois, nous rejetons catégoriquement cette hypothèse. Cette dernière en effet impliquerait que l'origine de ces galets marins soit liée à une remobilisation d'anciens dépôts brèchifiés d'âge pré-calabrien ou Pliocène, situés dans les environs de la grotte et qui auraient donc participé au remplissage du karst. Aucun témoin géologique n'appuie cette hypothèse. Par ailleurs, le tri dimensionnel observé au sein de notre population évoque un spectre d'origine artificielle et non pas naturelle. Les galets manuportés sans trace d'usure correspondent donc à des galets peu ou pas utilisés, ou à des galets utilisés sur des matériaux tendres, des végétaux par exemple. En l'état de nos connaissances, il est hasardeux de proposer une fonction et un mode de fonctionnement pour ces galets. Tout au plus pouvons-nous remarquer que des roches de différente nature ont été utilisées en percussion, et que des facettes différentes d'un même galet pouvaient être mobilisées lors de l'activité. La question des économies minérales et des propriétés des roches est certainement une réflexion à pousser davantage. Notons que les galets en grès présentent un effectif avec traces de percussion qui est beaucoup plus important que celui des calcaires (respectivement ca. $50 \%$ et $20 \%$ des galets non altérés). La nature des activités tout autant que les capacités d'enregistrement de la roche doivent contribuer à expliquer cette différence.

Enfin 4 galets, 2 en grès, 1 en calcaire et 1 en andésite, montrent les traces d'un débitage sur enclume (fig. 23), réalisés dans le plus petit axe d'allongement. Aucun des petits éclats retrouvés ne portent les traces d'un tel débitage, qui demeure donc anecdotique dans notre série. 

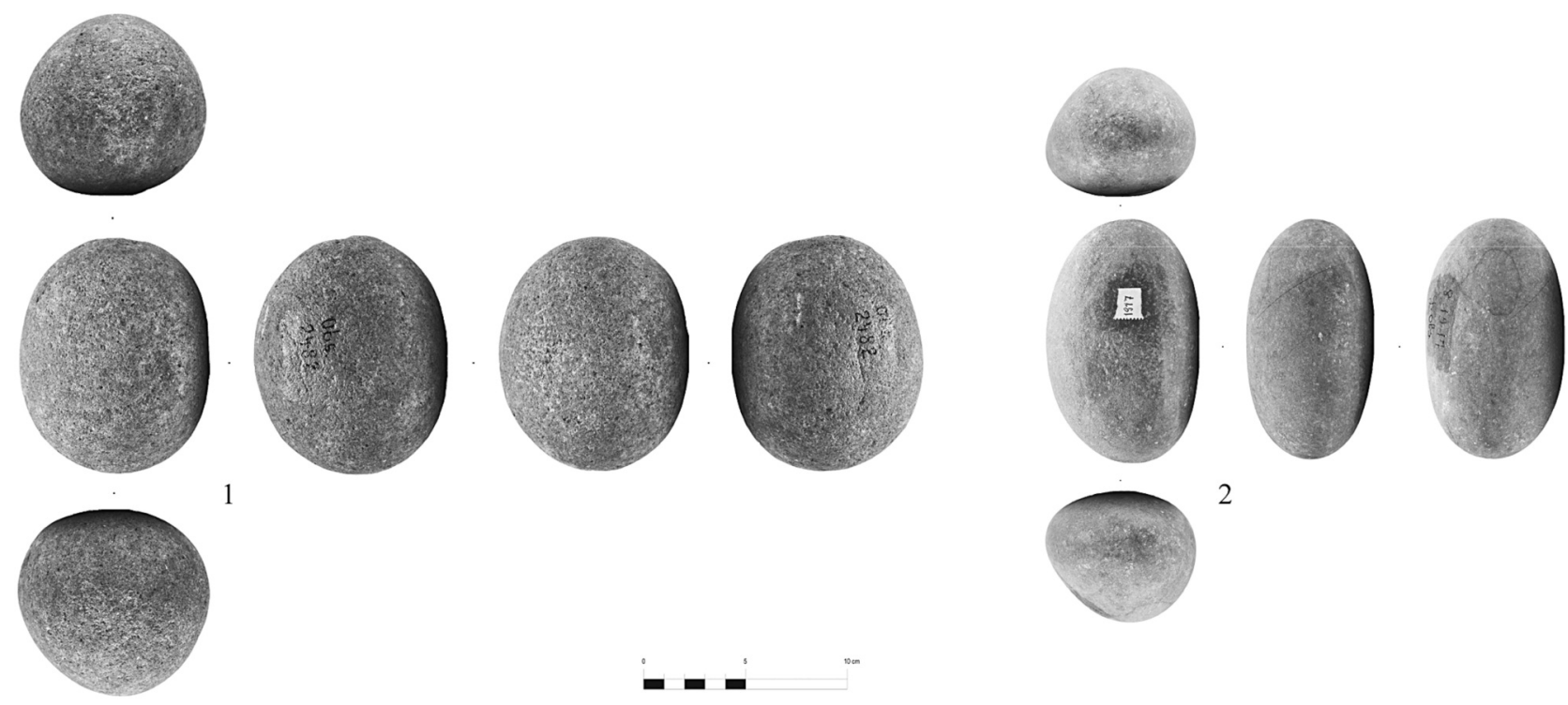

1

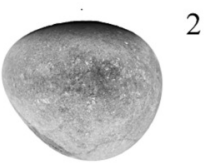

2
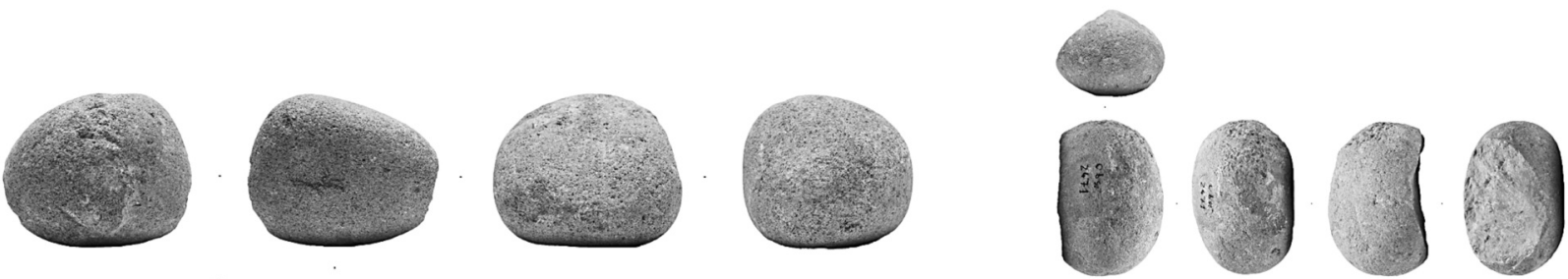

3
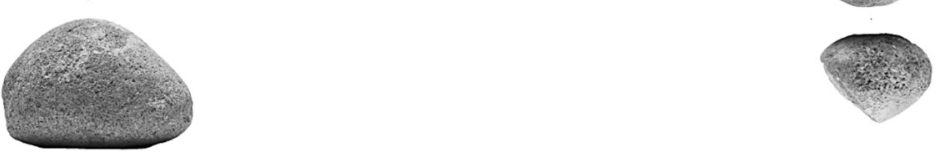

4
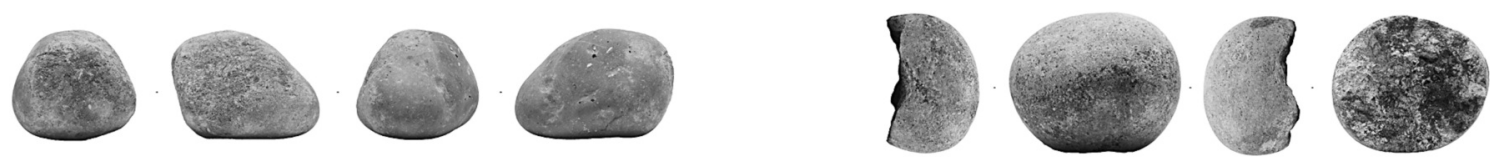

5

6
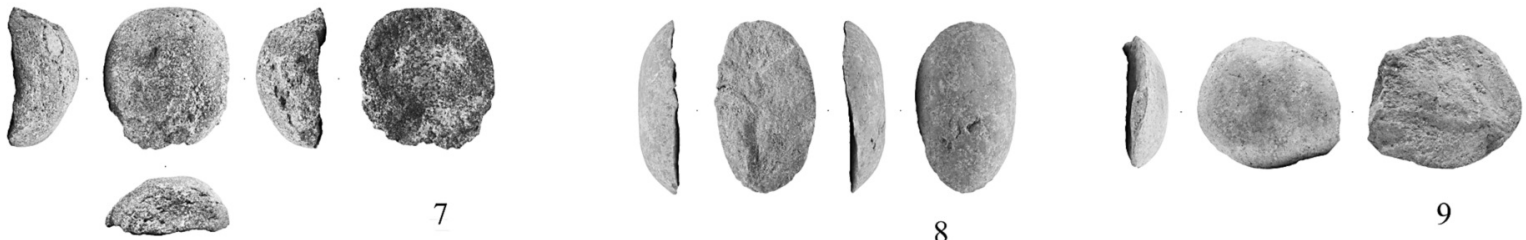

8

9

Figure 23 - Exemples de galets manuportés du foyer $k$ de la grotte de l'Observatoire ( $n^{\circ} 1$-3, 6 : grès, $n^{\circ}$ 4-5, 8-9 : calcaire, $n^{\circ} 7$ : andésite; $n^{\circ} 1-3,5:$ galets avec plages de percussion localisées; $n^{\circ} 6-7:$ galets avec traces d'un débitage sur enclume ; $n^{\circ} 4$ : galet à 1 enlèvement intentionnel ; $n^{\circ} 8-9$ : éclats de percussion) (clichés Michel Dagnino, DAO F. Burle, G. Porraz).

Figure 23 - Examples of cobbles from the hearth $k$ of the Observatoire Cave ( $n^{\circ}$ 1-3, $6:$ sandstone, $n^{\circ} 4-5,8-9$ : limestone, $n^{\circ} 7:$ andesite $; n^{\circ} 1-3,5:$ cobble with scars of a use in percussion : $n^{\circ} 6-7:$ cobbles with marks of an anvil percussion ; $n^{\circ} 4:$ cobble with one intentional removal ; $n^{\circ} 8-9$ : incidental flakes from a percussion) (clichés Michel Dagnino, DAO F. Burle, G. Porraz). 


\section{Le biface à base réservée}

Un biface est présent dans l'industrie (fig. 24). II s'agit d'un galet taillé en calcaire de grandes dimensions $(215 \times 98 \times$ $55 \mathrm{~mm}$ ), à base corticale réservée. Ce biface présente deux bords aménagés par plusieurs rangs d'enlèvements courts détachés alternativement sur une face et puis l'autre. Ces enlèvements créent deux tranchants biplans en section, de près de $100 \mathrm{~mm}$ de longueur et de délinéation rectiligne pour l'un, sinueuse pour l'autre. La partie apicale amincie résulte de la confection des bords tranchants et ne semble pas recherchée spécifiquement. Les angles de tranchant décroissent de la base vers la pointe, s'étirant respectivement de $70-80^{\circ}$ à $35-45^{\circ}$.

Nous avons déjà signalé que ce biface avait été associé à tort aux deux spécimens retrouvés dans les planchers III-II (fig. 75 : in Lumely-Woodyear 1969), alors même que celuici a été retrouvé près de $7 \mathrm{~m}$ en dessous du plancher III. Par ailleurs, il faut préciser que les deux pièces bifaciales du plancher III-II, également façonnées sur calcaire, se distinguent clairement du biface de notre collection. L'une de ces pièces bifaciales est un grand éclat fendu en "split » façonné partiellement, opposant un dos à un tranchant affuté. La seconde pièce bifaciale témoigne quant à elle d'une suite d'enlèvements qui ont rompu l'équilibre de la pièce avant son abandon. Cette différence avait été retenue par l'abbé H. Breuil et H. Kelley (1954) qui avaient qualifié notre biface à base réservée de biface abbevillien et les deux pièces bifaciales supérieures de biface chelléen.

Notons également la présence d'un très gros galet en calcaire, d'un poids de $1655 \mathrm{~g}$, taillé bifacialement à l'une de ses extrémités. L'originalité de cette séquence d'enlèvements, la nature des éclats détachés ainsi que l'émoussé présent sur le dièdre de débitage, d'angle très ouvert, nous conduisent à privilégier l'hypothèse d'un galet aménagé plutôt que celle d'une courte série de production.

\section{Synthèse}

L'assemblage lithique du foyer $\mathrm{k}$ de la grotte de l'Observatoire marie la présence de grands éclats, de galets naturels sélectionnés et d'un unique biface. L'accès au savoir-faire technique de ces populations repose donc essentiellement sur la collection des grands éclats, de laquelle se dégage une forte homogénéité. La synthèse que nous proposons du débitage d'éclats à biseau cortical, ou débitage de l'Observatoire (fig. 25), est une interprétation qui repose sur une suite de remontages mentaux (Pelegrin 1995) réalisés à partir de notre effectif de produits finis $(\mathrm{N}=132)$.

Les tailleurs de la grotte de l'Observatoire ont répété à l'identique une suite de gestes et d'opérations bien maîtrisées et particulièrement adaptées au matériau travaillé, qui avaient pour objectif la production d'éclats à tranchant transversal, de grande dimension et de forte masse. La conception du débitage impliquait la production d'un seul éclat prédéterminé par bloc. Seule une partie du volume était donc exploitée par les tailleurs, sans récurrence, sans solution technique appliquée pour reconfigurer le volume du nucléus à l'identique. Dans le cadre de cette production à courte séquence opératoire, nous reconnaissons deux opérations critiques : 1) la phase de conception ou initialisation du volume utile ; 2) les phases de détachement des éclats ou exécution des tâches.

La première étape de cette chaîne opératoire reposait sur la sélection d'un volume adapté au projet. Compte tenu de la brièveté des opérations de débitage, cette phase de sélection peut être considérée comme partie intégrante de la phase d'initialisation, qu'elle préfigure (Boëda 2013). Dans un contexte détritique probablement de plage ou de lit fluviatile, les tailleurs ont sélectionné des galets hémisphériques d'un volume suffisant pour retirer un ou des éclats d'au moins $100 \mathrm{~mm}$ de long. La masse du galet débité semble toutefois avoir représenté un critère de second ordre, derrière le critère de planéité. La morphologie des supports et les critères de convexité requis pour le débitage nous font privilégier l'hypothèse d'une exploitation des galets dans leur plus petit axe d'allongement.

La seconde étape consistait alors à détacher un éclat $(E 1)$ sur la surface d'exploitation, percuté dans un angle d'un rayon de $90^{\circ}$ par rapport au futur axe de débitage du produit recherché. Cet enlèvement est strictement prédéterminant, son objectif étant de rééquilibrer les convexités transversales naturelles du galet sélectionné. Le cas échéant, un second éclat (E1'), opposé au premier, était détaché, pareillement orienté dans un angle d'un rayon de $90^{\circ}$ par rapport au futur axe de débitage du produit recherché. Le choix ou non de retirer un deuxième éclat prédéterminant s'établissait alors en fonction des convexités naturelles offertes par le galet. Les données à disposition suggèrent une exploitation E1 qui était légèrement excentrée sur la surface d'exploitation (mettant à profit les convexités naturelles) et une exploitation E1' qui était quant à elle davantage centrée sur la surface. La mise en place préalable d'un plan de frappe pour assurer le bon contrôle des enlèvements $E 1 / E 1$ ' ne nous parait pas systématique. L'éclat fig. $15, \mathrm{n}^{\circ} 1$ serait potentiellement un exemple d'enlèvement de type $\mathrm{E} 1$, ainsi caractérisé par la présence de convexités naturelles transversales asymétriques.

Après configuration de la surface de débitage, l'intention visait à préparer la surface de plan de frappe du futur éclat recherché. L'objectif était de mettre en place une surface de plan de frappe très inclinée par rapport à la surface de débitage. L'opération consistait à détacher un éclat (E2) oblique ou perpendiculaire à l'axe de la surface de débitage, profitant alors de l'obliquité des négatifs d'enlèvements E1 ou E1', ou de l'obliquité de la surface naturelle du galet. L'éclat fig. $15 \quad n^{\circ} 2$ représente potentiellement un enlèvement de type E2 ; dans ce cas de figure, c'est la répartition des convexités naturelles, centrées et diffuses tout au long de l'axe longitudinal de l'éclat, qui suggère un détachement dans l'épaisseur du galet hémisphérique. 

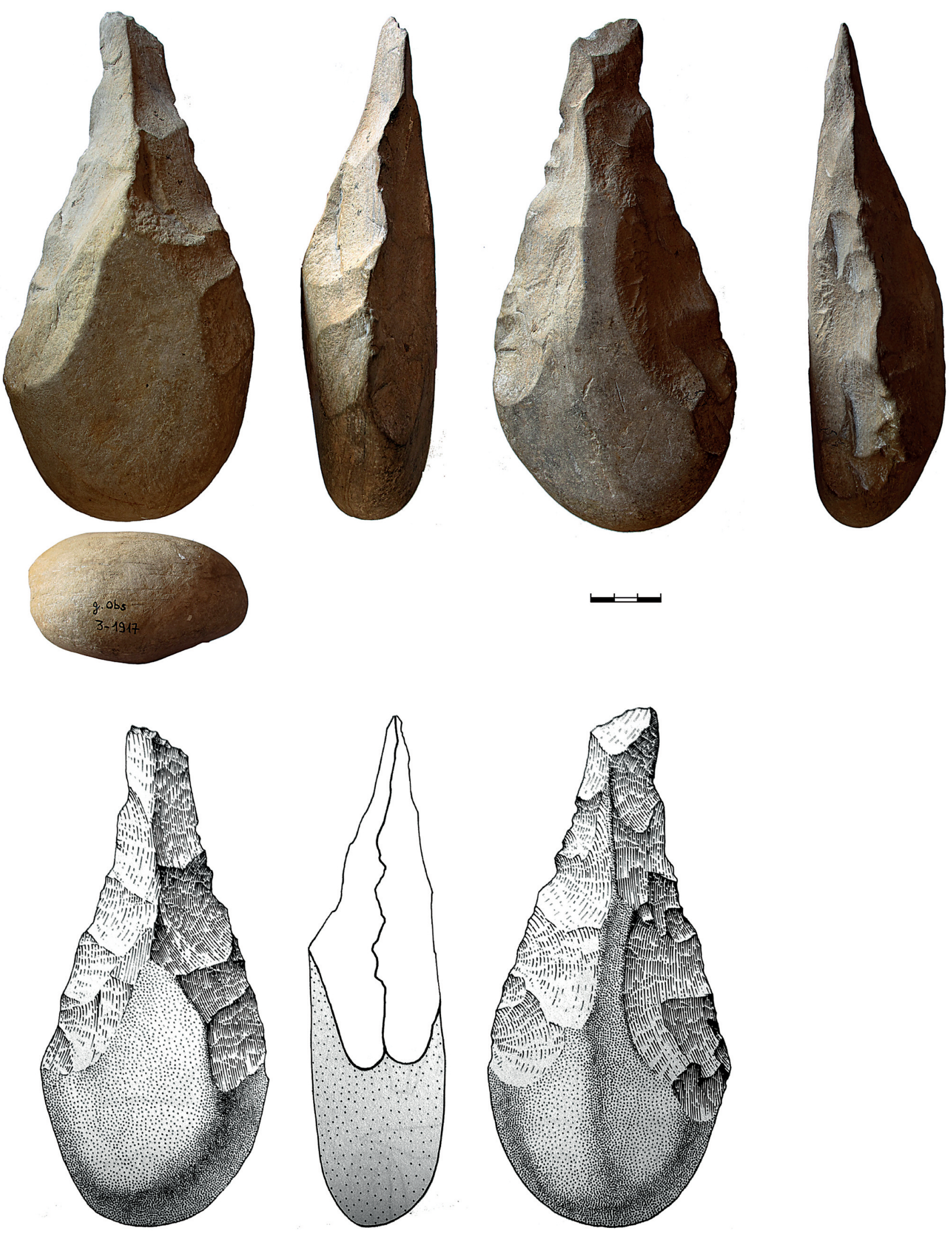

Figure 24 - Biface à base corticale réservée du foyer k de la grotte de l'Observatoire (Clichés et DAO E. Nicoud, dessin in Lumley 1969, p.113)

Figure 24 - Biface with an unmodified cortical base from the hearth $k$ of the Observatoire Cave. 
Séquences opératoires du débitage de l'Observatoire

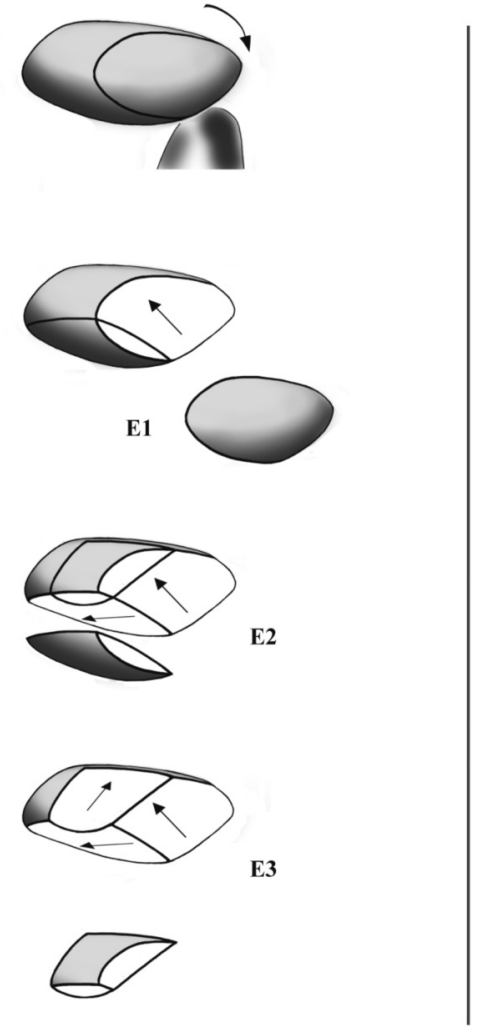

Modalité à préparation unilatérale
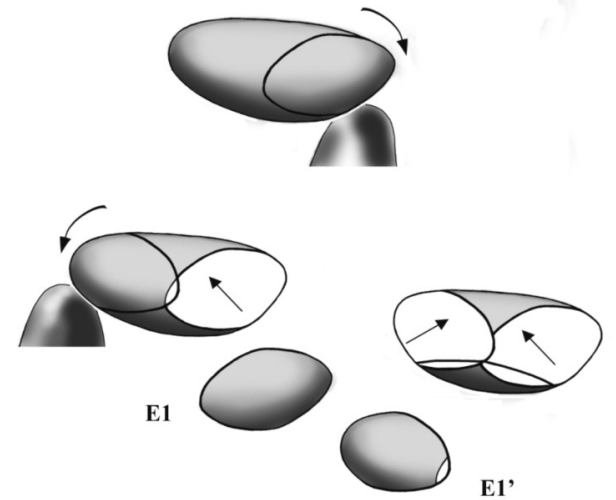

2

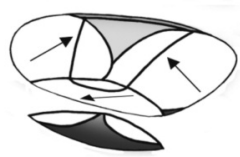

E3
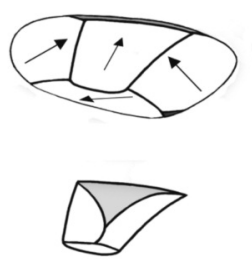

Modalité à préparation bilatérale
Figure 25 - Schéma synthétique du débitage préférentiel à séquence unique des grands éclats à biseau cortical, ou débitage de l'Observatoire (dessin M. Grenet). Après obtention de l'éclat prédéterminé (E3), le débitage pouvait se poursuivre par le détachement d'éclats à dos de débitage et d'éclats préparés. Toutefois la collection étudiée nous montre que cette poursuite du débitage non seulement n'était pas systématique, mais qu'elle était alors associée à un changement dans les intentions de production.

Figure 25 - Schematic drawing synthesizing the system of debitage of the large flakes with a cortical biseau, or debitage of the "Observatoire " type (drawing by M. Grenet). After the production of the predetermined flake (E3), this débitage could go on to produce naturally backed flakes or prepared flakes. However the study of the lithic collection shows us that this continuation in the production was not systematic and even so, was then associated with a change in the objectives of the production.
Les critères techniques de prédétermination du tranchant transversal étaient alors réunis pour détacher l'éclat prédéterminé (E3). Théoriquement, l'opération pouvait se reproduire une seconde fois, en fonction des dimensions et de la configuration de la surface de débitage, et après réaménagement de la surface du plan de frappe. Toutefois l'obtention d'un second éclat prédéterminé (E3') nous apparait, sinon opportuniste, du moins soumise à des variables qui ne semblent pas à avoir été délibérément contrôlées par les tailleurs.

Nous soulignons ici toute l'importance de la prédétermination (Tixier et al. 1980 ; Boëda 1994 ; Texier et Roche 1995 ; Mourre 2006). Ce concept repose sur une différence établie entre ce qu'un tailleur préfigure (il connaît les règles de la rupture mécanique, il anticipe le résultat de son geste de percussion) et ce qu'un tailleur prédétermine (il modifie la géométrie du bloc et par une suite de gestes, obtient ce qu'il projette). Dans notre cas de figure, et même si l'éclat recherché est au plus près des caractéristiques naturelles du galet sélectionné, son biseau ne préexiste pas à la forme naturelle du galet et est donc prédéterminé. C'est une suite d'enlèvements prédéterminants qui crée l'outil recherché.

À la suite du détachement de l'éclat préférentiel E3, le bloc était abandonné et l'opération répétée sur un autre galet. Alternativement, certains de ces nucléus ont été exploités dans le respect de nouveaux critères techniques, soulignant une plus grande souplesse des objectifs de taille. L'intention première semble avoir été de continuer à produire des éclats de grande dimension, soit à dos, soit préparés. Pour ce dernier cas de figure, certains exemples indiquent qu'une succession d'enlèvements de direction croisée ont été réalisées avant le détachement d'un éclat envahissant, l'angle d'éclatement de celui-ci soulignant alors un changement dans la géométrie du volume débité (fig. 21). Même si la prédétermination est au cœur du débitage de l'Observatoire, nous ne reconnaissons pas les principes d'une production Levallois (Boëda 1994), qui diffère dans sa géométrie, ses intentions et son principe de récurrence.

La réussite de ces opérations, fixée par la configuration géométrique donnée au nucléus, a aussi été déterminée 
par les techniques et la qualité des gestes de percussion, essentielles au bon contrôle des caractères prédéterminants et prédéterminés. Si nous reconnaissons l'usage strict de la pierre et de la percussion, les stigmates de taille nous semblent rendre compte de gestes et de masses percussives différemment combinées selon les objectifs et/ou la maniabilité du nucléus (voir Mourre et Colonge 2010). Nous reconnaissons au moins 2 techniques de percussion, combinant nucléus en station mobile et en station dormante :

- certaines entames (fig. 15, $\mathrm{n}^{\circ} 1$; fig. $16, \mathrm{n}^{\circ} 1$ ) nous montrent que l'ouverture du galet pouvait se faire par percussion du bloc sur percuteur dormant. Cette détermination repose sur la planitude de la face d'éclatement, marquée par une absence de renflement bulbaire et un écrasement prononcé au niveau du cône de percussion ;

- après ouverture du bloc, la technique principalement utilisée a été la percussion directe au percuteur dur, avec un maintien stable du nucléus. Compte tenu des larges volumes exploités, nous proposons un système d'immobilisation du nucléus au sol, facilitant une percussion rentrante et interne que nous qualifions « d'étouffée » (geste et type d'immobilisation). Nous rejoignons en cela l'hypothèse formulée par V. Mourre et D. Colonge (2010), seule solution autorisant une bonne précision dans le geste de percussion. Cette percussion est déterminante puisque c'est elle qui va assurer le caractère prédéterminé de la face d'éclatement du biseau (pour les éclats de type E3).

Cette chaîne opératoire visait la production d'éclats normalisés et prédéterminés dans leurs parties transformatives. Ces intentions se lisent indirectement par la nature des opérations de façonnage et de confection, puisque la partie transformative prédéterminée est toujours restée brute de débitage. La partie transformative était un biseau fin, d'angle compris entre $25^{\circ}$ et $40^{\circ}$, rectiligne à peu convexe, droit et de section biplan. Si l'absence d'une étude détaillée des microtraces d'utilisation gêne au discours spécifique sur la question des modes d'utilisation, la description des caractères techno-fonctionnels et des macrotraces nous autorisent néanmoins un premier développement. Nous envisageons un usage diversifié, impliquant aussi bien des actions incisantes que des actions percussives, avec des contacts transformatifs localisés sur le fil du tranchant (PT1) ou les proéminences de celui-ci (PT2) (fig. 18). Nous envisageons un fonctionnement de l'outil à plat ou de flanc, pour une préhension manuelle positionnant l'axe transformatif dans l'axe de préhension, ou à sa perpendiculaire. Nous privilégions donc l'hypothèse d'un outil plutôt souple dans ses fonctions et fonctionnements.

En outre, si le débitage s'est organisé autour d'un objectif techno-fonctionnel précis, l'outil recherché semblait intégrer automatiquement des caractères complémentaires non prédéterminés, non normalisés, mais néanmoins attendus, que nous qualifions de secondaires. En effet les bordstranchants adjacents au biseau représentent une solution fonctionnelle qui, dans certains cas, semble avoir été mise à profit par les utilisateurs (PT3) (fig. 18).

Le débitage préférentiel à séquence unique de l'Observatoire recouvre les principes d'un débitage de type D (Boëda 2013), où seuls les volumes utiles sont aménagés. La normalisation et la prédétermination des grands éclats à biseau cortical, pour certains d'entre eux obtenus en une suite de 3 coups seulement, témoignent d'un haut degré de conception du débitage (Roche et Texier 1991).

\section{Les premières occupations humaines à la grotte de l'Observatoire}

Dans l'arc liguro-provençal, les premières occupations humaines connues seraient celles de la grotte du Vallonnet (Lumley 1976). Toutefois les données les plus complètes et les plus fiables dont nous disposons aujourd'hui sont celles du site en plein air de Terra Amata, fouillé dans les années 1960. Ce site, qui comprend 3 niveaux archéologiques, rend compte d'installations humaines en bord de rivage méditerranéen dont les plus anciennes dateraient du stade isotopique 11 (Falguères, Yokoyama, Quaegebeur 1988 ; Lumley et al. 2009). À la suite de quoi, les sites régionaux les plus anciens aujourd'hui datés sont de la fin du stade 7 et du stade 6 , avec les occupations humaines de la grotte du Lazaret à Nice (Michel et al. 2009, Lumley et al. 2008) et de la grotte du Prince à Vintimille (Barral et Simone 1967 ; Simone 2008). II faut donc sortir de l'espace liguro-provençal pour enrichir la liste des sites Paléolithique ancien, avec notamment les premières occupations humaines de la Baume Bonne qui remonteraient au stade isotopique 10 (Gagnepain et Gaillard 2005). L'enregistrement archéologique est plus conséquent lorsque l'on s'ouvre à la région du Languedoc et à la vallée du Rhône, où de nombreux travaux ont montré l'ancienneté des occupations humaines dans ce secteur. Nous citerons notamment la grotte de Tautavel (stades 14 pour les occupations les plus anciennes, Falguères et al. 2004), la grotte d'Aldène (stade 11, stade 5, Barral et Simone 1972 ; Falguères et al. 1991), ou encore celle d'Orgnac 3 (stade 9 et 8, Moncel et al. 2011; Michel et al. 2013). Côté italien, peu de sites anciens dans un rayon proche de l'Observatoire ont jusqu'alors été signalés (Palma di Cesnola 2001 ; Grifoni et Tozzi 2006).

Les premières occupations humaines à la grotte de l'Observatoire seraient contemporaines ou antérieures au stade 7 , avec une date $\mathrm{U} / \mathrm{Th}>230000$ ans obtenue directement à partir du plancher III. Les données aujourd'hui disponibles sont donc très fragmentaires et limitent les possibilités de pousser les comparaisons avec d'autres occupations voisines sub-contemporaines. De la même façon, les grands éclats du foyer $k$ ne trouvent aucun équivalent régional d'un point de vue technologique. Les occupations de la grotte du Lazaret et de la grotte du Prince, plus récentes que celles de l'Observatoire, associent la présence de pièces bifaciales et d'éclats majoritairement en silex, pour certains retouchés en racloir. Une proximité un peu plus étroite peut être trouvée avec les 
collections de Terra Amata (Lumley et al. 1976), marquée par une exploitation de galets de calcaire et la présence de quelques hachereaux ( $\mathrm{n}=11$, in Villa 1983). Toutefois, les comparaisons techno-typologiques s'arrêtent là. À Terra Amata, l'exploitation des galets de calcaire se fait principalement sous la forme de « chopper-core », les quelques hachereaux sont peu caractéristiques et principalement confectionnés sur galet fendu (de type « Terra Amata »: in Villa 1983), et l'industrie lithique, qualifiée de non-clactonienne, comporte une production d'éclats en silex dont certains retouchés. L'industrie lithique du foyer $\mathrm{k}$ de la grotte de l'Observatoire s'individualise donc d'un point de vue régional, nous encourageant à une réflexion critique sur la signification de cet assemblage.

L'ancienneté des fouilles et notre méconnaissance des processus sédimentaires freinent notre compréhension des dynamiques de formation de l'assemblage lithique. Or, pour notre cas d'étude, c'est sa forte homogénéité qui interpelle et qui doit donc être discutée. L'assemblage est composé de grands éclats, de galets manuportés et d'un biface à base réservée. Toutefois le caractère unique de ce dernier ainsi que son positionnement stratigraphique (en dehors de la zone de concentration maximale des grands éclats) nous invitent à relativiser la signification chronoculturelle de ce biface et son rôle au sein du bagage techno-économique des populations de l'Observatoire. De la même façon, nous excluons l'hypothèse d'un tri sélectif des fouilleurs qui se serait fait exclusivement en faveur des seuls éléments de grande dimension en calcaire. Pour appuyer notre position, 1) nous relevons que les (petits) éclats en quartzite et silex des foyers $h$ et e ont bien été collectés (tout comme les éclats du Paléolithique moyen et les lamelles du Paléolithique supérieur), 2) nous rappelons que la fouille des déblais de de Villeneuve n'a pas conduit à une collecte importante de petits éclats (et par ailleurs aucun nucléus ou galet de calcaire volumineux n'a été retrouvé). Même s'il y a une perte d'information qui est définitive et que la nature de cette perte nous échappe, nous considérons toutefois que l'homogénéité techno-typologique et pétrographique du foyer $k$ de la grotte de l'Observatoire constitue bien un élément qui caractérise cette industrie.

L'effectif assez conséquent de grands éclats et de galets manuportés témoigne en faveur de multiples épisodes d'introduction de l'outillage et, in extenso, de plusieurs phases d'occupations. De façon schématique et simplificatrice, nous pouvons donc supposer une combinaison techno-économique (le «toolkit») associant grands éclats et galets manuportés. Pour un ordre d'idée, le ratio à la grotte de l'Observatoire est de 1 grand éclat pour 1 galet manuporté. La nature des outils permet de partitionner les registres d'activité, avec d'un côté les grands éclats incisants potentiellement utilisés en percussion posée et lancée, et de l'autre les galets contondants utilisés en percussion et/ou écrasement.

La grotte de l'Observatoire se situe dans un environnement escarpé, dominant la mer ou son horizon. Du point de vue du fractionnement des chaînes opératoires et de l'insertion de la grotte dans un territoire, nous observons un modèle qui se répète. Dans un rayon que nous pouvons raisonnablement évaluer à $5 \mathrm{~km}$ autour du site de l'Observatoire, les tailleurs sont allés sélectionner de grands galets de calcaire qu'ils ont débités, abandonnant derrière eux les déchets de taille et les produits jugés non conformes. Les grands éclats sélectionnés ont ensuite été transportés et utilisés dans la grotte de l'Observatoire ou son environnement proche, puis abandonnés à l'Observatoire. L'absence d'éclats accidentés et de nucléus appuie cette hypothèse d'opérations techniques qui étaient bien segmentées dans l'espace, avec la grotte de l'Observatoire comme site récepteur. II est probable que des activités de taille se sont déroulées également dans le site, comme la reprise de certains grands éclats par façonnage ou le débitage de quelques galets manuportés, mais les éléments aujourd'hui à disposition ne permettent pas réellement d'en apprécier les natures. La lecture techno-économique de la chaîne opératoire des galets manuportés se résume quant à elle à sa plus simple expression, à savoir une sélection au sein du cordon littoral, un usage/un transport et finalement un abandon à la grotte de l'Observatoire. Ainsi, tout comme les chaînes opératoires, la nature des comportements technoéconomiques est un élément original qui singularise les premières occupations humaines de ce site.

Dans d'autres contextes, ces comportements technoéconomiques seraient interprétés comme les signes d'occupations spécialisées, basées sur une introduction de produits finis mettant en jeu une anticipation des besoins dans le temps (Kuhn 1995). Les spécificités de l'assemblage lithique de l'Observatoire reflèteraient dès lors une variante de nature fonctionnelle, pour laquelle la signature « résidentielle » serait aujourd'hui relativement floue d'un point de vue archéologique. Nous sommes là en limite d'interprétation, qui imposerait de se nourrir de données contextuelles et de comparaisons avec d'autres sites régionaux.

Toutefois, indépendamment de ce registre fonctionnel qui vise à apprécier l'angle de variabilité observé, il nous faut nous intéresser aux systèmes techniques en propre afin d'expliciter la nature des comportements technoéconomiques adoptés. En effet, il nous faut considérer le caractère contraignant du phénomène macrolithique dans le cadre des stratégies d'approvisionnement et de renouvellement de l'outillage au Paléolithique ancien.

Les travaux aujourd'hui disponibles soulignent ponctuellement des transports de blocs depuis leurs lieux de collecte jusqu'à un lieu de transformation et d'abandon, mais ces déplacements n'interviennent jamais que sur de faibles distances et dans le cadre d'occupations en plein-air (e.g. Féblot-Augustins 1997 ; Lhomme 2007). De la littérature (Féblot-Augustins 1997 ; Turq 2000 ; Santonja et Villa 2006 ; Grégoire et al. 2007 ; Cauche 2012), nous retiendrons deux principaux points, intrinsèquement liés : d'une part l'existence de différences entre les occupations en plein-air (généralement sur ou proches des spots de matières premières) et celles en grotte-abri ; d'autre part des déplacements de macro-outils limités dans l'espace, ne 
dépassant qu'exceptionnellement la limite des $10 \mathrm{~km}$. Ainsi la supposée spécialisation du corpus lithique de l'Observatoire ne reflèterait-elle pas uniquement une adaptation fonctionnelle, mais également, voire premièrement, une adaptation d'ordre techno-économique conditionnée par la nature macrolithique de son outillage. Dans cette perspective, les faibles distances de transport observées à la grotte de l'Observatoire ne doivent pas être interprétées directement comme une faible mobilité des hommes (en amplitude), mais doivent être interprétée à la lumière d'un système technique contraignant la mobilité de l'outillage et contractant l'organisation techno-économique des activités dans l'espace.

\section{Les soucoupes de l'Observatoire: de l'arrivée lointaine à l'apparition locale}

L'industrie de la grotte de l'Observatoire, ses grands éclats en particulier, ne trouvent à ce jour que des équivalents très lointains. Toutefois, il nous faut revenir sur les déterminismes et adaptations qui pourraient expliciter le caractère unique de cette industrie dans son contexte régional. Si la nature des enregistrements archéologique et sédimentaire peut en être la cause principale, nous souhaitons ici nous interroger plus spécifiquement sur la question du macrolithisme et de ses relations aux matériaux et volumes œuvrés. Cette réflexion, fréquemment soulevée pour l'étude des grands éclats (Villa 1983 ; Santonja 1996 ; Sharon 2008), nous conduira à élargir notre champ de comparaison et à nous positionner sur la question des diffusions et des convergences.

La question de la présence des grands éclats, de leur existence même, tient à la définition de cette catégorie non pas foncièrement technologique, mais d'abord dimensionnelle. Ainsi les grands éclats, par défaut et par exemple, n'ont-ils jamais été débités sur les petits galets de silex des plages du Latium. Se pose alors la question de la signification du caractère macrolithique du point de vue des traditions techniques et des savoir-faire.

L'arc liguro-provençal présente l'intérêt de se partitionner en différents espaces géologiques (Porraz et Negrino 2008 ; Tomasso et al. soumis), qui ont su motiver des comportements et des adaptations différentes selon les traditions techniques et la nature des ressources minérales. Concernant la question des disponibilités en roche taillable, celles-ci sont présentes en grande quantité et en large volume tout au long du littoral, depuis le massif permien de l'Estérel à l'ouest et ses grandes effusions de Rhyolite, jusqu'au Flysch à Helminthoïdes à l'Est et ses blocs et galets de microquartzite. Entre ces deux grands ensembles dominent des galets de calcaire du type de ceux exploités à l'Observatoire, accessibles dans les conglomérats, dans les cordons littoraux ou d'anciennes terrasses fluviatiles (ayant remobilisé lesdits conglomérats). Dans notre région d'étude, la question de l'existence d'une tradition macrolithique ne souffre donc pas d'un déterminisme lithologique.
Toutefois, compte tenu des spécificités que nous avons relevées pour l'exploitation des galets de l'Observatoire (adaptation et mise à profit des volumes naturels), nous sommes en droit d'attendre des différences dans les schémas opératoires selon les morphologies débitées. Les tailleurs de l'Observatoire avaient adopté une démarche active privilégiant une morphologie (sur une partie du volume seulement) qui préfigurait le futur outil. Ainsi la formule des tailleurs de l'Observatoire n'existe-t-elle et ne pourra-t-elle exister que dans le cadre d'exploitation de surfaces naturelles faiblement bombées. Néanmoins, si les morphologies peuvent fixer des façons de faire, elles n'influencent en rien l'objectif techno-fonctionnel réalisé dans l'outil recherché.

Les grands éclats à biseau cortical de l'Observatoire définissent une population qui recouvre celle des hachereaux. Cet outil sur éclat se définit par la présence d'un tranchant large " ménagé » à un bout, selon l'heureuse expression de l'abbé H. Breuil (1924). Le type caractéristique du hachereau combine deux étapes techniques que sont 1) la préparation du tranchant par le détachement d'un éclat prédéterminant, 2) le façonnage des bords et de la base pour aboutir à l'outil achevé (Mourre 2003 pour une synthèse des travaux à ce sujet). Notre population de la grotte de l'Observatoire recouvre donc la structure du hachereau d'un point de vue technofonctionnel, mais s'en éloigne d'un point de vue strict des chaînes opératoires. Certes quelques exemples présentent un biseau prédéterminé par un négatif d'enlèvement, d'autres sont façonnés sur leurs bords, mais ces deux opérations ne sont que très rarement associées sur un même spécimen et, de façon générale, ne sont pas la norme technique à la grotte de l'Observatoire.

La norme à l'Observatoire est celle d'un éclat non ou peu transformé, à biseau cortical. Nous trouvons alors un rapprochement avec ce qui a été appelé proto-hachereau (ou hachereau 0) par J. Tixier (1956), à savoir des outils caractérisés par l'absence d'enlèvement prédéterminant au niveau du tranchant. Toutefois, le façonnage des parties non transformatives est présenté comme un critère de définition :

« II s'agit de fragments de galets à tranchant terminal obtenu par la rencontre de la face d'éclatement et de la surface naturelle du galet, présentant de plus des retouches marginales. Ces retouches partent soit de la face plane, soit de la face supérieure et sont quelquefois alternes. L'éclat a été percuté soit directement sur la surface naturelle du galet soit, moins souvent, sur un plan de frappe aménagé » (Tixier 1956 - p. 916).

Une caractérisation voisine du proto-hachereau est avancée par J. Heinzelein de Braucourt (1962 - p. 44) :

« modèle le plus simple du hachereau où le tranchant est obtenu par l'intersection de la face ventrale d'un gros éclat avec le cortex ou surface naturelle d'un galet ou d'un bloc. Les bords latéraux sont accommodés par des retouches marginales plus ou moins développées en vue de la 
préhension. Pourrait aussi être appelé hachereau de Ternifine ».

Si un certain nombre d'éclats à biseau cortical de l'Observatoire recouvrent la définition du hachereau 0 , nombre s'en éloigne par l'absence de façonnage. De plus, lorsque celui-ci est intervenu, il n'a généralement porté que sur des parties limitées des supports. Le façonnage était bien intégré à la démarche des tailleurs de l'Observatoire, mais n'était pas une opération structurante dans la confection de l'outil.

Ces écarts de définition que nous pouvons noter entre les éclats à biseau cortical de l'Observatoire et les hachereaux ou proto-hachereaux de la littérature témoignent d'une histoire de la recherche qui a vu les critères technologiques dominer le débat sur la définition de l'outillage, alors qu'aujourd'hui s'opère un rééquilibrage vers des approches descriptives techno-fonctionnelles. Dans cette perspective, nous rejoignons les conclusions de V. Mourre (2003 p. 250), qui place le biseau et sa prédétermination (i.e. sa nature intentionnelle) seuls au cœur de la définition du hachereau.

" un hachereau est un outil sur éclat présentant un tranchant brut formé par l'intersection de la face inférieure du support et d'une face supérieure correspondant selon les cas à un ou plusieurs négatifs antérieurs, à un positif, à un positif et un ou plusieurs négatifs, voire à une surface corticale, néocorticale ou naturelle. La prédétermination du tranchant n'est donc pas une caractéristique intrinsèque du hachereau à l'échelle de la pièce isolée ; en revanche, elle l'est à notre sens à l'échelle d'une série dans la mesure où il n'existe pas de série représentative composée uniquement de hachereaux au tranchant non prédéterminé. »

La recherche d'équivalents techniques régionaux aux grands éclats de l'Observatoire doit donc s'ouvrir plus généralement à toutes les séries à hachereaux qui, nous l'avons signalé, sont cependant quasi-absentes de l'arc liguro-provençal. En effet, seuls sont connus aujourd'hul quelques spécimens sur galet fendu dans le site de Terra Amata. Cette relative rareté de l'outil hachereau au Paléolithique ancien semble d'ailleurs caractériser l'ensemble de l'Europe occidentale (Mourre 2003 ; Santonja et Villa 2006 ; Nicoud 2013a). Entre les stades isotopiques 16 et 9 , le hachereau est ainsi absent des sites européens « acheuléens » en contexte stratigraphique susceptibles d'être datés (Nicoud 2010, 2013a). Le hachereau ne semble réellement se développer qu'à partir des stades isotopiques 9 et 8 , notamment en Espagne et dans le sud-ouest de la France (Mourre 2003 ; Sharon 2007 ; Mourre et Colonges 2010). Or c'est précisément à ce dernier ensemble géographique qu'a été limité en Europe le phénomène technique des grands éclats, ou « Large Flakes Industries » (Sharon 2007, 2011).

Les séries à grands éclats de la péninsule ibérique et du sud-ouest de la France, parmi lesquelles nous citerons par exemple les sites de El Sartalejo et de Pinedo, correspondent toutes à des occupations de plein air, positionnées sur d'anciennes terrasses livrant d'abondantes matières premières disponibles sous forme de galets. Les roches sélectionnées et débitées sont essentiellement représentées par le quartzite, le grès, quelques roches volcaniques et plus rarement le calcaire. Aucun âge absolu n'est disponible mais les études géomorphologiques tendent à positionner ces traditions techniques au cours des stades isotopiques 8 et 7 . Les études disponibles indiquent des séries largement dominées par les grands éclats, très majoritairement corticaux, témoignant de courtes séquences opératoires pour des phases très limitées d'aménagement des volumes. Or ces séries se distinguent aussi par la présence de hachereaux de type 0 . Cette tradition technique de la péninsule ibérique et de ses marges représenterait donc bien un équivalent éloigné à nos grands éclats de l'Observatoire.

Ces séries « ibériques » afficheraient de grandes ressemblances avec celles d'Afrique du Nord. Ces similitudes reposent sur la reconnaissance de la méthode dite du « débitage d'entames » (Sharon 2007, 2011). I s'agit d'un débitage relativement simple marqué par un fort investissement dans la sélection des blocs, orientée vers des galets -en quartzite pour la plupart- de morphologie aplanie. Les entames, parfois détachées après l'ouverture d'un plan de frappe, servent alors de supports au façonnage de bifaces et de hachereaux de type 0 . Ces proximités techno-typologiques, notées dès la deuxième moitié du XX' siècle, ont servi à l'élaboration d'un modèle de diffusion d'un Acheuléen depuis l'Afrique du Nord vers l'Espagne, via le détroit de Gibraltar (Bordes 1966 ; Alimen 1975 ; Tavoso 1986 ; Otte 1996 ; Sharon 2011).

Dans cette perspective générale, les grands éclats de l'Observatoire pourraient marquer un nouveau point d'extension, au-delà des frontières jusqu'alors connues de ce phénomène technique. À ce stade de notre étude, notre interrogation porte moins sur la question de la voie de migration en elle-même (le détroit de Gibraltar) que sur la validité de l'hypothèse de diffusion (la filiation technique). Quels degrés de convergence entretient la collection de l'Observatoire avec les séries documentées de la péninsule ibérique et d'Afrique du Nord?

La recherche d'éclats de grandes dimensions, l'exploitation préférentielle de surfaces naturelles aplanies, la brièveté des séquences opératoires et consécutivement l'importance des éclats corticaux ainsi que la présence de l'outil hachereau sont les éléments qui permettent de regrouper ces industries. Néanmoins, la collection de l'Observatoire s'individualise sous plusieurs angles d'analyse. Tout d'abord, à la grotte de l'Observatoire, nous ne reconnaissons pas les principes du débitage d'entames qui se traduit par une absence de prédétermination et par des axes de débitage diversement positionnés par rapport à celui du futur outil. Par ailleurs, d'autres chaînes opératoires (façonnage de biface et débitage d'éclats Kombewa) coexistent avec le débitage d'entames, ce qui n'est pas le cas à l'Observatoire. De même, les hachereaux 0 ne totalisent qu'un faible nombre de 
spécimens à la grotte de l'Observatoire. Enfin, rappelons que la plupart des roches débitées dans la péninsule ibérique et ses marges sont des roches tenaces, alors qu'il s'agit exclusivement de roches tendres (exploitées et disponibles) à la grotte de l'Observatoire. Derrière un phénomène de convergence de premier degré se cacheraient donc des différences qui individualisent en propre la série de l'Observatoire.

Quelle peut être l'origine des soucoupes de l'Observatoire? De quels moyens disposons-nous et sur quels degrés de convergence asseoir notre discours ? À ce jour, en l'absence d'une documentation suffisante, nous rejetons l'hypothèse d'une transformation graduelle intervenue sur la base d'un substrat local. Nous privilégions donc deux pistes de réflexion : la diffusion et l'innovation locale.

La diffusion est souvent l'hypothèse privilégiée dans la littérature : une innovation a un point d'origine (généralement non connue pour le Paléolithique ou au mieux, supposée) et celle-ci diffuse sous forme d'idées (interactions) ou de biens (peuplements). Interroger la réalité de cette diffusion repose alors sur le recours à des données contextuelles (e.g. des dates incertaines voire incohérentes) et/ou l'adoption d'un discours théorique sur l'histoire évolutive des techniques (Boëda 2013 ; Simondon 1958). Dans ce dernier cas de figure, l'outil a une lignée évolutive qui lui est propre, certes influencée par le milieu extérieur, mais néanmoins déterminée par sa structure de fonctionnement et la nature initiale du besoin auquel celui-ci vient répondre. Cette lignée se traduit par des stades d'évolution qui tendent vers une concrétisation de l'outil, celui-ci en quelque sorte se spécialisant dans sa tâche et dans son rôle ; les analyses et comparaisons à large échelle permettent alors de développer un argumentaire à ce sujet (e.g. Chevrier 2012a).

Le hachereau est invariable dans sa partie transformative, il présente un concept unique, accentuant les difficultés à penser ses stades d'origine. II s'agit d'un outil massif, macrolithique, organisé sur la présence d'un tranchant transversal brut, rectiligne à convexe, de section biplan, pour des angles généralement compris entre 30 et $60^{\circ}$ (Mourre 2003). Nous serions ici face à un universel fonctionnel, i.e. un tranchant biplan d'angle de taillant de $\pm 40^{\circ}$, qui « correspond à des coupants faibles, mais de grande longévité et à la capacité d'effectuer des travaux durs sur différents matériaux » (Geneste et Plisson 1996 - p. 356). Cet universel fonctionnel du hachereau conduit dès lors à penser sa variabilité (et son potentiel évolutif) sous deux principaux angles : 1) le degré de prédétermination de sa partie transformative, 2) la nature des caractères secondaires ou parties non transformatives. Dans cette recherche d'une histoire des techniques, J. Tixier (1956) considère l'éventualité d'une succession chronologique derrière sa suite typotechnologique de hachereaux, ceux de plus faible degré de prédétermination et d'élaboration (de type 0) constituant potentiellement la forme première de cet outil.

Nous avons vu que les éclats à biseau cortical de l'Observatoire recouvrent bien le concept de l'outil hachereau. Néanmoins, il se dégage du corpus de l'Observatoire une plus grande souplesse, que viennent appuyer les faibles fréquence et intensité de transformation des parties nontransformatives. Dans certains cas d'ailleurs, ces éclats à biseau cortical semblent avoir intégré plusieurs parties transformatives (cf. supra). D'autres, pourtant issus d'une même chaîne opératoire, s'éloignent du modèle type par la présence de tranchants plus obliques par rapport à l'axe de débitage et des délinéations plus convexes (fig. $9, n^{\circ} 1$ ). Si le façonnage consacre une spécialisation du hachereau, par la mise en fonction exclusive du biseau, alors la population de l'Observatoire pourrait bien s'inscrire dans une dynamique différente, marquée par une plus grande maniabilité fonctionnelle et conceptuelle.

La souplesse de l'outil à biseau cortical de l'Observatoire, à l'inverse du hachereau stricto sensu, ainsi que les différences observées avec les Large Flakes Industries de la péninsule ibérique et d'Afrique du nord, nous conduisent à envisager l'hypothèse d'une innovation autonome et potentiellement isolée. Si le besoin précis auquel est venue répondre cette innovation nous échappe, nous pouvons remarquer que celle-ci s'est inscrite dans une trajectoire macrolithique, tournée vers une recherche d'outils polyvalents et normalisés par un débitage d'éclats prédéterminés. Dans notre contexte d'étude, la recherche d'éclats à biseau terminal, caractérisés par des parties transformatives à section biplan de 30 à $40^{\circ}$, a pu représenter la solution physique la plus efficace, voire incontournable, pour mettre en fonction les calcaires tendres disponibles localement.

Au terme de cette étude, nous minimisons donc l'hypothèse d'une filiation entre les traditions techniques de l'Observatoire et celles de la péninsule ibérique, bien que nous reconnaissions le caractère aujourd'hui énigmatique qui entoure l'origine et le développement de ce phénomène technique en Europe occidentale, vraisemblablement au cours des stades isotopiques 8 et 7 . Tout au plus devonsnous rappeler que les outils à biseau se retrouvent indépendamment dans différents contextes, comme dans l'Acheuléen de Barbas (appelé typo-biseau : Boëda et al. 1996) ou encore le Middle Stone Age de Sibudu (Conard et al. 2012). Le hachereau réapparait en Europe occidentale au cours du Vasconien (Bordes 1953 ; Deschamps 2010), phase d'un Paléolithique moyen récent qui semble bien consacrer l'hypothèse d'une convergence technique (Deschamps 2014).

\section{Pour conclure}

La première ambition de cette étude était de participer aux discussions sur la nature et la signification des traditions techniques qui traversent le Paléolithique ancien en Europe occidentale. Nous avons fait reposer notre réflexion sur la série quasi-inédite des grands éclats de l'Observatoire, dont l'originalité était à même de faire oublier l'ancienneté du contexte de fouille. Ces grands éclats nous ont conduits à aborder la question des aires culturelles, en développant une comparaison avec des industries à grands éclats et hachereaux 0 de la péninsule ibérique et d'Afrique du Nord. Au terme de l'étude, nous minimisons l'hypothèse d'une 
filiation directe entre ces industries à grands éclats et celle de l'Observatoire et envisageons celle d'une apparition locale.

À partir de la série de la grotte de l'Observatoire, nous avons pu reconnaître une nouvelle chaîne opératoire de production d'éclats-hachereaux ou éclats à biseau cortical, dénommée « débitage de l'Observatoire ». Ce débitage préférentiel à séquence unique opère au travers du respect de quelques règles qui mettent à profit des volumes naturels soigneusement sélectionnés. Ce débitage rend compte du contrôle de règles géométriques simples qui favorisaient un développement du front de fracture de telle sorte que les deux bords de l'éclat prédéterminé divergeaient. Les tailleurs se sont adaptés aux matériaux disponibles et ont recherché des morphologies spécifiques, qu'ils transformaient selon un schéma opératoire efficace. L'absence de récurrence, soit l'impossibilité de reconfigurer le volume à l'identique, est pareillement un élément qui caractérise ce système de production et ses principes de prédétermination. Cette absence de récurrence souligne avec intérêt l'étroitesse de la relation conceptuelle (une impasse ?) entre d'une part l'opportunité créée par le tailleur à partir d'une configuration naturelle, et d'autre part la normalisation des critères fonctionnels vers laquelle semble tendre le système technique.

Cette étude nous a permis finalement de lever une discussion sur les spécificités de l'outil hachereau, dans l'histoire des techniques et dans ses caractères structurants sur les sociétés humaines. Cet outil, structuré sur un biseau brut de débitage, traverse le Paléolithique mais demeure néanmoins caractéristique des périodes anciennes. Massif, il nous renvoie l'image de sociétés qui se reconnaissaient également par un mode de perception des ressources minérales et par une organisation territoriale I.s. qui nous demeurent aujourd'hui encore partiellement étrangères.

\section{Remerciements}

L'étude des grands éclats s'est imposée à nous alors que nous révisions les collections du Paléolithique supérieur de l'Observatoire, dans le cadre du PCR ETICALP dirigé par $D$. Binder, que nous remercions. Cette étude a profité d'un financement de la fondation Alexander von Humdoldt, dans le cadre d'un projet postdoctoral (GP) conduit à l'Université de Tuebingen. Merci à Mr Henry de Lumley pour son accord préalable pour l'étude des éclats conservés à I'Institut de Paléontologie Humaine ainsi qu'à Mme Amélie Vialet pour son accueil. Merci également à Mr Michel Olive, pour les clichés de l'Observatoire, à Mrs Michel Dagnino et Jean-François Bussière pour les photographies du matériel lithique ainsi qu'à Mr François Burle pour la DAO des figures 3 et 23. Merci à Pierre-Jean Texier pour ses conseils et astuces de calcul des rayons de courbure. Merci enfin à deux relecteurs pour avoir contribué à alléger et éclaircir le contenu de cet article.

\section{Références bibliographiques}

ALIMEN M.-H. 1975 - Les «isthmes» hispano-marocain et sicilo-tunisiens aux temps acheuléens, L'Anthropologie, Paris, 79, 3, p. 399-436.

BARRAL L., SIMONE S. 1967 - Nouvelles fouilles à la grotte du Prince (Grimaldi, Ligurie italienne). Découverte de Paléolithique inférieur. Bull. Mus. Anthropol. Prehist. Monaco 14, p. 5-23.

BARRAL L., SIMONE S. 1972 - Le Mindel-Riss et le Riss à la grotte d'Aldène (Cesseras, Hérault), Bull. Mus. Anthropol. Prehist. Monaco, 18, p. 45-68.

BOËDA E. 1994 - Le concept Levallois : variabilité des méthodes, Paris, CNRS, $280 \mathrm{p}$.

BOËDA E. 2013 - Techno-logique et technologie : une paléo-histoire des objets tranchants. Archéo-édition.com. $259 \mathrm{p}$.

BOËDA E., KERVAZO B., MERCIER N., VALLADAS H. 1996 - Barbas C'3 base (Dordogne), une industrie bifaciale contemporaine des industries du Moustérien ancien : une variabilité attendue, In : A. Bietti. et S. Grimaldi (Éds.), Proceedings of the International Round Table: Reduction processes («chaînes opératoires») for the European Mousterian, Rome, Quaternaria Nova VI, p. 465-504.

BORDES F. 1953 - Essai de classification des industries " moustériennes », Bulletin de la Société Préhistorique Française. L, 7-8, p. 457-466.

BORDES F. 1966 - Acheulean cultures in southwest France. In : D. Sen et S. Ghosh, S (Éds), Studies in Prehistory - Robert Bruce Foote memorial volume, Calcutta, p. 49-63.

BOSINSKI G. 2006 - Les premiers peuplements de l'Europe centrale et de l'Est. C. R. Palevol 5, p. 311-317

BOULE M., VILLENEUVE L. de 1927 - La grotte de l'Observatoire à Monaco, Archives de l'Institut de Paléontologie Humaine. 113p.

BREUIL H. 1924 - Hache taillée en quartzite, Bulletin de la Société Préhistorique Française, 21, p. 253-254.

BREUIL H. 1932 - Le Paléolithique ancien en Europe Occidentale et sa Chronologie. Bulletin de la Société préhistorique de France, 29, 12. p. 570-578

BREUIL H., KELLEY H. 1954 - Le Paléolithique ancien. Bulletin de la Société préhistorique de France. 51, 8. p. 9-26.

CAUCHE D. 2012 - Productions lithiques et comportements techno-économiques de groupes humains acheuléens et moustériens en région liguro-provencale, C. R. Palevol, 11, p. $519-527$ 
CHEVRIER B. 2012a - Les assemblages à pièces bifaciales au Pléistocène inférieur et moyen ancien en Afrique de l'Est et au Proche-Orient : nouvelle approche du phénomène bifacial appliquée aux problématiques de migrations, de diffusion et d'évolution locale. Thèse de l'Université de Paris X-Nanterre.

CHEVRIER B. 2012b - Ni espace ni temps en Préhistoire ancienne. "Out of Africa" ou le paradigme de la flèche. M@ppemonde, 106, 19 p.

CONARD N.J., PORRAZ G., WADLEY L. 2012 - What is in a name, characterizing the "post-Howiesons Poort" at Sibudu. South African Archaeological Bulletin, 67(196), p. $180-199$

DESCHAMPS M. 2010 - Le Vasconien : révision de sa signification à partir des industries lithiques d'Olha I et II, d'Isturitz et de Gatzarria PALEO, 21, p. 103-126

DESCHAMPS M. 2014 - La diversité culturelle au Paléolithique moyen récent : le Vasconien et sa signification au sein des faciès moustériens. Thèse de Doctorat de l'Université de Toulouse. 580p.

FALGUĖRES C., YOKOYAMA Y., QUAEGEBEUR J.P. 1988 - Datations de sédiments quaternaires par la méthode de résonance de spin électronique (ESR). L'Anthropologie 92 (2), p. 723-725.

FALGUĖRES C., AJAJA O., LAURENT M., BAHAIN J.-J. 1991 - Datation de la grotte d'Aldène (Cesseras, Hérault), Comparaison par les méthodes du déséquilibre de la famille de l'uranium et de la résonnance de spin électronique, Bulletin du Musée d'Anthropologie de Monaco, 34, p. 17-27.

FALGUĖRES, C., YOKOYAMA, Y., SHEN, G., BISCHOFF, J.L., KU, T.L., LUMLEY H. de 2004 - New U-series dates at the Caune de l'Arago, France. Journal of Archaeological Science 31, p. 941-952.

FÉBLOT-AUGUSTINS J. 1997 - La circulation des matières premières au Paléolithique, Liège, ERAUL $n^{\circ} 75$. $536 \mathrm{p}$.

GAGNIĖRE S. 1970 - Provence-Côte-d'Azur-Corse. In: Gallia préhistoire. 13(2), p. 551-583.

GAGNEPAIN J., GAILLARD C. 2005 - La grotte de la Baume Bonne (Quinson, Alpes de Haute-Provence) : synthèse chronostratigraphique et séquence culturelle d'après les fouilles récentes (1988-1997). BAR Int. Series 1364, p. 73-85.

GENESTE J.-M., PLISSON H. 1996 - Production et utilisation de l'outillage lithique dans le Moustérien du SudOuest de la France : les Tares à Sourzac, Vallée de l'Isle, Dordogne, In : A. Bietti et S. Grimaldi (Éds), Proceedings of the International Round Table : Reduction processes ("chaînes opératoires») for the European Mousterian, Rome, Quaternaria Nova VI, p. 343-367.
GRÉGOIRE S., MOIGNE A.M., BARSKY D., LUMLEY de H., 2007 - Gestion et sélection des ressources au sein d'un territoire. Un exemple de comportement économique au Paléolithique inférieur dans le sud de la France. In : Moncel, M.-H., Moigne, A.-M., Arzarello, M., Peretto, C. (Eds.), Aires d'approvisionnement en matières premières et aires d'approvisionnement en ressources alimentaires. Approche intégrée des comportements. Workshop 23, $\mathrm{XV}^{\mathrm{e}}$ Congrès UISpP, 4-9 septembre 2007 Lisbonne. BAR International Series 1364, vol. 5.

GRIFONI R., TOZZI C. 2006 - L'émergence des identités culturelles au Paléolithique inférieur : le cas de l'Italie. Comptes Rendus Palévol, 5, p. 137-148.

HEINZELIN DE BRAUCOURT J. de 1962 - Manuel de typologie des industries lithiques. Bruxelles, Institut Royal des Sciences Naturelles Belges, 74 p.

KLEINDIENST M.R. 1962 - Components of the East African Acheulian assemblage: an analytic approach. In: Mortelmans, G. (Ed.), Actes du IVeme Congrès Panafricain de Préhistoire et de l'Etude du Quaternaire, vol 40. Musée Royal de l'Afrique Centrale, Tervuren (Belgique), p. 81-105.

KUHN S.L. 1995 - Mousterian Lithic Technology: An Ecological perspective. Princeton University Press.

LHOMME V. 2007 - Tools, space and behaviour in the Lower Palaeolithic: discoveries at Soucy in the Paris basin. Antiquity, 81, p. 536-554.

LUMLEY H. de 1960 - Clactonien et Tayacien dans la région méditerranéenne française. ????

LUMLEY-WOODYEAR H. de 1969 - Le Paléolithique inférieur et moyen du Midi méditerranéen dans son cadre géologique, Ve supplément à Gallia Préhistoire, 2 vol., 453 p. et 445 p.

LUMLEY H. de 1976 - Les civilisations du Paléolithique inférieur en Provence, In : H. de Lumley (Éd.) La Préhistoire française t. I : Les civilisations paléolithiques et mésolithiques., Ed. du CNRS, p. 819-851.

LUMLEY H.de, LUMLEY M-A. de, MISKOVSKY J-C., RENAULT-MISKOVSKY J. 1976 - Le site de Terra-Amata Impasse Terra Amata, Nice, Alpes-Maritimes, in : $\mathrm{H}$. de Lumley et L. Barral (Éds), Sites paléolithiques de la région de Nice et Grottes de Grimaldi - Livret-guide de l'excursion B1 - IX Congrès de l'UISPP, Nice, p. 15-49.

LUMLEY H. de, AROBBA D., CAUCHE D., DESCLAUX E., ÉCHASSOUX A., KHATIB S., RICCI M., ROUSSEL B., SIMON S., TOZZI C., VALENSI P., VICINO G. 2008 - Les cultures acheuléennes et moustériennes dans les AlpesMaritimes et en Ligurie. Bull. Mus. Anthropol. Prehist. Monaco, suppl. 1, p. 11-20. 
LUMLEY DE, H., FALGUÈRES C., MICHEL V., YOKOYAMA Y. 2009 - Datations des formations pléistocènes du site acheuléen de Terra Amata. In : Lumley de, H. (Ed.), Terra Amata. Nice, Alpes-Maritimes, France. Tome I. Cadre géographique - Historique - Contexte géologique-Stratigraphie-Sédimentologie-Datation. CNRS Éditions, Paris, p. 469-486.

MICHEL V, SHEN G, SHEN C-C, WU C-C, VÉRATI C, GALLET S., MONCEL M.H., COMBIER J., KHATIB S., MANETTI M. 2013 - Application of U/Th and ${ }^{40} \mathrm{Ar} / 39 \mathrm{Ar}$ Dating to Orgnac 3, a Late Acheulean and Early Middle Palaeolithic Site in Ardèche, France. PLOS ONE 8(12): e82394

MONCEL M-H, MOIGNE A-M, YOUSSEF S, COMBIER J. 2011 - The Emergence of Neanderthal Technical Behavior: New Evidence from Orgnac 3 (Level 1, MIS 8), Southeastern France. Current Anthropology 52, p. 37-75.

MOURRE V. 2003 - Implications culturelles de la technologie des hachereaux. Unpublished $\mathrm{Ph}$. D. dissertation, University of Paris X-Nanterre. 3 tomes, 303 p., 259 p. et 333 p.

MOURRE V. 2006 - Emergence et évolution de la prédétermination au Paléolithique. In : Astruc L., Bon F., Léa V., Milcent P.-Y., Philibert S. (Eds) Normes techniques et pratiques sociales. De la simplicité des outillages pré- et protohistoriques. $X X V^{e}$ rencontres internationales d'archéologie et d'histoire d'Antibes. Editions APDCA, Antibes, p. 61-74

MOURRE V., COLONGES D. 2010 - La question du débitage de grands éclats à l'Acheuléen. In : Mourre V., Jarry M. (Eds) Entre le Marteau et l'enclume... La percussion directe au percuteur dur et la diversité de ses modalités d'application. Actes de la table ronde de Toulouse, 1517 mars 2004, Paleo, numéro spécial, p. 35-48

NICOUD É. 2010 - The Acheulian in Western Europe : Technical systems and peopling patterns of Europe, in S.A. Vasil'ev et V.E. Schelinsky, SPb (ed.), The earliest inhabitants of the Caucasus and Hominid dispersals at Eurasia,: Sankt-Petersburg Centre for Oriental Studies Publishers, p. 197-210.

NICOUD É. 2011 - Le phénomène Acheuléen en Europe occidentale : approche chronologique, technologie lithique et implications culturelles, Thèse de doctorat, Université de Provence et Università degli Studi di Roma « La Sapienza », 483 p.

NICOUD É., 2013a - Le paradoxe Acheuléen. Comité des Travaux Historiques et Scientifiques, Documents Préhistoriques 32/ Bibliothèque des Ecoles françaises d'Athènes et de Rome $356 p$.

NICOUD É. 2013b - What Does the Acheulean Consist of? The Example of Western Europe (MIS 16-9) Mitteilungen der Gesellschaft für Urgeschichte - 22. P. 41-60

OTTE M. 1996 - Le paléolithique inférieur et moyen en Europe, Paris, Masson \& Armand Colin, $296 \mathrm{p}$.
PALMA DI CESNOLA A. 2001 - I/ Paleolitico inferiore e medio in Italia. Firenze, Museo Fiorentino di Preistoria «Paolo Grazioso », 352 p.

PELEGRIN J. 1995 - Technologie lithique : le Châtelperronien de Roc-de-Combe (Lot) et de La Côte (Dordogne), Paris, CNRS Editions, Cahiers du Quaternaire $n^{\circ} 20,297$.

PORRAZ G., NEGRINO F. 2008 - Espaces économiques et approvisionnement minéral au Paléolithique moyen dans l'aire Liguro-provençale. In : D. Binder, X. Delestre et $\mathrm{P}$. Pergola (Eds.) Archéologies transfrontalières (Alpes du Sud, Côte d'Azur, Piémont et Ligurie). Bilan et perspectives de recherche. Actes du colloque de Nice 13-15 décembre 2007. Bulletin du Musée d'Anthropologie de Monaco, p. 29-40

PORRAZ G., SIMON P., PASQUINI A. 2010 - Identité technique et comportements économiques des groupes proto-aurignaciens à la grotte de l'Observatoire (Principauté de Monaco), Gallia Préhistoire, 52, p. 33-59.

POTTIER G. 1938 - La chronologie du Paléolithique inférieur (Acheuléen et Clactonien). Bulletins et Mémoires de la Société d'anthropologie de Paris, VIII, 9, 4-6, p. 69-72.

ROCCA R. 2013 - Peut-on définir des aires culturelles au Paléolithique inférieur? Originalité des premières industries lithiques en Europe centrale dans le cadre du peuplement de l'Europe. Thèse de l'Université de Paris X-Nanterre.

ROCHE H., TEXIER P-J. 1991 - La notion de complexité dans un ensemble lithique. Application aux séries acheuléennes d'Isenya (Kenya), In : 25 ans d'Etudes technologiques en Préhistoire, Juan-les-Pins, Xlèmes Rencontres Internationales d'Archéologie et d'Histoire d'Antibes, Ed. ADPCA, p. 99-108.

SANTONJA M. 1996 - The Lower Palaeolithic in Spain: sites, raw material and occupation of the land. In: N. Moloney, L. Raposo et M. Santonja (Éds), Non-flint stone tools and the Palaeolithic occupation of the Iberian Peninsula, Tempus Reparatum, BAR International Series 649, p. $1-20$.

SANTONJA M., VILLA P. 2006 - The Acheulean of Western Europe. In : Goren-Inbar, N. and Sharon, G. (eds.), Axe Age - Acheulian Tool-making from Quarry to Discard. London: Equinox Publishing, p. 429-478.

SHARON G. 2007 - Acheulean large flake industries: Technology, chronology, and significance. BAR (British Archaeological Reports) International Series 1701. Oxford: Archaeopress. 320 p.

SHARON G. 2008 - The impact of raw material on Acheulian large flake production. Journal of Archaeological Science 35, p. 1329-1344

SHARON G. 2009 - Acheulian Giant-Core technology. A worldwide perspective. Current Anthropology 50, 3, p. 335-367 
SHARON G. 2011 - Flakes crossing the straits? Entame flakes and northern Africa-lberia contact during the Acheulean. African Archaeological Review 28, p. 125-140

SIMON P. 2008 - Les grottes des Balzi Rossi : Historique des découvertes. La nascita della paletnologia in Liguria: personaggi, scoperte e collezioni tra XIXe XX secolo: atti... 15, p.171.

SIMONDON G. 1958 - Du mode d'existence des objets techniques. Paris, Ed. Aubier

SIMONE S. 1993 - Préhistoire de Monaco. Bulletin du Musée d'Anthropologie Préhistorique de Monaco, 36, p. 59-63.

SIMONE S. 2008 - Le Pléistocène moyen à la grotte du Prince (Ligurie italienne). Arch. Instit. Paleontol. Hum. 39, p. 89-94.

TAVOSO A. 1986 - Le Paléolithique inférieur et moyen du Haut-Languedoc. Gisements des terrasses alluviales du Tarn, du Dadou, de l'Agout, du Sor et du Fresquel, Université de Provence, Ed. du Laboratoire de Paléontologie Humaine et de Préhistoire, Etudes Quaternaires, 5, (1978), $404 \mathrm{p}$.

TOMASSO A., BINDER D., SIMON P., PORRAZ G., MARTINO G. Soumis - Entre Rhône et Apennins : le référentiel MP-ALP, matières premières de Provence et de l'arc ligure. In : A. Tomasso, D. Binder, G. Martino, N. Naudinot (Eds.) Ressources lithiques, productions et transferts entre Alpes et Méditerranée. Séance de la société préhistorique française organisée à Nice les 28 et 29 Mars 2013.
TEXIER P.-J. 1996 - Evolution and diversity in flaking techniques and methods in the Palaeolithic, In : Oltre la pietra - Modelli e tecnologie per capire la preistoria, Forlí, XIII UISPP Congress, A.B.A.C.O. Ed, p. 281-321.

TEXIER P.-J., ROCHE H. 1995 - The impact of predetermination on the development of some acheulean chaînes opératoires. In: Evolucion humana en Europa y los yacimientos de la Sierra de Atapuerca. Junta de Castilla y Leon, Vol. 2, p. 403-420.

TIXIER J. 1956 - Le hachereau dans l'Acheuléen nordafricain. Notes typologiques. Congrès Préhistorique de France. $X V^{*}$ session, Poitiers-Angoulême, p. 914-923.

TIXIER J., INIZAN M.-L., ROCHE H., DAUVOIS M. 1980 Préhistoire de la pierre taillée - 1. terminologie et technologie, Paris, CREP, 120p.

TURQ A. 2000 - Paléolithique inférieur et moyen entre Dordogne et Lot. Paleo, supplément 2 ; 456 p.

VILLA P. 1983 - Terra Amata and the Middle Pleistocene Archaeological Record of Southern France. Anthropology 13, University of California Press, Berkeley and Los Angeles. 303 p.

VILLA P. 1991 - Middle Pleistocene prehistory in southwestern Europe: the state of our knowledge and ignorance. Journal of Anthropological Research 47, p. 193-218. 